\title{
Higher Music Education Students' Experiences and Management of Performance Anxiety: A Qualitative Study
}

Damla Tahirbegi

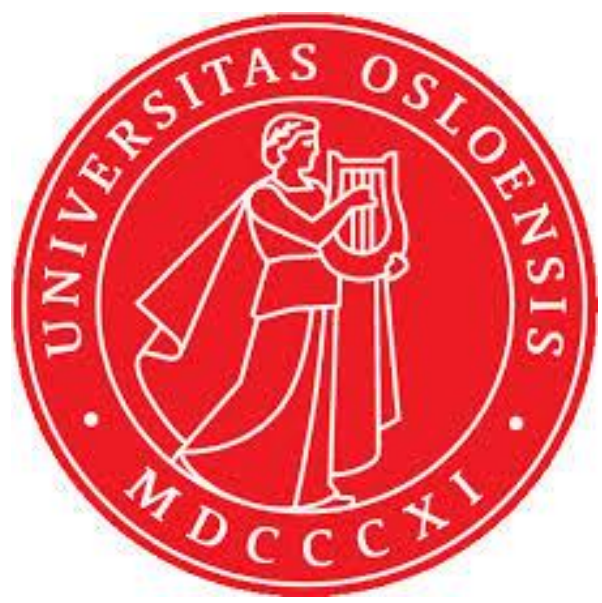

Master Thesis

Department of Educational Research UNIVERSITETET I OSLO

Fall 2019 
(C) Damla Tahirbegi

2019

Higher Music Education Students' Experiences and Management of Music Performance Anxiety: A Qualitative Study

Damla Tahirbegi

http://www.duo.uio.no/

Trykk: Reprosentralen, Universitetet i Oslo 


\begin{abstract}
In the last few decades, scholars have increasingly turned to Music Performance Anxiety (MPA) as a topic of empirical inquiry. Existing research has shown that MPA is highly prevalent among both professional and student musicians; however, there has been limited qualitative inquiry into individual experiences and management of MPA in educational settings. In order to address this gap, the current thesis reports on a qualitative study conducted at a Higher Music Education Institution in Norway, exploring students' experiences and management of MPA. In particular, the study investigated students' MPA regulation efforts, namely their use of various coping strategies and the role of social and institutional support within educational settings. Data relevant to the coping strategies were analysed using an analytical framework of the socio-cognitive view of Self-Regulated Learning (SRL) proposed by Zimmerman (1989). A semi-structured interview approach was used as the main data collection method. Interviews were conducted with 10 students who, at the time, were enrolled as a performance major at their institution. Findings from this study indicated that manifestations of MPA varied widely among the participants. Some of the reported manifestations were not limited to the stage but also were experienced for days or weeks approaching a performance. The most common coping strategies mentioned were increasing individual practice time, mental skill practices — such as creating a map-overview of the repertoire - and playing mock performances for peers. Students unanimously mentioned that their musical and technical preparation was the key component in gaining selfconfidence, leading to higher self-efficacy beliefs. As such, the role of self-efficacy beliefs in this study was identified to be one of the most important factors in the management of MPA. Within the self-regulation framework, these self-efficacy beliefs appeared to be shaped both during the preparation and post-performance reflection phases. In addition, teachers and peers were perceived as integral in sustaining students' wellbeing and MPA regulation efforts. Consequently, students' attitudes towards and management of MPA were highly influenced by the social support around them. In particular, the role of the instrumental teacher appeared to be highly significant. A positive teacher attitude towards the management of MPA encouraged students' help-seeking efforts. Collectively, the findings of this study provide insight valuable to instrumental teachers and administrators seeking ways to support students' health and emotional wellbeing. Higher Music Education Institutions should consider ways to support students' self-regulation and emotion regulation efforts in the management of MPA through instructional approaches, and various performance-based practices.
\end{abstract}




\section{Acknowledgements}

To my supervisor, Monika Bærøe Nerland, thank you for your continuous support and guidance throughout this research. I cannot stress enough how important it was for me that you allowed time and space for me to learn and explore while providing clear tasks and expectations that helped me to move forward in completing this thesis. I would also like to extend my appreciation to the Department of Education at the University of Oslo and to the programme coordinators, Kristi Barcus and Samia Iram, for their continuous support over the last two years.

To the students who participated in this project, I extend my appreciation to you all for sharing your stories so wholeheartedly. I was blown away by your resourcefulness and dedication to your trade. Your contribution was invaluable and without you this project would not have been possible. I would also like to thank the student leaders who helped me recruit participants through various institutional platforms.

To my loving and kind parents, anneciğim ve babaciğim, you two have been pillars of support, and a source of encouragement since the day I was born. I am forever grateful for all you have done and continue to do for me.

To my partner, Nicholas, thank you for keeping my feet on the ground when I need it the most. Your love and support was integral in the completion of this project, especially during my times of self-doubt. Thank you for being the best dad to Linus and Albert. I am so grateful for all you have done for me and for our little family.

To my sons, thank you for the happiness you bring to my life. The playfulness and curiosity you inspire in me help me endure every challenge I encounter. You are the light of my world, my rock, my constant.

This degree was completed with the support of the Centers for Excellence in Education (SFU) grant awarded by the Norwegian Agency for Quality Assurance in Education.

A special thanks to CEMPE, Centre of Excellence in Music Performance Education, for supporting this project. 


\section{Table of Contents}

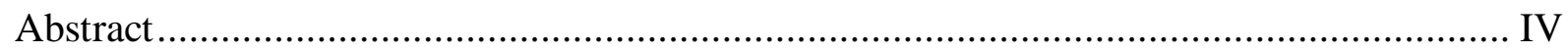

Acknowledgements ............................................................................................. VI

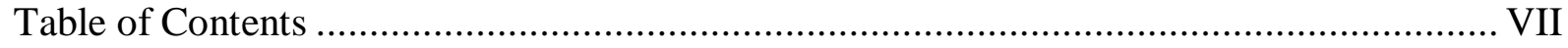

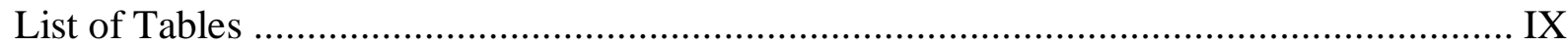

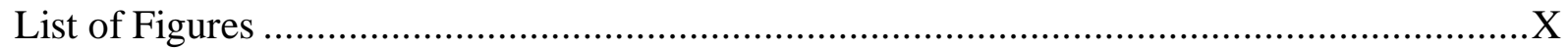

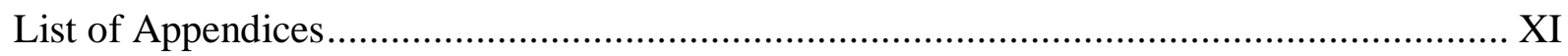

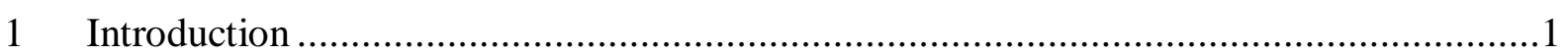

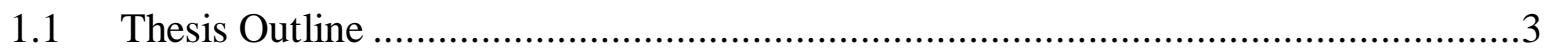

2 Overview of Music Performance Anxiety …………………........................................5

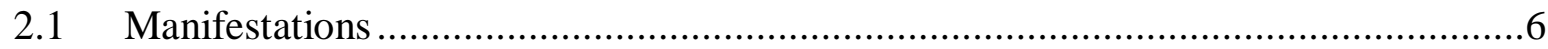

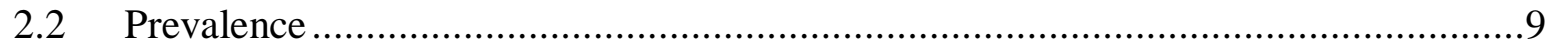

2.3 Coping with Music Performance Anxiety …….....................................................11

2.3.1 Coping Strategies Reported by Musicians.......................................................11

2.3.2 Various Treatment Approaches in Management of MPA …………………......12

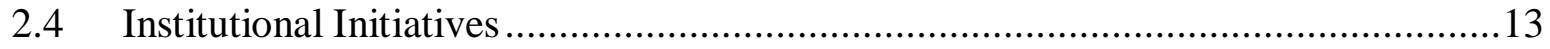

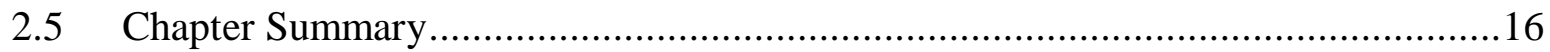

3 Theoretical Concepts and Analytical Framework ………….......................................17

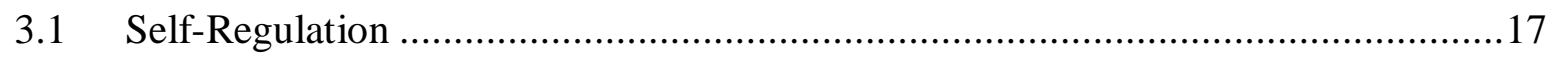

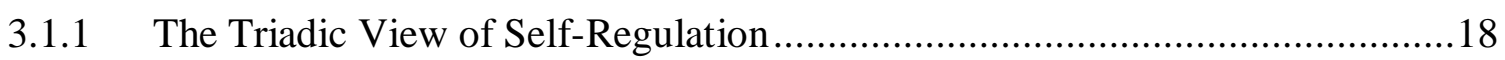

3.1.2 The Cyclical Structure of Self-Regulatory Processes .......................................20

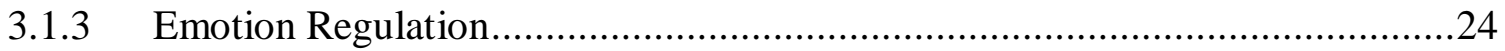

3.2 Research on Self-Regulated Learning in the Context of Music Performance ...........25

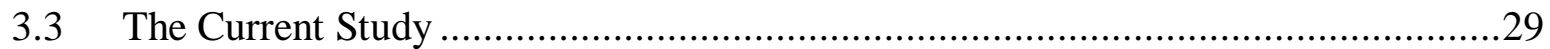

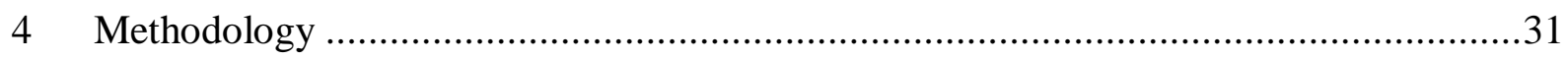

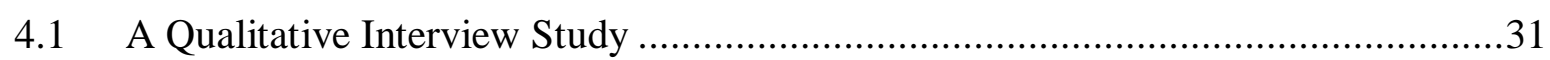

4.2 Recruitment of Participants for the Study ………..................................................32

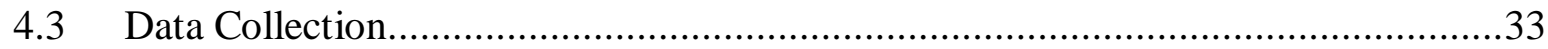

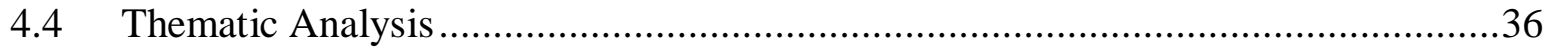

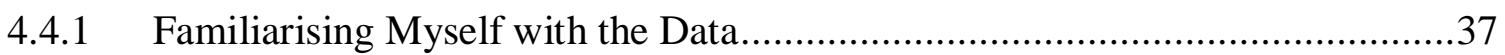

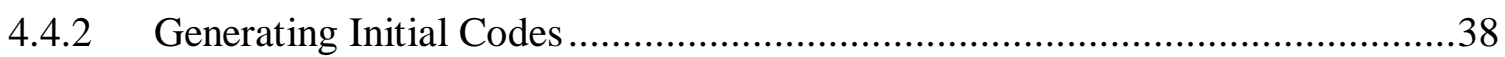

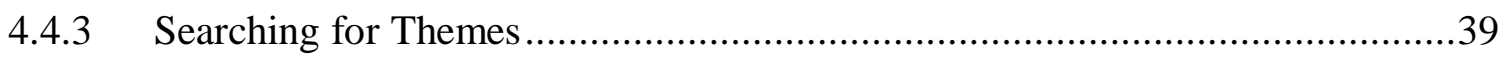

4.4.4 Defining and Naming Themes ....................................................................40 


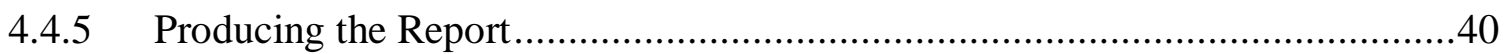

4.5 Academic Rigour and Trustworthiness ............................................................. 41

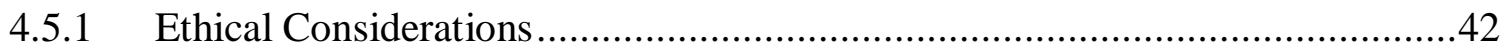

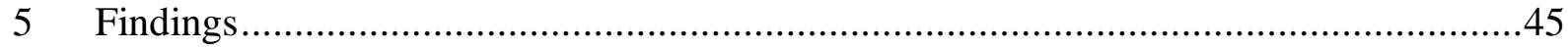

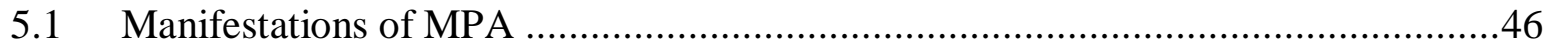

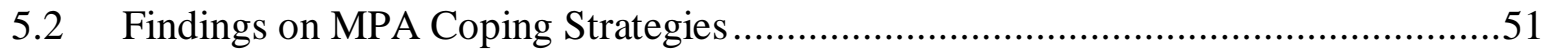

5.2.1 Strategies Used in the Forethought Phase: .................................................52

5.2.2 Strategies Used in the Performance Phase.....................................................56

5.2.3 Strategies Used in the Self-Reflection Phase ..................................................58

5.3 The Role of Social Support in Management of MPA .......................................60

5.3.1 The Significance of the Teacher-Student Relationship .................................60

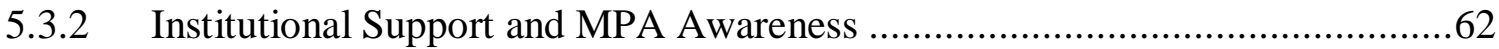

5.3.3 Regulation of Emotions Through Peer-Support ..........................................65

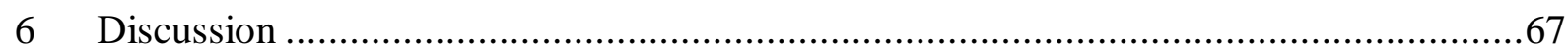

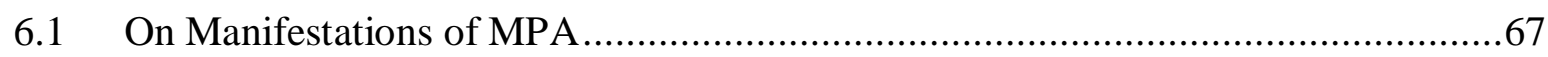

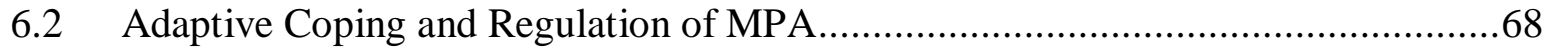

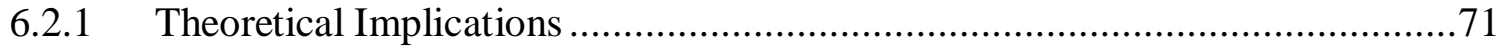

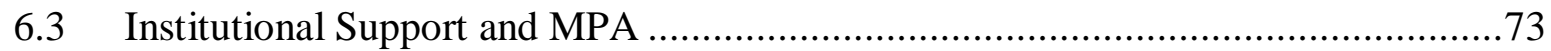

6.3.1 Implications for Higher Music Education ................................................... 73

6.4 Limitations and Future Research Directions ...................................................... 75

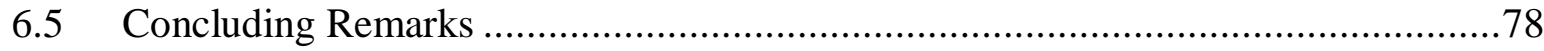

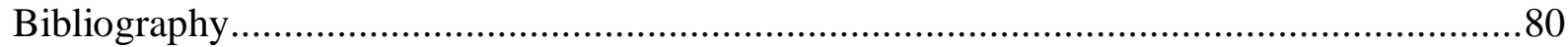

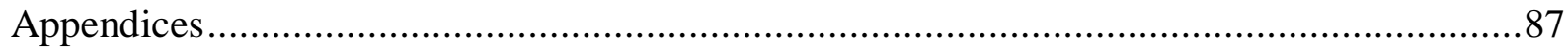




\section{List of Tables}

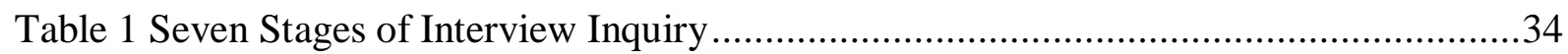

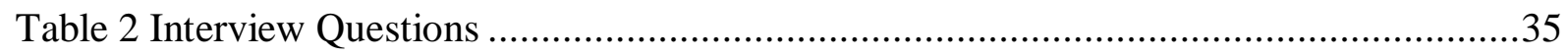

Table 3 Six-Step TA Framework by Braun and Clarke (2006, p.87) …..............................37

Table 4 Over-arching themes and sub-themes emerging from the 10 interviews...................45

Table 5 Various manifestations of MPA reported in this study.........................................46

Table 6 Coping Strategies Reported by Music Students to Manage Performance Anxiety .....51 


\section{List of Figures}

Figure 1 Triadic Forms of Self-Regulation................................................................... 18

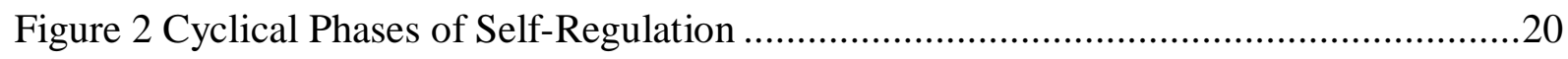

Figure 3 Phases and Subprocesses of Self-Regulation................................................22

Figure 4 Analytical Framework for the Current Study ................................................... 30

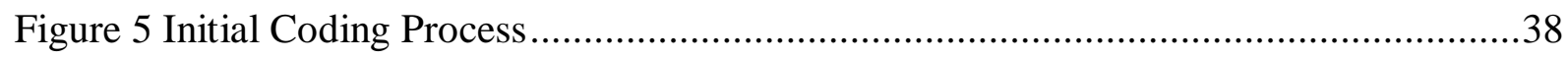

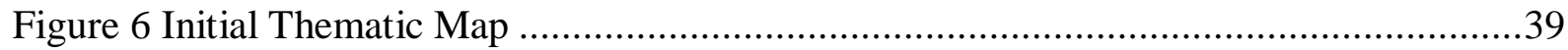

Figure 7 Final Thematic Map, Showing 3 Overarching Themes and Sub-themes .................40

Figure 8 Theoretical Implications - A Multi-Directional SRL Model ................................72 


\section{List of Appendices}

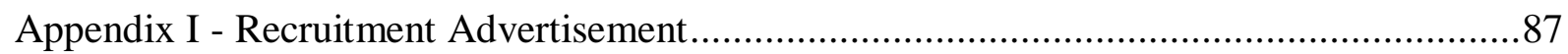

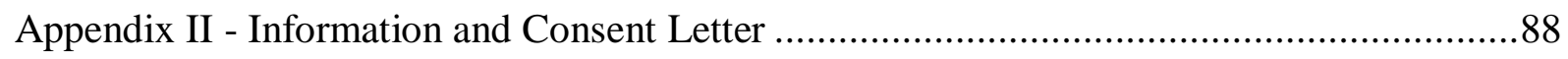

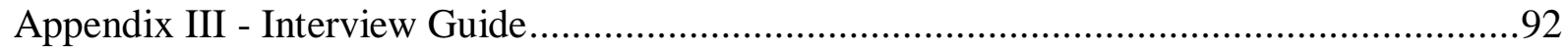

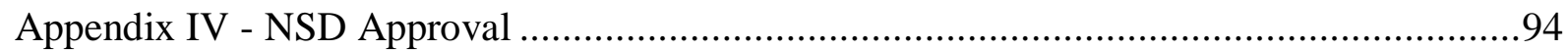





\section{Introduction}

In recent years, researchers have become increasingly interested in the broad range of skills needed for accomplishing and sustaining expert-level musicianship (Ginsborg, Kreutz, Thomas, \& Williamon, 2009; Schneider \& Chesky, 2011; Williamon, 2004). Within this field, much interest has emerged in understanding music performance anxiety (MPA). Over the last few decades, research on MPA has expanded with conferences, journals, masterclasses and musicians' health clinics directing their efforts to studying its various aspects (Kenny, 2011; Papageorgi, Hallam, \& Welch, 2007; Valentine, 2002). There appear to be a couple of reasons behind this increased empirical attention. Firstly, through musicians' health and wellbeing research, MPA has been identified as highly prevalent in both student (Kenny, 2011; Papageorgi et al., 2007; Tamborrino, 2001; Valentine, 2002; Williamon, 2004) and professional musicians (Fishbein, Middlestadt, Ottati, Straus, \& Ellis, 1988; Kenny, Driscoll, \& Ackermann, 2014; Vaag, Bjørngaard, \& Bjerkeset, 2016; Van Kemenade, Van Son, \& Van Heesch, 1995). Secondly, there is a high reported incidence of maladaptive pre-performance anxiety which may spread out to days or even weeks before the actual performance (Kenny, 2006, 2011; Papageorgi et al., 2007) effecting students overall wellbeing, and performance outcomes.

This increased empirical attention has generated valuable knowledge about the health and wellbeing of performing musicians and indicated fruitful avenues for addressing others. However, like most emotion-related phenomena, MPA has proven to be a complex subject to investigate; despite the increased attention, the field is still considered in its infancy (Kenny, 2011; Matei \& Ginsborg, 2017). Most research on MPA has considered it in relation to physiology (Holden, 2006; Thurber, Bodenhamer-Davis, Johnson, Chesky, \& Chandler, 2010), performers' personal characteristics (Cox \& Kenardy, 1993; Kenny, 2011), or the elements shaping the immediate performing environment (Aufegger, Perkins, Wasley, \& Williamon, 2017). So far, investigations have mostly been confined to quantitative inquiries. Although considerable amount of research has been devoted to physiology and medical treatments (See Reviews by: Brugués, 2011a; Brugués, 2011b; Kenny, 2005; McGinnis \& Milling, 2005) of the phenomenon, less attention has been paid to investigating the lived experiences of students in Higher Education institutions through qualitative inquiries. In particular students' experiences, the coping strategies they utilize in order to regulate their MPA, and the role of the institution on the students' regulation efforts deserve further investigation. In order to address this gap the current study investigates the following main 
research question: How do students in Higher Music Education experience and manage music performance anxiety?

In order to meaningfully investigate this question, the study employs the following three sub-questions:

- What are the manifestations of MPA among the participants?

- What coping strategies do the participants use to regulate their MPA?

- What is the role of the educational environment in supporting students' MPA regulation?

In order to empirically investigate students' experiences and management of MPA in educational settings, the current study adapted an analytical framework drawn from sociocognitive views of self-regulated learning (SRL). Existing research suggests that selfregulated learning is an essential component in increasing competency in musical performance skills (Gary E McPherson, Miksza, \& Evans, 2018; Gary E McPherson \& Renwick, 2011; Nielsen, 1999, 2001; Zimmerman, 1989). SRL is defined as an active constructive process where individuals direct and control their thoughts and actions to achieve their goals and respond to environmental stimuli (Zimmerman \& Schunk, 2001). While preparing for a performance, often over long periods, music students continuously monitor and revise output to fulfil their personal standards of quality. Indeed, their ability to effectively do so is crucial to successful future musical careers (Gary E McPherson et al., 2018). Additionally, educational researchers have argued that regardless of what is being targeted thorough self-regulation, be it emotions, learning or motivation, the same basic executive functions like attention-focusing, and higher order processes like metacognition and effortful action underlie self-regulation (Pekrun, Goetz, Titz, \& Perry, 2002; Perry \& Rahim, 2011; P. H. Winne \& Hadwin, 2010; Zimmerman \& Schunk, 2001). As research indicates that MPA is highly prevalent among professional musicians (Fishbein et al., 1988; Kenny et al., 2014; Vaag et al., 2016; Van Kemenade et al., 1995), acquiring self-regulation tools in the management of MPA could support the overall wellbeing of performing musicians.

In order to document personal accounts of MPA, 10 in-depth interviews were conducted with music students currently enrolled at a Higher Music Education institution in Norway. The students were invited to talk about their experiences, coping strategies they utilised, performance preparation, as well as the institutional and other social support they 
received. The methodology involved a phenomenological approach alongside a thematic analysis of the data.

By utilising a qualitative approach, the current study aims to make an empirical contribution by providing descriptive accounts of the everyday, lived experiences and management of MPA among Higher Music Education students. Such descriptions are valuable as they can help lay the groundwork for music institutions looking to enhance students' performance skills and overall wellbeing. Furthermore, a better understanding of these personal experiences may also provide foundational information in building curricula to foster a teaching and learning environment to better enable students' adaptive coping strategies.

\subsection{Thesis Outline}

The literature review relevant to this thesis spreads over two chapters: Chapter 2 lays out the background information on MPA and identifies some of the gaps in the literature. This chapter first presents the commonly used definitions of the phenomenon, its manifestations, prevalence, and management. It then discusses some of the institutional initiatives from around the world that aim to enhance music students' performance skills, including management of MPA. The chapter finishes with a summary of the main aspects of the literature review on MPA and generates potential research directions yet to be addressed. Chapter 3 introduces the theoretical framework used to analyse the data. The socio-cognitive view of self-regulation theory is discussed in detail followed by a section on the applications of self-regulation theories on musical learning and development. The chapter concludes with an analytical framework for the study based on self-regulation models.

Chapter 4 presents the research methodology with detailed focus on the motivation behind utilising a qualitative phenomenological research design, as well as reflections on the validity of the findings and the ethical considerations. Chapter 5 presents the findings, followed by the discussions in Chapter 6 in light of the analytical framework and the literature reviewed. 


\section{Overview of Music Performance Anxiety}

This chapter presents an overview of the Music Performance Anxiety (MPA) literature by drawing on empirical publications of the last three decades. Performance anxiety occurs frequently among professional and student musicians and may create a considerable amount of distress in their lives. Fisbein et al. (1988) found that MPA is the most frequent nonmusculoskeletal medical problem reported by the International Conference of Symphony and Opera Musicians in 1988. Van Kemenade et al. (1995), in a study of Dutch orchestral players, found that 59 percent reported debilitating performance anxiety. Regardless of age and level of expertise, MPA tends to manifest from early age to adolescence (Fehm \& Schmidt, 2006; Margaret S. Osborne \& Kenny, 2008; Ryan, 2005) and into professional life (Fishbein et al., 1988; Kenny et al., 2014; Vaag et al., 2016). It also appears to afflict distinguished and experienced performers as well; Enrico Caruso, Artur Rubinstein, Vladimir Horowitz, Sergei Rachmaninoff and Pablo Casals have been documented as sufferers of the phenomenon (Kenny, 2011; Valentine, 2002).

Several aspects of the MPA have been investigated in varying contexts. Performance anxiety appears to be higher in student musicians than in professionals (Kenny, 2011; Steptoe \& Fidler, 1987). Tamborino (2001), examining the level of performance anxiety among college music majors, reported that 97.1 percent of students have experienced performance anxiety before a performance, and $86.5 \%$ indicated experiencing MPA during a performance (Tamborrino, 2001). A recent study using a virtual reality performance simulator has reported that the audience does not even have to be 'real' for music student's anxiety to be triggered and for heart-rate to elevate (Aufegger et al., 2017). The problem appears to be more severe among women than in men (Fishbein et al., 1988; Margaret S Osborne \& Franklin, 2002; Rae \& McCambridge, 2004; Vaag et al., 2016; Wesner, Noyes, \& Davis, 1990). Moreover, the three causes of MPA most commonly cited by musicians are "pressure from self", "excessive arousal", and "inadequate preparation for performance" (Kenny, 2011, p. 92).

Like other forms of performance anxiety, including those related to public speaking, test-taking, and sports, MPA is a complex phenomenon with multiple causes, encompassing the individual's past-experiences, emotions, cognition and behaviours, as well as genetics and environmental stimuli (Kenny, 2011).

In order to better understand MPA the following sections provide an overview of the main strands of the construct; namely its various components, prevalence, coping and 
regulation strategies in management of MPA, as well as the institutional initiatives aiming to enhance health and wellbeing of music students.

\subsection{Manifestations}

Definitions of MPA differ among researchers; there seems to be, however, consensus that performance anxiety in musicians is characterised by an apparent apprehension about performing, which may or may not be optimal for the performance itself (Kenny, 2011; Salmon, 1990; Valentine, 2002). The most frequently used terms are "stage fright" and “performance anxiety" but "music performer's stress syndrome" has also been proposed (Brodsky, 1996). When stage fright and performance anxiety refer to unwarranted and/or excessive fearfulness during performances, the terms appear to be used interchangeably:

Performance anxiety, or stage fright, is a situational manifestation of anxiety, and is related to the fear of making a mistake or not being able to control one's actions in front of other people (Cox \& Kenardy, 1993, p. 49)

On the other hand, Kenny (2011, p. 50) argues that "stage fright is a sudden onset of intense feelings of fear whereas performance anxiety can build gradually over days or weeks before a performance" In this paper the term "music performance anxiety" (MPA) will be used to address both of these problematic levels of anxiety.

According to Salmon's (1990, p. 3) widely used definition, music performance anxiety is "the experience of persisting, distressful apprehension about and/or actual impairment of, performance skills in a public context, to a degree unwarranted given the individual's musical aptitude, training and level of preparation". To date, this is the most cited definition of the phenomenon and is explicitly referred to in a number of studies (Brodsky, 1996; Fehm \& Schmidt, 2006; Thurber et al., 2010; Valentine, 2002; Williamon, 2004).

Salmon (1990) argues that MPA can manifest itself in three loosely related components: physiological, behavioural, and cognitive (or mental); which are highly interactive yet also partially autonomous. The physiological and behavioural components of MPA are associated with the autonomic nervous system (ANS), and the cognitive component is associated with anticipation of stressful events - musical or otherwise.

The physiological components of anxiety are linked to the over-arousal of the ANS, and they include increased heart-rate, shortness of breath, sweating, nausea, dry-mouth, and urinary urgency. The over-arousal of the ANS, also known as the human stress response, has 
been characterised both physiologically and behaviourally as the "flight-fight" mechanism and played an important role in our ancestor's survival process (Cannon, 1932). Valentine (2002) describes these manifestations in a performance context as follows:

This flight-fight response ... , is highly detrimental to musicians requiring dexterity and fine muscular control over their instruments. Trembling limbs and slippery fingers are likely to hinder rather than help the performer. In addition, this autonomic arousal may have become associated with fear as a result of past experience. Increased arousal generally leads to a narrowing of the focus of attention, which may also be deleterious (p.168).

Behavioural components of anxiety include tremor, muscle tension, shaking, and dead-pan expression (Salmon, 1990; Williamon, 2004). Most people automatically brace and tighten up under stress as result of the primitive responses discussed above. For musicians muscular tension often occurs on the very muscles needed to play their instruments. This unwarranted muscular tension may pose a threat to a performance as it can actually impair the performance itself, e.g. shaking of a cellist's bow arm. Additionally, increased arousal often causes poor concentration which may also be damaging in a performance/audition situation.

Cognitive (or mental) components are subjective feelings of anxiety and negative reflections about performing (Salmon, 1990). Some examples of cognitive manifestations of MPA include fear of becoming anxious, being distracted and having memory lapses, likelihood and consequences of a negative evaluation from peers and judges, and loss of prestige. Negative contemplation manifests itself as another problematic manifestation: "catastrophising," which may involve worrying about making mistakes and their potential consequences and the irrational exaggeration of the likelihood of a disaster (Steptoe, 2001; Steptoe \& Fidler, 1987; Valentine, 2002).

The three-component model of MPA discussed above is well-supported in the literature and has been used in many empirical publications (see e.g.: Craske \& Craig, 1984; Lederman, 1999; Salmon, 1990; Valentine, 2002; Williamon, 2004).

A more recent definition by Kenny (2011), however, proposes a fourth component taking into account research on anxiety. It is also aligned with contemporary ideas on social phobia and anxiety disorders. Kenny's definition originates from the emotion-based model of anxiety proposed by Barlow (2000). According to Barlow (2000, p. 1249), anxiety is "a unique and coherent cognitive-affective structure within our defensive motivational system" and at its heart lies an uncontrollable focus "on possible future threats, danger, or other 
upcoming potentially negative events". Thus, anxiety in this definition may be characterised as a state of incompetency that arises from an inability to "predict, control, or obtain desired results or outcomes in certain upcoming personally salient situations" (Barlow, 2000, p. 1249). Kenny's definition highlights some of the characteristics that are specific to MPA and it differentiates MPA from other forms of performance anxiety (e.g., public speaking, or testanxiety):

Music Performance Anxiety is the experience of marked and persistent anxious apprehension related to musical performance that has arisen through specific anxietyconditioning experiences. It is manifested through combinations of affective, cognitive, somatic and behavioural symptoms and may occur in a range of performance settings, but is usually more severe in settings involving high ego investment and evaluative threat. It may be focal (i.e. focused only on music performance), or occur co-morbidly with other anxiety disorders, in particular social phobia. It affects musicians across the lifespan and is at least partially independent of years of training, practice, and level of musical accomplishment. It may or may not impair the quality of the musical performance (Kenny, 2011, p. 433).

To my knowledge, this is the most comprehensive description of the construct to date. One of the features of MPA that distinguishes it from other forms of performance anxiety is the high levels of ego-investment (Kenny, 2011). This ego-involved orientation may thrive in a competitive conservatory environment where students often begin learning their instruments at an early age with formal instruction. Additionally, students are expected to meet certain criteria in their programme and this is assessed through external-evaluation such as ensemble auditions, graded-public recitals and end-of-term juries. MPA researchers have found that music performers experience the highest levels of anxiety in evaluative situations and fear of negative evaluation is identified as one of the main causes of the phenomenon (Cox \& Kenardy, 1993; Craske \& Craig, 1984; Fehm \& Schmidt, 2006; Kenny, 2006; Margaret S Osborne \& Franklin, 2002; Wilson \& Roland, 2002). Additionally, the formal performance environment shaped by the social context of the Western concert tradition may also exacerbate MPA as it consists of strict observance of the performer and their psychological separation from the audience (Lehmann, Sloboda, \& Woody, 2007; Williamon, 2004). Lehmann (2007) argues that due to this formal environment, classical musicians are more susceptible to MPA than the musicians in the Jazz genre who often perform in more informal venues. This argument is also supported by Kaspersen and Götestam (2002), whose survey 
study of Norwegian tertiary-level students found that jazz majors reported substantially less MPA than the students in orchestral programmes.

These relatively high levels of anxiety are not always a cause for concern. A certain amount of arousal is widely accepted as beneficial to performance (Steptoe, 2001; Valentine, 2002; Williamon, 2004; Wilson \& Roland, 2002). Performance is thought generally to be best at moderate levels of arousal: if arousal is too low, the performance will be mundane and uninteresting; if it is too high, it will interfere with the performance as it might trigger some of the manifestations mentioned above. This optimal arousal is referred to as "flow" or a "buzz" state in the literature. A study by Steptoe cited in Valentine (2002) confirms this pattern for student and professional singers. For both groups, performance quality was reported highest when emotional tension was at intermediate levels (Valentine, 2002). The relationship between MPA and performance quality however, is quite complex and it has to encompass various accounts such as trait anxiety, the level of technical proficiency in performance and the degree of situational stress that is shaped by environmental pressures (Wilson \& Roland, 2002). As the interpretation of the arousal by the performer determines its positive or negative contribution to the performance (Salmon, 1990), one may conclude that some degree of MPA may occur without having any adverse effects on performance quality. Additionally, if the performer manages to keep their anxiety under control, the accompanying physiological arousal can then lay the groundwork and therefore may have positive effect on concentration. Thus, there is a need to make a distinction between maladaptive (or debilitating) and adaptive (or facilitating) forms of MPA when discussing related issues.

The key definitions and various manifestations of MPA were discussed in this section. Additionally, an overview of the manifestations was also included in this section as it was seen as necessary when evaluating coping strategies and their effectiveness in educational settings. This overview is used to analyse the data in particular when investigating the manifestations of MPA among the participants. Prevalence of MPA among professional and student musicians is discussed below.

\subsection{Prevalence}

Several empirical reviews of the prevalence of MPA among professional and student musicians indicate that the phenomenon is widespread and problematic for a significant proportion of musicians. A large survey study, with 2210 professional musicians of the International Conference of Symphony and Opera Musicians (ICSOM), concluded that 
twenty-four percent of musicians reported performance anxiety to be a problem, with $16 \%$ rating it as a severe problem. Women (19\%) were more likely to report performance anxiety as a severe problem than men (14\%) (Fishbein et al., 1988). Steptoe and Fidler (1987) carried out a questionnaire study with three groups of musicians: experienced professional orchestral players $(n=65)$, music students $(n=41)$, and members of an amateur orchestra $(n=40)$. Performance anxiety was lowest in the professional group (42.2\%) and highest among students (50.3\%). Wesner et al., (1990) studied aspects of MPA in tertiary music students and faculty at the University of Iowa, Faculty of Music. The authors surveyed 302 musicians and reported that $16.5 \%$ of the respondents indicated that their performance was impaired by anxiety. Over $21 \%$ of the respondents reported that they experienced marked distress while performing, and $16.1 \%$ reported that music performance anxiety had negatively affected their careers. Not surprisingly, auditions and solo performances were rated as the most anxietyevoking situations. Marchant-Haycox and Wilson (1992) conducted a comparative study of various groups of performing artists, and reported orchestral and solo players with the highest proportion of MPA (47\%), followed by singers (38\%), dancers (35\%), actors (33\%).

Van Kemenade et al., (1995) surveyed all the members of professional orchestras in the Netherlands and reported that $59 \%$ of respondents (91 out of 155) have been affected by performance anxiety. Moreover, they found a substantial percentage of musicians (10\%) displayed symptoms of anxiety for days, weeks, and even months prior to a performance A more recent study by Tamborrino (2001) examining the level of performance anxiety among college music majors reported that $97.1 \%$ of students have experienced performance anxiety before a performance, and $86.5 \%$ indicated experiencing MPA during a performance. String players reported the highest levels of anxiety. The results of a survey study by Karpersen and Götestam (2002), revealed that MPA is a problem among Norwegian music students. In the total sample of 126, $36.5 \%$ reported a need for help with MPA related issues Vaag et al., (2016) investigated mental health problems among professional musicians; they compared the symptoms of anxiety among musicians to data on the general workforce collected in the Norwegian Survey of Level of Living 2012. The results suggest that psychological distress was more prevalent among musicians than in the total workforce sample. Musicians in solo/lead performance and those playing within the classical music genre reported the highest prevalence.

On the basis of the research described above, music performance anxiety is widespread and problematic for a large number of musicians, particularly tertiary-level music 
students. It appears that a considerable amount of research has been devoted to investigating MPA prevalence through quantitative survey studies, however qualitative inquiries on MPA coping strategies appear to be underutilised.

\subsection{Coping with Music Performance Anxiety}

\subsubsection{Coping Strategies Reported by Musicians}

Musicians use a variety of coping strategies to manage their musical performance anxiety. Steptoe (1989, p. 9) defines coping as "the efforts made by people to avert or reduce the impact of potentially stressful events." He further describes that these efforts may be cognitive or behavioural in nature, for example, they may involve a person's attempts to modify or escape from a situation or they may relate to their efforts to regulate their emotional response to that particular situation (Steptoe, 1989). Steptoe's (1989) study involved 65 members of the Royal Philharmonic Orchestra and the London Philharmonic Orchestra, and 41 advanced music students from the Guildhall School of Music and Drama. Both groups were approached at rehearsals and asked to complete a series of questionnaires. The nonpharmaceutical coping strategies reported by the musicians included deep breathing (38\%), self-distraction (28\%) and muscle relaxation (23\%). More recently, in another quantitative inquiry, Kenny et al. (2014) surveyed 377 professional musicians in Australia, and reported on the various MPA coping strategies brought up by the participants. Increasing practice time was reported by $91 \%$ of the participants as the main MPA coping strategy, along with deep breathing and other relaxation techniques, as well as positive self-talk, and mock performance practice (Kenny et al., 2014).

Studies have also used mixed methods and qualitative inquiries to determine musicians' coping strategies. Fehm and Schmidt (2006, p. 101) studied MPA in younger music students: MPA was assessed with a questionnaire, while the coping strategies and the "unmet needs for coping assistance" were assessed using open ended questions. Rehearsing difficult parts of the composition was the most frequently used strategy reported. In the same study, participants were invited to describe other strategies they used immediately before the performance. A wide variety of strategies such as "washing hands with warm water," "eating chocolate," "cleaning the instrument and talking to it," among others, were described (Fehm \& Schmidt, 2006, p. 105). The study concluded that many of the participants managed their MPA by not only acquiring specific strategies but also by asking for social support from mainly their teachers or other personal connections outside of the educational settings. 
In his study investigating how professional performers manage MPA, Roland (1994), presented an array of short- and long-term MPA coping strategies. The results indicated that the participants had developed psychological, musical and lifestyle strategies for managing their MPA. In particular, Musical (e.g.: practice, simulating performances), Behavioural (e.g.: spending time alone before a performance), Cognitive (e.g.: building confidence, positive self-talk, mental rehearsal) and Lifestyle (e.g.: maintaining physical health, resting on the day of the performance) strategies were reported among others. One important implication of this study was that all the strategies reported by the participants could be taught by various professionals. Various interventions and performance enhancement programmes were considered by several researchers, as outlined below.

\subsubsection{Various Treatment Approaches in Management of MPA}

Three major systematic reviews emerged over the last two decades on the management of MPA (see: Brugués, 2011a, 2011b; Kenny, 2005; McGinnis \& Milling, 2005). These studies have reported both on pharmaceutical and non-pharmaceutical ways of coping. McGinnis \& Milling (2005) concluded that despite the methodological limitations of the existing literature, the most effective treatments appears to incorporate cognitive restructuring and exposure therapy. Brugués (2005) placed particular importance on cognitive-behavioural therapy (CBT). Kenny (2005) stated that Alexander Technique, hypnotherapy, music therapy and meditation confirm potential effectiveness but more research is needed to propel the field forward. All of the reviews have pointed out the fact that it is difficult to draw any conclusions from these results as many of the reported studies appear to be methodologically weak, and these limitations are acknowledged by their authors. Despite this, these comprehensive reviews provide the best basis for the development of a more robust direction for future research on MPA (Kenny, 2005; Matei \& Ginsborg, 2017).

Cognitive behavioural therapy (CBT) is widely used as a coping strategy. CBT emerged from a union of originally two separate forms of therapy - it focuses on the way people think (“cognitive") and act/react ("behavioural”) (Spahn, 2015, p. 133). CBT employs "cognitive restructuring" strategies including recognition, evaluation and modification of maladaptive behaviours and problematic thinking patterns such as negative self-talk (Spahn, 2015). As discussed in previous chapters, negative self-talk, "catastrophising," and overemphasising negative performance experiences heighten performance anxiety (Spahn, 2015; Steptoe \& Fidler, 1987; Valentine, 2002; Wilson \& Roland, 2002). The effects of CBT 
were investigated by Kendrick et al., (1982) who concluded that CBT based treatment was effective in self-reported measures of MPA compared to the control group. Significant improvements were observed in the reduction of visual signs of MPA, improvement in musical performance and a significant decrease in negative self-talk. No statistical significance was observed in heart-rate measurements

Kenny's (2005, p. 195) comprehensive review of the treatments of MPA reports on two different studies by Montello on the effects of music therapy on MPA. Montello (1989) and Montello et al. (1990) assessed the effect of a 12 week music therapy on freelance musicians. The study entailed improvisation sessions, three musical performances in front of an audience, awareness techniques and verbal processing of musicians' anxiety responses. In the second study, a replication of the first, additional outcome measures and attentional control group was added. The findings of the second study suggested that participants showed significant improvement in confidence and displayed a decline in their anxiety.

In the early 1980s, some researchers proposed beta-blockers as the pharmacological solution to the management of MPA (Lehrer, 1987). These inhibit the over-arousal of the autonomic nervous system, thus helping eliminate MPA manifestations such as tremor and dry mouth (Wilson \& Roland, 2002). Lehrer's review (1987) revealed that beta-blockers may reduce some of the physiological components of the music performance anxiety but had very little effect on reducing the psychological components. The use of beta-blockers among performing musicians is well documented: the ICSOM survey (Fishbein et al., 1988) reported that $27 \%$ of the musicians used beta-blockers, most of them without a doctor's prescription, and $96 \%$ of these respondents reported these effective in reducing MPA. Kenny et al's (2014) survey, reported $31 \%$ of musicians taking beta-blockers to alleviate MPA. More recently, data from 1500 Norwegian musicians suggest higher use of psychotropic medication (e.g. sedatives, antidepressants, hypnotics and medication for attention-deficit hyperactivity disorder), particularly among string players (Vaag et al., 2016).

\subsection{Institutional Initiatives}

Having reviewed various aspects of MPA, including key definitions and manifestations, I now turn the focus to a review of institutional initiatives aiming to improve music students' health and wellbeing. It is becoming increasingly apparent that music students require not only musical skills but also physical and mental ones in order to adequately prepare for performances. Today, most conservatory and university music 
departments have some sort of established programme for both treatment and prevention of performance related problems, including MPA. Presented below are some of the MPA related initiatives at a selection of institutions, compiled with the information available on their websites.

The Hannover University of Music and Drama offers one of the most comprehensive programmes on the health and wellbeing of musicians. The institute offers a compulsory yearlong programme in Health and Music Physiology in 11 modules, two of which are dedicated to MPA. The institute also offers elective seminars on performance anxiety. Each student also has the opportunity to arrange an individual consultation on playing-related issues which includes a physical examination by a physician and an examination at the instrument. The institute offers Alexander Technique and yoga/relaxation as part of their injury prevention and body-awareness initiatives. ${ }^{1}$

The Royal College of Music in London offers a variety of resources to its students. Students are offered courses on various topic from nutrition to physical fitness, to mental wellbeing. RCM is also home to the performance simulator, a distinctive training facility that offers musicians opportunities to practise their performing and audition skills and develop skillsets to manage their performance. The performance simulator comes with a realistic backstage and on-stage areas and currently has four functions: concert, audition, press conference, and evaluation simulation. Some empirical evidence exist on the effectiveness of the simulator as well. For instance, Williamon at al. (2014) conducted a study where they designed, tested and explored the possible uses of these interactive and simulated environments which provided participants with real cues from real-life performance situations. In this case, these included a small recital and audition setting offering "key visual, auditory, and other environmental cues commonly found backstage and on stage at international performance venues" (Williamon, Aufegger, \& Eiholzer, 2014). They found that the simulation training they employed has a lot to offer musicians (Williamon et al., 2014). However further experimental work is needed in order to precisely use the simulator in varying ways in order to help students with different skill levels. ${ }^{2}$

The Julliard School of Music and the Colburn School of Music both have had Don Greene, whose background is in sports psychology, on faculty to help their students' performance skills. Don Greene's method is currently taught by different instructors at both institutions. These methods are derived from sport psychology and assist students in achieving

\footnotetext{
${ }^{1}$ https://bit.ly/2VQkIUm

2 https://www.rcm.ac.uk/courses/undergraduate/bmus/
} 
optimal performance levels. Through a series of practical exercises and mock auditions, students employed pre-structured strategies and techniques, such as mental rehearsal and the “Centering” process for achieving peak performance. ${ }^{3}$

The Norwegian Academy of Music (NMH) offers modules in several disciplines involving body control and the correct use of the body. They include Alexander Technique, tai chi, qigong, eurhythmics, and Timani. There are various performance enhancement courses offered as well, such as "Musician in Motion," where students explore various movements to release physical tension associated with playing musical instruments and practise breath awareness and mental attention. The academy also offers the services of an inhouse psychologist. ${ }^{4}$

Alexander Technique (AT) deserves further discussion as it is offered widely by conservatories and university music departments around the world. Klein et al (2014)'s comprehensive review of the effectiveness of AT sessions in musicians concluded that AT may improve music performance anxiety in musicians. Interestingly, however, its effect on respiratory function and posture remained inconclusive (Klein, Bayard, \& Wolf, 2014). AT is a "psychophysical method" developed by the Australian actor Fredrick Alexander and it is characterised as improved kinaesthetic awareness and "voluntary inhibition to prevent nonbeneficial movement patterns" (Klein et al., 2014, p. 2).

Furthermore, many institutions offer various other approaches to performance enhancement and the effectiveness of some of these interventions have been documented by researchers. Khalsa et al. (2009) evaluated the benefits of yoga and meditation for young adult professional musicians. Participants volunteered to participate in a 2-month programme of yoga and meditation and were randomised into a yoga lifestyle intervention group (receiving additional weekly group practice and discussion sessions $)(n=15)$ or into a group practising yoga and meditation only $(n=15)$, in addition a control group that did not practise yoga or meditation $(n=15)$. Both yoga groups displayed a trend towards less music performance anxiety and significantly less general anxiety/ tension, depression, and anger, but showed no changes in performance-related musculoskeletal disorders, stress, or sleep (Khalsa, Shorter, Cope, Wyshak, \& Sklar, 2009). Chang et al. (2003) investigated the effect of meditation on music performance anxiety in 19 students from four institutions. The participants in the experimental group were encouraged to practise meditation daily. After the 8-week training

\footnotetext{
${ }^{3}$ https://bit.ly/2Ed1AuZ

${ }^{4}$ https://nmh.no/studier
} 
period, results indicated a decrease in MPA among participants in the meditation group (Chang, Midlarsky, \& Lin, 2003).

\subsection{Chapter Summary}

This Chapter has established a basis for the current study by reviewing the literature on MPA with respect to the components, prevalence, coping approaches and institutional initiatives concerning. The MPA literature reviewed encompassed studies varying in methodology and subsequent analysis. These studies on MPA have considered it in relation to various anxiety factors (e.g., cognitive, behavioural and/or physiological), preparation of the performer for the performance (e.g., level of expertise in the domain), or their personal characteristics (e.g., occupation, gender and/or genetics). It appears that there have been few attempts to understand the meaning that students ascribe to their MPA, and coping strategies they employ by exploring their perspectives through their own words. While it is clear that the various forms of MPA previously studied are distinct emotional and cognitive responses to be researched in clinical settings, there appears to be an intimately intertwined relationship between the musician as the learner, the performance and the institution that deserves further investigation. In order to empirically investigate students' experiences and management of MPA in educational settings, the current study adapts an analytical framework drawn from emotion and self-regulation theories. 


\section{Theoretical Concepts and Analytical Framework}

This chapter presents the theoretical concepts and the analytical frameworks guiding the analysis in this thesis. First, I will present the key concepts and perspectives on selfregulation. I discuss the main processes involved in self-regulation and how these may form cyclical phases. I also include a section on emotion regulation mainly due to its importance in management of MPA. In Section 3.2. I will then turn to a literature review of the applications of self-regulation theories on musical learning and development. Finally, I will present the analytical framework for the current study in light of the reviewed literature.

\subsection{Self-Regulation}

In its more general sense, self-regulation refers to self-directed cognitive and metacognitive processes to set personal goals, plan strategies, and monitor and evaluate continuous behaviour (Cervone \& Pervin, 2015). In academic contexts, with a more specific reference to learning and learning processes, self-regulated learning (SRL) is typically viewed as an active constructive process where individuals set goals, monitor, organise and control their cognition, motivation and emotions in order to achieve desired explicit or implicit academic goals (Pintrich \& Zusho, 2002; Philip H Winne \& Perry, 2000; Zimmerman, 2000). Educational researchers agree that the most effective learners are equipped with selfregulatory properties (Butler \& Winne, 1995; Gary E McPherson et al., 2018; Nicol \& Macfarlane-Dick, 2006; Nielsen, 2001; Vohs \& Baumeister, 2016; Zimmerman, 2011). Existing research on students' self-regulated learning have focused on processes that learners utilise to direct their behavioural conduct but also to activate and prolong their cognitive and affective functioning (Boekaerts, 2011; Zimmerman \& Schunk, 2001). Research on such processes have revealed that students who are effective at self-regulating are able to set goals for improving their knowledge on a task, deliberating about strategies to select the most suitable plan of action, and monitoring the acquired effects of their engagement. Furthermore, the term "self-regulated" is often used to describe learners who are metacognitive, motivated, persistent, and strategic, meaning that they hold the ability to evaluate their strengths and weaknesses as learners in relation to pre-set goals or assigned tasks and then utilise a strategical approach to confront challenges to achieve optimal outcomes (Perry \& Rahim, 2011; Philip H Winne \& Perry, 2000; Zimmerman \& Schunk, 2001).

Zimmerman (2002, p. 65) claims that "self-regulation is not a mental ability or an academic performance skill; rather, it is the self-directive process by which learners transform 
their mental abilities into academic skills" and learning in this sense is viewed as "... an activity that students do for themselves in a proactive way rather than as a covert event that happens to them in reaction to teaching".

This self-directed process inherently involves various influences, namely person, behaviour and environment, that function proactively and reactively in attainment of personal goals (Bandura, 1986). The triadic definition of the construct and its cyclical structure are discussed below.

\subsubsection{The Triadic View of Self-Regulation}

The triadic view of self-regulation emerged from social-cognitive theory (SCT), and it refers to a person's "self-generated thoughts, feelings and actions that are planned and cyclically adapted for the attainment of personal goals" (Zimmerman, 2000, p. 14). As previously mentioned, social-cognitive theory addresses human motivation mainly by studying the motivational impact of thoughts about oneself or on self-relevant thinking. As such, the key thinking processes often involve the self and are developed through interaction with one's environment (Cervone \& Pervin, 2015).

As such, the triadic view of SRL is explained as an interaction of personal, behavioural and environmental triadic processes (see Figure 1) which interact under the influence of one's beliefs and motives (Bandura, 1986; Zimmerman, 1989). Zimmerman's triadic view of self-regulated learning is in accordance with Bandura's view of the construct. Their view assumes that the process of self-regulation occurs in a reciprocal relationship between the following three processes:

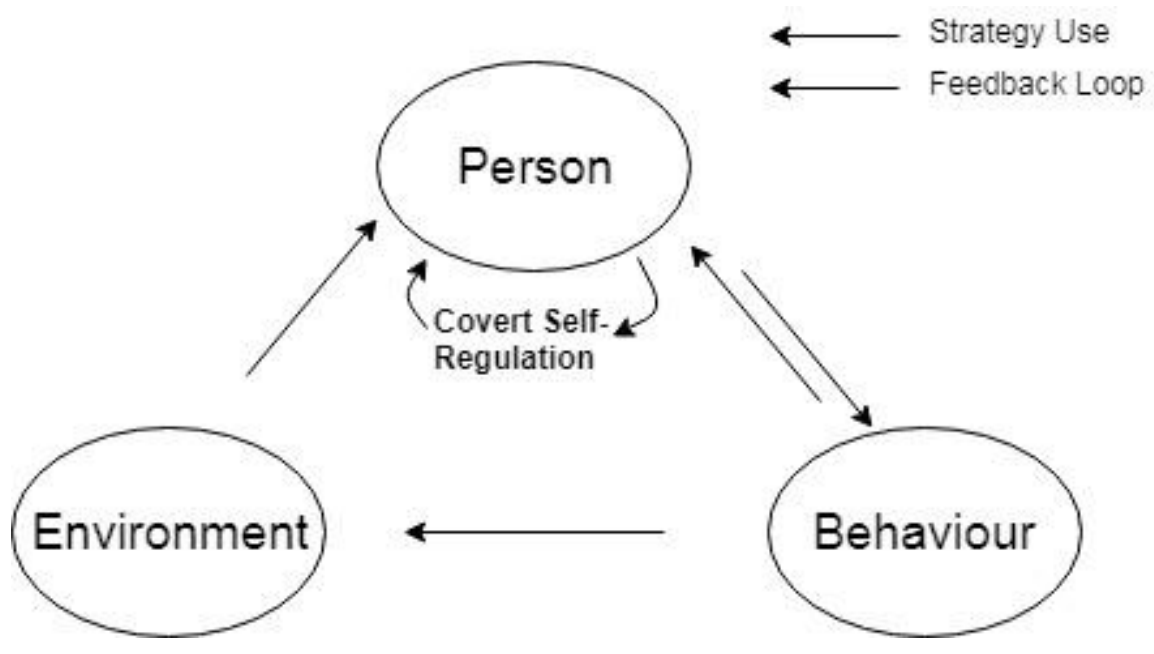

Figure 1 Triadic Forms of Self-Regulation.

Note. From "A social cognitive view of self-regulated academic learning," by B. J. Zimmerman, 1989, Journal of Educational Psychology, 81, p. 330. 
The process is described as cyclical because the feedback from a prior performance (e.g. math test) is used to make adjustments in a student's current learning efforts. These continuous adjustments are seen necessary as the personal, behavioural, and environmental factors are continuously changing during the course of learning. Any given student may have different skill sets, beliefs and standards in various learning situations, therefore their behaviour naturally changes across different learning situations, reflecting their self-relevant characteristics. Furthermore, contextually related self-processes such as perceived selfefficacy or self-control, have been utilised by researchers in order to explain the variations in personal motivations that self-regulate one's learning (Cervone \& Pervin, 2015; Philip H Winne \& Perry, 2000; Zimmerman, 2000).

The triadic system displayed above is closely linked to the student's underlying sense of self-efficacy beliefs (Bandura, 2010; Zimmerman, 2000). Self-efficacy refers to "people's judgements of their capabilities to organise and execute courses of action required to attain designated types of performances" (Bandura, 1986, p. 391). During a self-regulation process, student's self-efficacy serves as a "thermostat" that regulates their strategic efforts to attain new knowledge or a skill through enactive feedback loops (Zimmerman, 1989). Feedback loops are comprised of a cyclical process in which students assess the effectiveness of their strategy use and then self-react by providing further feedback in various ways. For example, a student may choose to continue studying the same way for her history exam if the result was successful or change strategies (e.g. chose a different memorisation strategy) when it was not. As such, the feedback loops function in a sequential way by enabling students to be both sensitive and adaptive to their output in return altering their perceived self-efficacy beliefs.

According to Zimmerman (1989), the behaviour process displayed in Figure 1 refer to students' proactive use of a self-regulation strategy (e.g. checking science homework). The strategy use then provides information about the accuracy of the task performed and further planning if modifications are needed to attain the designated level of attainment. The environment process refers to student's self-regulation of the physical or social setting in which they learn. This process involves student's proactive use of an environmental-control strategy (e.g. moving to a quieter part of the house to finish the reading assignment) and it is continued or modified depending on its effectiveness. And finally the covert self-regulation involves "monitoring and adjusting cognitive and affective states" for instance, thinking of a happy memory to reduce anxiety in an exam situation (Zimmerman, 1989, p. 14). Figure 1 indicates that a learner's self-regulatory processes are reciprocally interactive with each other. 
Both Bandura (1986) and Zimmerman (1989, 2000) cautioned that this reciprocity does not equal to symmetry in strength of these influences; personal influences, for example, may be stronger than the environmental or behavioural ones depending on the context (Bandura, 1986; Zimmerman, 1989, 2000).

\subsubsection{The Cyclical Structure of Self-Regulatory Processes}

There are a wide variety of contributions that exist in the SRL literature. For the current thesis the focus is mainly placed on the socio-cognitive view of SRL through the contributions of Zimmerman (1989, 2000, 2002), Schunk (1989), and Bandura (1986, 2010). This is because these models directly highlight constructs such as self-efficacy beliefs, goal setting, mastery experiences and motivation when discussing SRL processes, all of which are considered relevant to the current study.

The socio-cognitive models of self-regulation delineated by Zimmerman (1998, 2000, 2002) as well as Schunk and Ertmer (2000) and Bandura (1986) discuss separate phases of self-regulation. These theorists view the structure of the self-regulation process in three cyclical phases: forethought, performance or volitional control and self-reflection (See Figure 2). The forethought phase refers to the processes and beliefs that occur before the learning effort takes place; the performance phase refers to the processes that occur during behavioural application; and self-reflection refers to the processes that occur after each learning effort (Zimmerman, 2002).

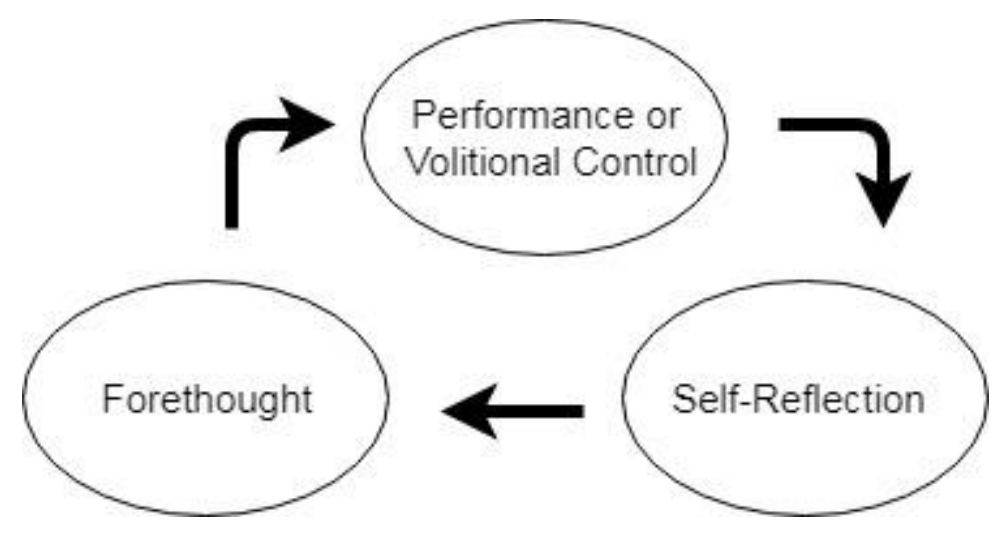

Figure 2 Cyclical Phases of Self-Regulation

From Self-Regulated Learning: From Teaching to Self-Reflective Practice. (p. 3), by D. H. Schunk and B. J. Zimmerman (Eds.), 1998

The forethought phase is where individuals plan their course of action for achieving a specific goal and engage and activate various motivational beliefs, values and aims. During 
the forethought phase there are two distinctive but closely related sources of self-regulation: task analysis and self-motivational beliefs (Zimmerman, 2011). Task analysis involves goal setting and strategic planning. Highly self-regulated individuals appear to set specific proximal goals for themselves in order to attain desired level of achievement (e.g. memorising a word list for a spelling test). Such strategic planning is needed in order for a skill to be mastered and performed optimally. These strategies are defined as specifically tailored personal processes and actions directed at acquiring or performing certain skills (Zimmerman, 1989). Zimmerman argues that self-regulation "entails not only behavioural skill in selfmanaging environmental contingencies, but also the knowledge and the sense of agency to enact this skill in relevant contexts." The self-regulatory skills appear to have little value if the student is not motivated to use them, and as such, self-motivation stems from student's selfbeliefs about learning (Bandura, 2010; Zimmerman, 2000). The key self-motivational beliefs, such as self-efficacy, intrinsic interest, and outcome expectations are considered underlying drivers of the forethought process. As discussed earlier, self-efficacy refers to personal beliefs about having the capacity to succeed in a task, whereas outcome expectations refer to personal consequences of learning (Bandura, 2010; Zimmerman, 2011). Bandura (1986) stated that an individual's beliefs in regards to personal efficacy, developed as result of individual experiences, were essential for a continuous behaviour over an extended period of time. Indeed both self-regulation (Zimmerman \& Schunk, 2001) and self-efficacy (Bandura, 2010) research have indicated that there is an apparent link between high-stress performance situations (e.g. a science presentation, or a math test) and affective reactions such as anxiety. Moreover, such reaction is highly influenced by the presence or absence of particular moderating factors. In addition, a perceived inability to control negative thoughts and environmental stimuli had been directly linked to anxiety response (Bandura, 2010). These implications in particular make the SRL framework an ideal fit for studying MPA. 

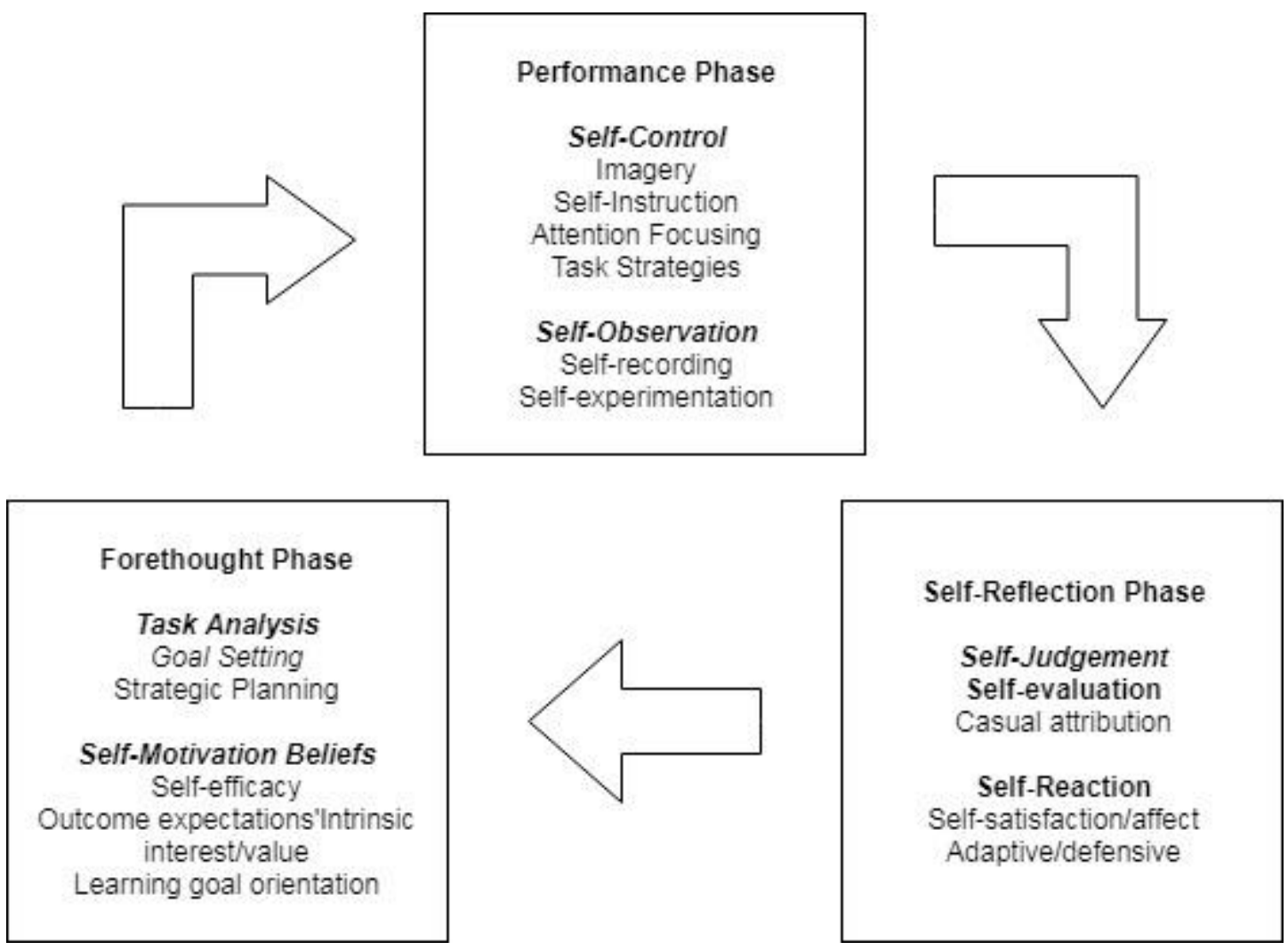

Figure 3 Phases and Subprocesses of Self-Regulation.

Taken from: Barry J. Zimmerman (2002) Becoming a Self-Regulated Learner: An Overview, Theory Into Practice, (p.67)

The performance phase involves monitoring during the course of learning: this is the phase where the learner monitors both performance and motivation, and attempts to be in charge of these elements. Performance phase processes are divided into two categories: selfcontrol and self-observation.

Self-control refers to students' proactive action to deploy a set of specific strategies selected and acquired during the forethought phase. Key types of self-control empirically investigated in the past that are relevant to this study are the use of imagery, self-instruction and attention focusing. Imagery or the use of mental pictures is a widely used self-control technique to assist performance. For example, figure skaters create a mental map of their planned routines in order to enhance performance. Self-instruction involves overtly or covertly describing how to proceed as one performs a task, such as memorising a formula and calling it in a explanatory way in an exam situation, such verbalisation is shown to improve students learning and performance (Zimmerman, 1989). Another form of self-control strategy, attention focusing, is designed to enhance concentration by eliminating external distractions. This may involve for example environmental structuring to eliminate diversions (e.g. turn the music off to read the history assignment), or slow motion task execution to enhance motor 
coordination (e.g. a string player practising double stops slowly). The second type of performance control method involves self-observation, referring to students' cognitive tracking of their personal functioning. The process entails enhancing learner's self-awareness of the "specific aspects of their own performance, the conditions that surround it, and the effects that it produces" (Zimmerman, 1989, p. 19) This process is quite relevant to high expertise domains such as music performance, for example, when a solo pianist monitor their hand positioning, they can reactively enable a fine-grained adaptation to enhance their performance.

The self-reflection phase is where the student engages in reflections on performance after completing certain learning activities. During the self-reflection phase the student makes an active effort to understand why different outcomes took place, manage her emotions with respect to the accomplishments, and enter a self-evaluative/reflective state about the learning situation just experienced (Zimmerman, 2000; Zimmerman \& Schunk, 2001).

There are two major processes that fall under self-reflection: self- judgement and selfreaction. Self-judgement involves self-evaluation of one's performance and attributing causal significance to the outcome (Bandura, 1986). The causal-attribution refers to beliefs about the cause about one's failures and successes, such as a grade on a chemistry exam. These attributional judgements are considered pivotal to self-reflection, as attribution of failures to a limited ability may prompt learners to react negatively; resulting in decreased motivation to improve in the future (Zimmerman, 2002). The self-judgement is also done through comparisons of evaluating how well one's own performance compares to a standard or to the performance of others. Self-reaction (reactions to performance outcomes) involves perceptions of satisfaction or dissatisfaction and a corresponding affect regarding one's performance outcome (Zimmerman, 2002). When these reactions are favourable, specifically in response to lack of success, students are more likely to continue. As such, increases in selfsatisfaction result in enhanced motivation, whereas decreases may undermine future attempts to learn (Zimmerman, 2002, 2011).

It is to be noted that the theoretical frameworks described above define the selfregulation process as cyclical, its utilization in practice however is a non-linear process mainly due to the aforementioned feedback loops. As discussed above the knowledge gained in one cycle may feed into other phases or back into itself. 
In short, the socio-cognitive view of self-regulation emphasises the importance of selfefficacy beliefs, goal setting, causal attributions, and motivation in regulating behaviour directed at mastering a task or a skill. Once a student engage in a task, they then must monitor their progress, judge its outcome and enact adjust to those outcomes in order to regulate and propel their leaning and behaviour forward.

\subsubsection{Emotion Regulation}

Although the study of emotion regulation (ER) is a complete area of the literature unto itself, there is some important overlap with the study of self-regulation. Theories involving regulating emotions are grouped under two main categories: those that study different types of emotion regulation strategies that may be utilised in everyday life, and those that study emotion regulation as part of self-regulation processes that are involved in learning and performance. For the purposes of this paper, ER is discussed under the umbrella of the selfregulated learning (SRL) framework.

Emotion regulation has been defined as a processes in which an individual manages to influence the emotions they experience: how they experience them and when they experience them (Gross, 1998). It also refers to one's capacity to understand one's own emotions, and their competency in modifying and altering aspects of their emotional correspondence (Boekaerts, 2011). Studies of regulation of emotion in educational settings have been slow to emerge despite the construct's central role in SRL (Boekaerts, 2011). Koole et al., (2011) state that self-regulation and emotion-regulation are so intertwined that it is hard to point out where one ends and the other begins. Consequently, emotions appear to play a critical role in self-regulation of learning and performance (Boekaerts, 2011; Pekrun et al., 2002; Pekrun \& Linnenbrink-Garcia, 2012). As emotion and cognition dynamically interact to guide the learning process, students may benefit from learning to regulate their emotions in order to aid their learning objectives. Positive emotions associated with academic achievements facilitate self-regulated learning, additionally negative emotions may motivate the individual to rely on external guidance such that learning activities to be guided to meet the demands of performance tasks (Pekrun \& Linnenbrink-Garcia, 2012). So what does ER in an academic settings mean in practice? Educational researcher Wolters (2003) defines ER as a learner's ability to monitor, evaluate, and adjust the occurrence or intensity of a specific emotional experience. More specifically emotion control in academic settings entails students' ability to regulate their emotional experience to ensure effortful completion of an academic task. In this 
context, ER is often viewed as essential for reducing "negative affective response and deleterious effects associated with performance evaluations" (Wolters, 2003, p. 199).

Wolters (2003) gives examples to tension-reduction attempts such as slowly counting to 10 , mindfully controlling the breath so that it is slow and deep or engaging in self-talk strategies to control their affective reaction. For example, performers might focus on internal dialogue to identify negative self-talk (e.g. "I am going to fail my performance exam") and substitutes these with more positive and realistic affirmations (e.g. "This concerto is difficult but I will master it with hard work") (Kenny, 2011, p. 189). Furthermore, ER in an MPA context can be discussed in light of the findings that reveal the basic difference between appraisals that lead to further anxiety in a performance situation and to those that lead to states of optimal arousal as discussed in Chapter 2. These two outcomes are shaped by various factors, some of them are musicians' expectations of success, external evaluation, and perceived coping potential (Kenny, 2011; Valentine, 2002; Williamon, 2004).

In summary, both anxiety and buzz/flow states emerge from appraisals that involve seeing the performance opportunity as being important to one's future goals and seeing it as potentially not going according to the plan. However, the difference lies within performers' skill in "modifying and tempering aspects of their emotional experiences if they interrupt them from pursuing their goals" (Boekaerts, 2011). When studied in this respect, emotion regulation may be understood as a form of self-regulated behaviour where the person achieves regulation through a steering mechanism that comprises of two main components. The first step is a monitoring process where the individual compares her current state with a desired one, and in the second step she then takes the necessary steps in order to bring herself closer to the desired emotional state (Vohs \& Baumeister, 2016). As previously mentioned, in this study emotion regulation is discussed as a self-regulated and task-oriented behaviour in relation to an individual's learning, achievement and performance goals.

\subsection{Research on Self-Regulated Learning in the Context of Music Performance}

Research into the practice habits of musicians has long been a fruitful source of discussion (see e.g.: Ericsson, Krampe, \& Tesch-Römer, 1993; Flesch, 1939; Hallam et al., 2012; Jørgensen, 2004). Theoretical inquiry into the myriad of factors involved in musical learning, however, only started in the 1990s (Varela, Abrami, \& Upitis, 2016). During this time the rise of constructivism and its associated theories have come to represent a 
fundamental shift in the paradigms of learning and instructional design. This resulted in new constructivist-inspired frameworks for educational research and inquiry (Land \& Hannafin, 2000). A series of studies conducted and published under the leadership of McPherson in the late 1990s contributed to drawing empirical attention to the educational construct known as self-regulated learning and its further application into music education research. There are various reasons why SRL is relevant in music domain. Music students typically practise alone, often over long periods, while continuously monitoring and revising output to fulfil personal standards of quality. Additionally, the level of mastery, often, depends highly on student's intrinsic commitment to task as many younger musicians have usually made the choice to pursue musical learning, rather than having to take it as part of a curriculum (Gary E McPherson et al., 2018).

SRL researchers in music have highlighted that mastering a musical instrument requires a great deal of self-regulation where musicians actively react by choosing, modifying and adopting their playing based on performance outcomes (Gary E McPherson \& Renwick, 2011). In these settings, musicians use evaluative criteria, e.g. feedback from instrumental teachers and peers, and other external reference points to define their future learning and performance goals. McPherson and his colleagues state that self-regulation of instrumental practice is related to musical achievement and performance, and that musicians' use of selfregulatory strategies have an indirect effect on performance outcomes through self-efficacy and formal practice (McCormick \& McPherson, 2003; Gary E. McPherson \& McCormick, 1999; Gary E McPherson \& Renwick, 2011).

Although musical performance is a public endeavour, the preparation for a concert, jury or audition usually takes place privately for a period of weeks or even months. During this preparatory period music students make many different choices for their learning, some of which reflect their personal values, interests and preferences, e.g. practice habits. Other choices are rooted in their interpersonal ties and social interactions, e.g. those acquired through one-to-one instruction or group lessons. By employing these various influences, students, as individuals, develop agency over their own learning, steer and direct various cognitive and motivational processes to achieve their performance goals including management of their MPA. Additionally, through interactions with their social environment, they affect and are affected by one another in advancing towards a performance goal. The individual and collaborative processes of musical preparation are both important in discussions surrounding the management of MPA. 
One of the most influential studies on musicians' practice was done by Ericsson (1993) and his colleagues at a tertiary-level music institution. Ericsson et al. proposed the concept of "deliberate practice" as a way of learning that is task-oriented, metacognitive and strategic, in which motivation, learning environment and focal attention determine the quantity and the quality of practice undertaken (Ericsson et al., 1993). They argued that merely engaging in a sufficient amount of practice, regardless of the structure of the practice, is not enough to improve performance. Individuals must prompt and restructure their skills to overcome challenges. Deliberate practice requires persistence, effort and high focus and is usually achieved through a formal feedback system, e.g. instrumental teacher. Formal practice is another term used by researchers when discussing the practice habits of musicians.

McPherson and McCormick define "formal practice" as "a warmup routine, practicing scales/arpeggios, plus studies and études, and sight-reading music" (Gary E McPherson \& McCormick, 2006, p. 327). In the literature "deliberate practice" appears to be associated with formal music practice where the aim is directly linked to improving specific skillsets. "Informal practice" on the other hand is defined as playing by ear, improvising, "messing around" with music, playing favourite music by memory and so on. Researchers agree that musicians might benefit from engaging in both formal and informal practice. Ericsson at al. (1993) differentiates these terms as follows:

Consider three general types of activities, namely, work, play, and deliberate practice. Work includes public performance, competitions, services rendered for pay, and other activities directly motivated by external rewards. Play includes activities that have no explicit goal and that are inherently enjoyable. Deliberate practice includes activities that have been specially designed to improve the current level of performance. The goals, costs, and rewards of these three types of activities differ, as does the frequency with which individuals pursue them (Ericsson et al., 1993, p. 368)

As just mentioned, musicians with higher task-specific or instrumental-specific skills, in other words more advanced self-regulatory properties, manage to use their practice time more efficiently. As students develop their ability to learn how to use expert practising strategies, they adopt a more positive outlook towards practising, and are more likely to engage in planning and monitoring their improvement in order to set more cognitively complex goals. In short, self-regulation, continuous and deliberate practice should be appraised simultaneously in order to achieve optimal musical performance. 
The research that deals with self-regulated learning in music consists mainly of descriptive studies of tertiary-level musician's practice habits (Hallam et al., 2012; Miksza \& Tan, 2015; Nielsen, 1999, 2001, 2004) and young musician's skill acquisition analysed within a SRL framework (McPherson, 2005). Nielsen $(2004,2008)$ identified that the use of metacognitive, cognitive and resource management strategies (e.g. structure, goal-setting, and managing practice time effectively) had a positive relation to self-efficacy. Hallam et al., (2012) also found that only organisation and strategic approach were effective in predicting performance, and learners at higher levels of expertise reported employing more effective practising strategies.

Miksza (2015) investigated the effects of self-regulation instruction on tertiary-level music student's performance achievement and self-efficacy. He found that participants who received an instruction, including video guidance, in both self-regulated learning principles, such as goal setting and self-reflection, and practice behaviours, made more progress during a 20-min practice session than participants who were only given instruction about practice behaviours. There were no differences in self-efficacy as a function of practice condition; however, students who reported having passion for long-term goals and reflection in their practice reported being more efficient, more likely to be in the "flow", and having greater self-efficacy for self-regulation.

Musical expertise requires refined and specialised skills in order to perform complex cognitive and motoric tasks. Like elite athletes, musicians must maintain their skills at peak form, engage in hours of solitary, repetitive practice and constantly self-evaluate and monitor their development. Some researchers have examined the effects of mental skills training methods employed by athletes on musician's psychological and metacognitive attributes, such as resilience, endurance, motivation, anxiety reduction and self-confidence (Johannes L. Hatfield, 2016; Johannes L Hatfield \& Lemyre, 2016; Williamon et al., 2014). Hathfield (2016) argues that psychological skills training such as goal setting, emotion/arousal regulation, and positive self-talk have been used successfully in sports for the last five decades but are rarely explored by musicians. His study adopted Weinberg and Gould's (2014) 15- week psychological skills training (PST) programme for the context of music performance. Hathfield (2016) merged the PST programme with Zimmerman's cyclical model for SRL: forethought, performance, and self-reflection. Six tertiary level music performance students received personalised one-to-one training that dealt mainly with mental performance issues such as goal setting, self-observation, and journaling. The findings 
suggested that the PST programme generally helped the participants engage in cyclical selfregulation processes; the quantitative measures revealed a significant increase in the use of psychological skills such as goal setting, self-observation and arousal-regulation.

Additionally, the PST-intervention reduced the participant's level of anxiety in performance situations (Johannes L. Hatfield, 2016).

These findings have provided valuable depictions of the kinds of expertise and metacognitive strategies that can be acquired through self-regulated learning. In addition, we see that the positive effects of SRL strategies on the management of musical performance anxiety deserve further investigation.

\subsection{The Current Study}

Before proceeding to the analytical framework for the current study, a few distinctions needed to be highlighted in order discuss MPA with a self-regulatory lens. Revisiting Kenny's definition (see page. 7 of this thesis) of the construct will help us bridge MPA and selfregulation theories. In her definition she highlights the anxious apprehension related to musical performance that is accentuated by specific past "anxiety-conditioning" experiences (Kenny, 2011, p. 433). According to Kenny's definition, in a performance situation, performers form a memory of their stressful performance experience before an audience or a jury where high "ego-investment" and "evaluative threat" are involved. Given this, selfregulation appears to have important implications for learning within music performance, as it may assist students to develop adaptive coping strategies that are carried forward into professional life. Music students may also benefit from using the self-regulatory tools at their disposal towards reducing negative emotions about performing before they are carried forward into future performance situations. Therefore, learning approaches or interventions where a student musician acquires long-term self-regulatory skills to prevent and improve performances affected by MPA have particular importance.

Given the complexity of music performance anxiety, an analytical framework that can account for the various emotional states, and musical preparation processes that students employ was needed. In addition, this study required an approach that recognises that many facets of self-regulation processes and coping with anxiety occur within social contexts, meaning that the results of self-regulation extend beyond the concept of "self-directed" accomplishments to those that are shaped and acquired through social and interpersonal 
relationships within educational settings. The framework below encompasses the various self and social factors in students' MPA regulation efforts.

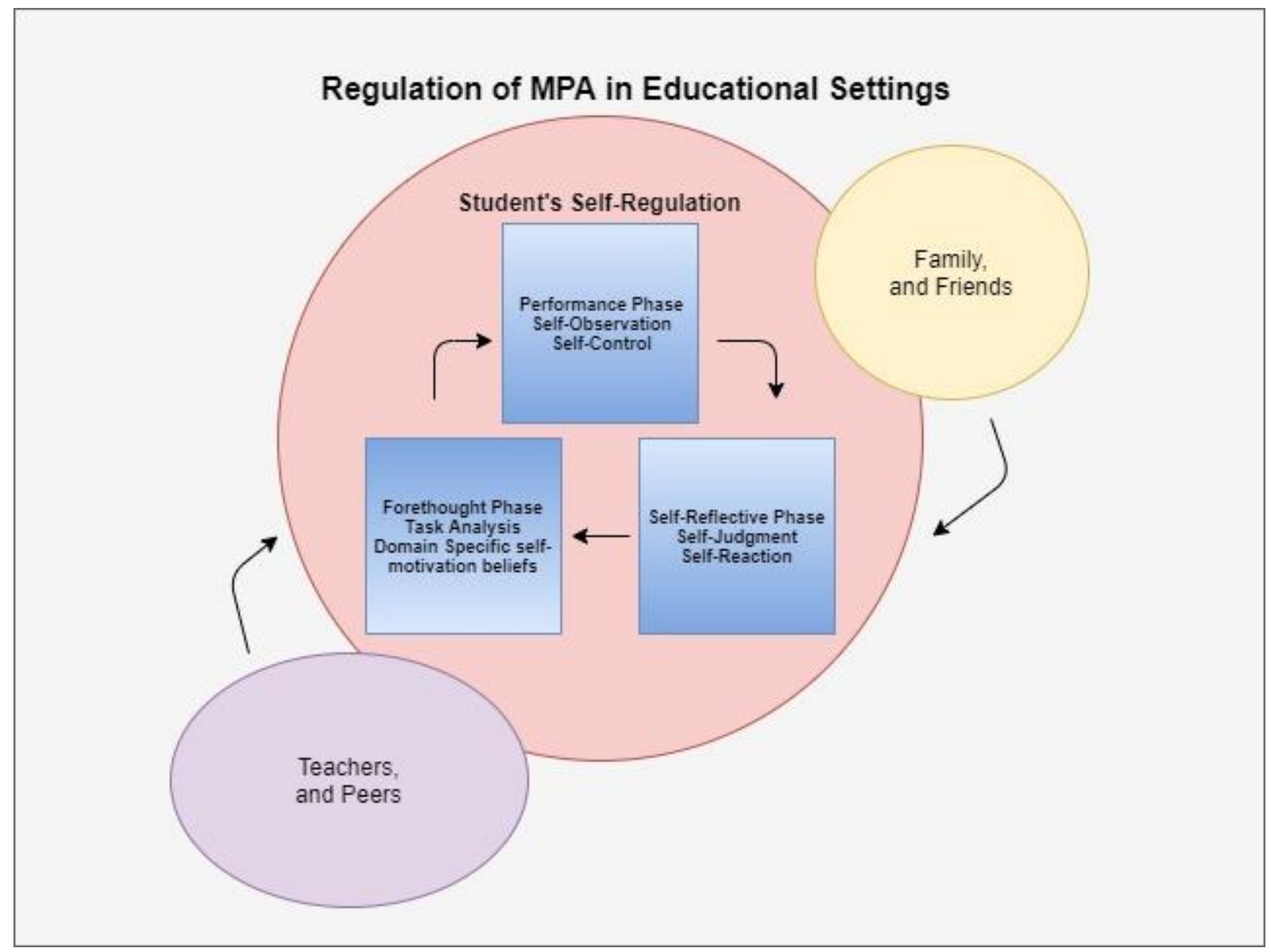

Figure 4 Analytical Framework for the Current Study

The framework above is used to identify strategies used to deal with various manifestations of MPA in educational settings. This framework also highlights the role of social support within institutional settings that is influential in students' regulation efforts. 


\section{Methodology}

In this chapter, the research methodology will be described and will include information in the following areas: the motivation behind utilising a qualitative research design; participants, data collection methods and thematic analysis; and finally validity in light of trustworthiness and academic rigour

\subsection{A Qualitative Interview Study}

MPA is a highly complex and multi-layered area of study; my primary focus is to capture students' experiences and management of MPA within Higher Education settings and while participating in public performance.

Polkinghorne (2005, p. 138) argues that the primary purpose of qualitative research is to "describe and clarify experience as it is lived and constituted in awareness." A qualitative study allows the researcher to investigate and interpret the world of research participants by learning about the sense they make of their social and tangible circumstances, as well as their perspectives and experiences (Creswell \& Poth, 2017). Researching MPA within a qualitative framework helped retain the complexity and uniqueness of each student. It also allowed observation for the re-occurring and shared themes across research participants. The data collected was a rich, and complex depiction of MPA from the student's point of view. The thematic analysis was then conducted in light of the MPA overview and the theoretical framework presented in earlier chapters.

The qualitative methodology used in this study falls within the phenomenological tradition. Creswell (2017, p. 57) claims that "a phenomenological study describes the meaning for several individuals of their lived experiences of a concept or a phenomenon." This approach allowed me to explore the construct through different points of view, supporting the multiple facets of the research theme to be revealed and understood. In addition, as the study aimed to gain a deeper understanding of students' experiences and management of MPA, obtaining their experiential descriptions was an important starting point. Van Manen (1996), states that the point of phenomenological inquiry is "to 'borrow' other people's experiences and their reflections on their experiences in order to better be able to come to an understanding of the deeper meaning or significance of an aspect of human experience, in the context of the whole human experience." (Van Manen, 1996, p. 62). Therefore, with the goal of prioritising lived experiences of MPA, interviews were chosen to gather data. This way of inquiry gave access to first-person accounts of what it is like for 
students to experience and manage MPA in the preparation, performance and postperformance periods. The face-to-face interview approach was also helpful in extracting the relevant data on the various MPA coping strategies students utilized; students description of the MPA manifestations were often followed by what they do or currently preparing to do, strategically, in order to cope with the particular MPA manifestation they experience.

Additionally, by documenting these elaborate descriptions, the reader is brought as close as possible to the everyday, lived experiences (Polkinghorne, 2005) of MPA in Higher Music Education settings. As mentioned in Chapter 2, most of the studies on MPA consist of self-reported, large questionnaires that do not fully capture personal accounts (Such as, Fishbein et al., 1988; Kenny et al., 2014; Vaag et al., 2016). Therefore gaining a greater understanding of students' lived experiences of MPA through qualitative research can be useful in areas such as identification of the gaps in the current educational support structures around anxiety and mental health, as well as exploring new frontiers in teaching and learning practices that may potentially benefit students with performance anxiety.

\subsection{Recruitment of Participants for the Study}

Given the relative absence of research on MPA that relies on the lived, everyday experiences of students in Higher Education, I decided to seek a sample of students at a Higher Music Education Institution in Norway.

Recruiting began in March 2019 through multiple channels: departmental contacts (e.g. instrumental teachers' listserv emails), and in-person recruitment, flyers were posted at the institution message boards and on social media with the support of the Student Union. Some of the students recruited were asked whether they were aware of others who might be interested in participating to the study. This "snowballing strategy," provided an additional form of recruitment that increased the participant pool. Across all available platforms, a short recruitment message was distributed with additional information about the general purpose of the study: to investigate students' experiences with MPA, and ways of coping, including teacher guidance and other forms of institutional support (See Appendices I and II). If interested, students were provided with additional information and face-to-face interviews were scheduled at their convenience. The interview phase lasted from April 42019 to June 21 2019.

In a typical qualitative inquiry, a relatively small sample between 3-10 participants is recommended (Creswell \& Poth, 2017). In regard to sample size, Braun et al., (2019) state 
that some contextual considerations such as the breadth of the research questions, the diversity of the population, and the richness of the data collected from each student are the main determinants. Accordingly, the recommendation is to have at least "five or six interviews" for a small research project given that the "data set is rich" and collected from a "homogenous" sample with a strong orientation towards the research questions (Braun et al., 2019 , p. 852). The sample for this study comprised of 10 music students aged between 19 and 29 years of age. The participation criteria was limited to those students undertaking studies in the Western classical tradition. The reason for this criterion-based approach was to keep the sample tight in order to investigate a group of people who experience the same phenomenon within a shared genre (Creswell \& Poth, 2017).

Additionally, I initially planned to include three more interviews with instrumental teachers, however in order to prioritise students' views in the study, I narrowed the participant pool to students only. Therefore the research questions in the Information and Consent Letter (See Appendix II) that was given to the participants were later amended and the final versions are presented in Chapters 1 and 5.

\subsection{Data Collection}

The qualitative research strategy discussed above provides a methodological framework for the study. Face-to-face, semi-structured interviews were chosen as the main method of data collection. I have created an interview based research protocol (see Table 1) following the "Seven Stages of Interview Inquiry" by Kvale and Brinkmann (2015, p. 128). Kvale (1996, pp. 5-6) defines a semi-structured interview as "an interview whose purpose is to obtain descriptions of the life world of the interviewee with respect to interpreting the meaning of the described phenomena". Face-to face interviews were the most appropriate method of inquiry as they allowed for a friendly atmosphere where the participants were encouraged to raise questions and immediately clear out the uncertainties they may have on the questions asked. Furthermore, face-to-face interviews allowed me to collect elaborate data on individual's personal stories, perspectives, and experiences. The interview process was flexible with an emphasis on how the participants frame and understand MPA. 
Table 1 Seven Stages of Interview Inquiry

\begin{tabular}{|c|c|}
\hline 1. Thematising & $\begin{array}{l}\text { Formulated the purpose of this specific MPA investigation prior to } \\
\text { the interviews. The thorough literature review, also the } \\
\text { investigations of institutional initiatives on students' health and } \\
\text { wellbeing were done to clarify the "why" and "what" of this } \\
\text { inquiry. }\end{array}$ \\
\hline 2. Designing & $\begin{array}{l}\text { The design of this study initially began at the advanced method } \\
\text { course that was offered part of the Higher Education Masters' } \\
\text { Programme at the UiO. It was later refined in order to obtain the } \\
\text { intended data. }\end{array}$ \\
\hline 3. Interviewing & $\begin{array}{l}\text { Interviews were conducted by using the carefully designed } \\
\text { interview guide (See Appendix III). }\end{array}$ \\
\hline 4. Transcribing & $\begin{array}{l}\text { The data were transcribed and read through multiple times before } \\
\text { the initial coding began. }\end{array}$ \\
\hline 5. Analysing & $\begin{array}{l}\text { On the basis of the scope of the research questions the initial coding } \\
\text { themes were sketched out. The analysis of the data employed a } \\
\text { hybrid approach, meaning both inductive and deductive methods of } \\
\text { analysis were used. The initial codes were formed deductively using } \\
\text { the theoretical framework and the MPA literature reviewed in } \\
\text { Chapters } 2 \text { and } 3 \text {. This process was then followed by an inductive } \\
\text { reading of the text where the codes were adapted and modified } \\
\text { based on various emerging and reoccurring themes. }\end{array}$ \\
\hline 6. Verifying & $\begin{array}{l}\text { Validity of the interview findings were confirmed (See Section } \\
\text { 4.5.). }\end{array}$ \\
\hline 7. Reporting & $\begin{array}{l}\text { Results were gathered into a readable product and presented in a } \\
\text { formatting template provided by the UiO. }\end{array}$ \\
\hline
\end{tabular}

According to Kvale (1996, p. 27), a semi-structured interview is "neither an open conversation nor a highly structured questionnaire". As I was interested in collecting accounts of personal experiences of MPA and gain insight into the management thereof, it was imperative to get descriptions that are close to the experience as lived. In order to collect this kind of data it is suggested to ask the person to think of a specific instance or a situation, then further explore their experience in detail by probing the conversation with additional followup questions (Kvale \& Brinkmann, 2015; Van Manen, 1996). With these guidelines (See Appendix III) in mind, I prepared a set of questions that focused on certain themes around MPA (see Table 2). For example, my first question invites the participant to think of a time when they experienced anxiety in a performance situation, this point of entry set the stage for further discussion where the person's experiences were refreshed as they were "transported" back in time to recall the situation. Additionally, I included questions addressing the coping strategies before, during and after the performance, as well as some open-ended questions 
regarding the social support, including the teachers and the peers, in students' regulation efforts.

Table 2 Interview Questions

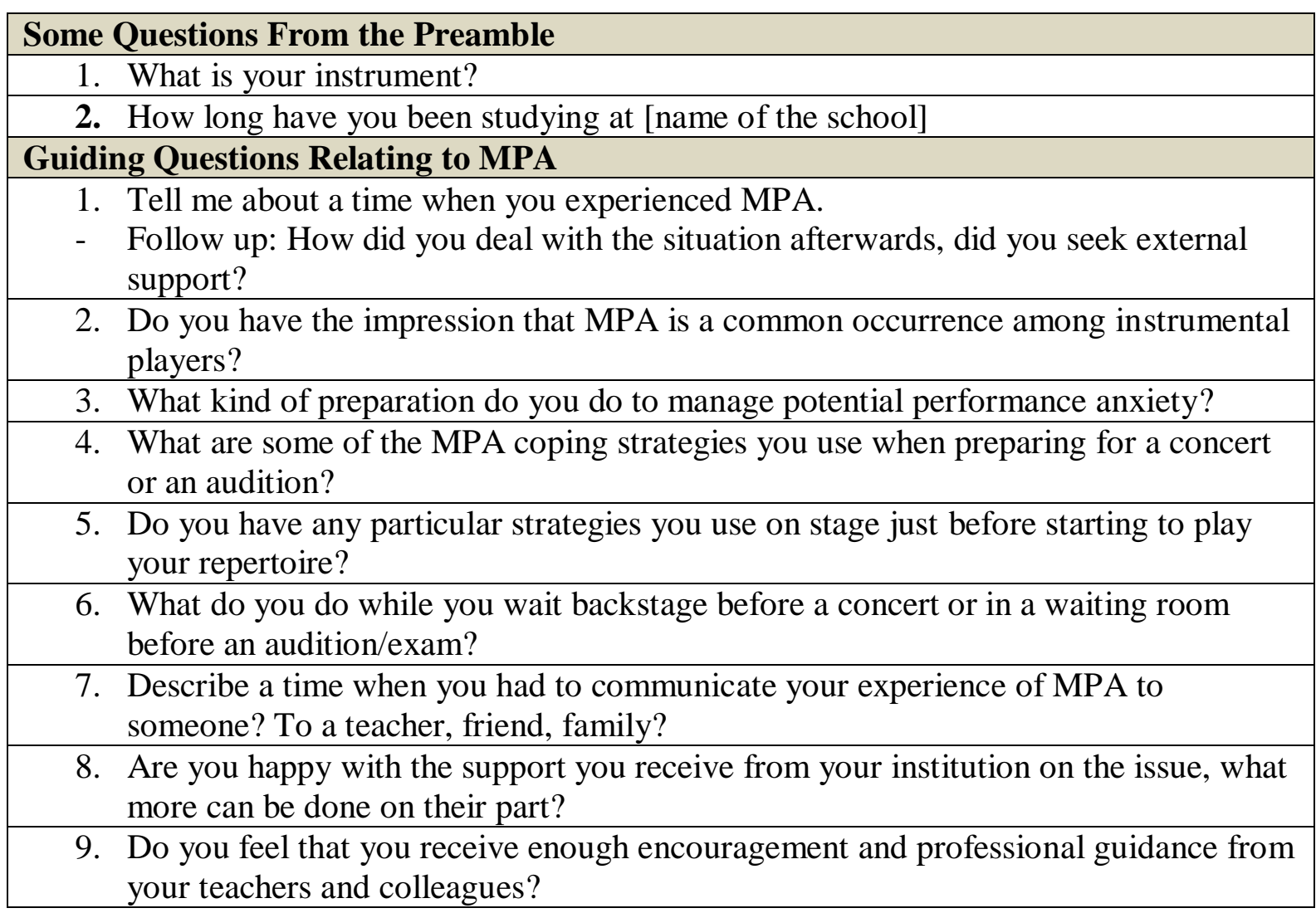

The questions above and follow-up probes were used to address the three key themes of inquiry: (1) MPA manifestations, (2) regulation strategies, (3) perceived support from institution, including teachers, peers and others. A thorough preparation allowed for a wellorganised interview atmosphere, and helped to minimise feelings of uncertainty both for me as a researcher and the participants. The questions were kept "open-ended" in nature, allowing the participant to introduce a dimension of their experiences of MPA. The individuality of these experiences required a critical follow-up with questions tailored to the situation with the goal of extracting the participant's experience.

Using the interview protocol (see Table 1), data were collected from maximum 60 minutes semi-structured interviews that took place on the UiO campus. With participant consent, I audio-recorded the interview. The information letters and consent forms (see Appendix II) were sent via email prior to the interview and a copy was made available to be handed in before the interview process began. The interview rooms were located in various UiO libraries on Blindern Campus, they were quiet, private spaces to ensure that the participants would feel comfortable and speak freely. Interviews were conducted in English. 
During the interview process I made handwritten notes on my interview guide in order to fine tune some of the discussions in the next interview. This process helped me improve as an interviewer and enhanced the data collection phase as it spread out over two months. In the week following the interview, I sent each participant a thank-you email and delivered their compensation for the study. The data were transcribed verbatim for the analysis.

\subsection{Thematic Analysis}

It is to be noted that the way the interview data were analysed employed a hybrid approach, meaning both inductive and deductive methods of analysis were used. The initial codes were formed deductively using the theoretical framework discussed in Chapter 3 and the MPA literature reviewed in Chapter 2. This process was then followed by an inductive reading of the text where the codes were adapted and modified based on various emerging and reoccurring themes.

Braun and Clark (2006, p. 79) state that qualitative approaches are highly diverse and distinct, thematic analysis (TA), however, should be seen as foundational to any qualitative inquiry. According to them, thematic analysis is "a method for identifying, analysing and reporting patterns (themes) within data" (p. 79) . TA is theoretically flexible, meaning that it can be applied within a range of theoretical frameworks making it suitable for a wide range of research interests. A "theme" in this sense refers to an "element (motif, formula or device)" which appears frequently in a transcribed text (Van Manen, 1996, p. 78).

For the present study, I follow Braun and Clarke's (2006) six-step framework. This approach to TA provides a clear and efficient framework that is flexible yet structured enough to keep the researcher on track. It is presented as follows: 
Table 3 Six-Step TA Framework by Braun and Clarke (2006, p.87)

\begin{tabular}{ll}
\hline Phase & Description of the process \\
\hline $\begin{array}{l}\text { 1. Familiarizing } \\
\text { yourself with your } \\
\text { data: }\end{array}$ & $\begin{array}{l}\text { Transcribing data (if necessary), reading and re-reading the data, } \\
\text { noting down initial ideas. }\end{array}$ \\
\hline $\begin{array}{l}\text { 2. Generating initial } \\
\text { codes: }\end{array}$ & $\begin{array}{l}\text { Coding interesting features of the data in a systematic fashion } \\
\text { across the entire data set, collating data relevant to each code. }\end{array}$ \\
\hline $\begin{array}{l}\text { 3. Searching for } \\
\text { themes: }\end{array}$ & $\begin{array}{l}\text { Collating codes into potential themes, gathering all data relevant to } \\
\text { each potential theme. }\end{array}$ \\
\hline $\begin{array}{l}\text { 4. Reviewing } \\
\text { themes: }\end{array}$ & $\begin{array}{l}\text { Checking if the themes work in relation to the coded extracts (Level } \\
\text { 1) and the entire data set (Level 2), generating a thematic 'map' of } \\
\text { the analysis. }\end{array}$ \\
\hline $\begin{array}{l}\text { 5. Defining and } \\
\text { naming themes: }\end{array}$ & $\begin{array}{l}\text { Ongoing analysis to refine the specifics of each theme, and the } \\
\text { overall story the analysis tells, generating clear definitions and } \\
\text { names for each theme. }\end{array}$ \\
\hline $\begin{array}{l}\text { 6. Producing the } \\
\text { report: }\end{array}$ & $\begin{array}{l}\text { The final opportunity for analysis. Selection of vivid, compelling } \\
\text { extract examples, final analysis of selected extracts, relating back to } \\
\text { the analysis of the research question and literature, producing a } \\
\text { scholarly report of the analysis. }\end{array}$ \\
\end{tabular}

I have followed these steps to produce a comprehensive depiction of the entire data set. In the following paragraphs, I discuss the process in more detail.

\subsubsection{Familiarising Myself with the Data}

The first step of TA is to become familiar with the data to the extent that the content is learnt in depth and breadth (Braun \& Clarke, 2006). In order to realise that, the data needed to be transcribed into a written form. The transcription process was the first step in getting to know the material, although at times it seemed mundane and time-consuming. As I continued to collect and transcribe further, I realised that this is a key phase in getting to know my data. The recorded interviews were transcribed and names were replaced by participant numbers. Identifying information - e.g., names of the instruments, instrumental teachers; students' nationalities - was removed from the transcripts. Once the data were transcribed, I read, and re-read all the material and started searching for relevant patterns. The entire data set was read at least a couple of times before the initially coding began. I took some notes and marked some ideas down based on the literature reviewed to go back to in subsequent phases of my analysis. 


\subsubsection{Generating Initial Codes}

This phase began once I familiarised myself with the entire data set. Having my initial ideas and notes from the earlier reading process gave me a solid starting point for the coding process. This research was my first experience using thematic analysis, therefore there was a lot to be learnt in order to move forward efficiently. I started with some definitions to identify what a "code" is in a qualitative inquiry and identified Saldaña's definition to be a suitable one for this inquiry. According to Saldaña $(2015$, p. 3) a code in qualitative work is often "a word or short phrase that symbolically assigns a summative, salient, essence-capturing, and/or evocative attribute of language-based or visual data". By working through the full data set, I identified the initial codes. I then organised the gathered information in chart-form in order to visualise patterns and to expand or deduct codes if needed. Here is a sample table from the initial coding phase:

\begin{tabular}{l|l}
\hline Data (Statements taken from Interviews) & Code \\
\hline $\begin{array}{l}\text { For that concert I was so nervous and just telling myself on } \\
\text { stage "oh I have to play all the right notes - don't make a } \\
\text { mistake". }\end{array}$ & Fear of becoming anxious \\
\hline $\begin{array}{l}\text { I get dry-mouth, sweaty hands, feet and knees shaking, that is } \\
\text { what I often experience at a performance but days } \\
\text { approaching to the event I get nervous in my stomach, } \\
\text { diarrhoea and everything. }\end{array}$ & $\begin{array}{l}\text { Physiological and } \\
\text { behavioural manifestations } \\
\text { Fear of negative } \\
\text { evaluation }\end{array}$ \\
$\begin{array}{l}\text { Cold hands, increased heart-rate, sometimes I felt my foot } \\
\text { shaking on the pedals, I felt like people are watching my feet. }\end{array}$ & \\
\hline $\begin{array}{l}\text { The strangest thing is I judge myself as a person, it goes so } \\
\text { low I can't even describe it, ... like you are worthless as a } \\
\text { person, it is like you shouldn't even exist.. }\end{array}$ & $\begin{array}{l}\text { Affective/ Cognitive } \\
\text { manifestations } \\
\text { (negative self-talk) }\end{array}$ \\
\hline $\begin{array}{l}\text { Another thing that helped me in a practice situation is to also } \\
\text { work on thinking positively, ... so I try to find a way to not } \\
\text { get stuck in practising. So for example I would practise a } \\
\text { passage } 3 \text { times and move on to the next thing. }\end{array}$ & $\begin{array}{l}\text { SRL (Systematic, cyclical } \\
\text { practice habits) }\end{array}$ \\
\hline $\begin{array}{l}\text { I go through the notes in my head and discover some spots } \\
\text { that I can't recall then I go back to the score and practise those } \\
\text { passages so I eliminate making mistakes in those parts. }\end{array}$ & $\begin{array}{l}\text { SRL (Memorisation) } \\
\text { strategy) }\end{array}$ \\
\hline $\begin{array}{l}\text { My teacher brings my attention to other aspects that helps my } \\
\text { playing and then by focusing on something else in a } \\
\text { performance, for example just trying to focus on the feeling of } \\
\text { being free in the body, and feeling grounded. }\end{array}$ & $\begin{array}{l}\text { SRL (Teacher as a } \\
\text { facilitator) }\end{array}$ \\
$\begin{array}{l}\text { Institutional Support } \\
\text { Fig }\end{array}$ & \\
\hline
\end{tabular}




\subsubsection{Searching for Themes}

During this phase the analysis was widened by augmenting the themes further and classifying the codes into different potential themes (Braun et al., 2019). I utilised a theoryinformed approach to extract the general themes, then followed with inductive reading to identify the sub-themes and variation in the material. To study efficiently, I used mind-maps that helped me visualise and organise the thematic information. At the end of this phase, potential themes, sub-themes and the remaining data codes were identified.
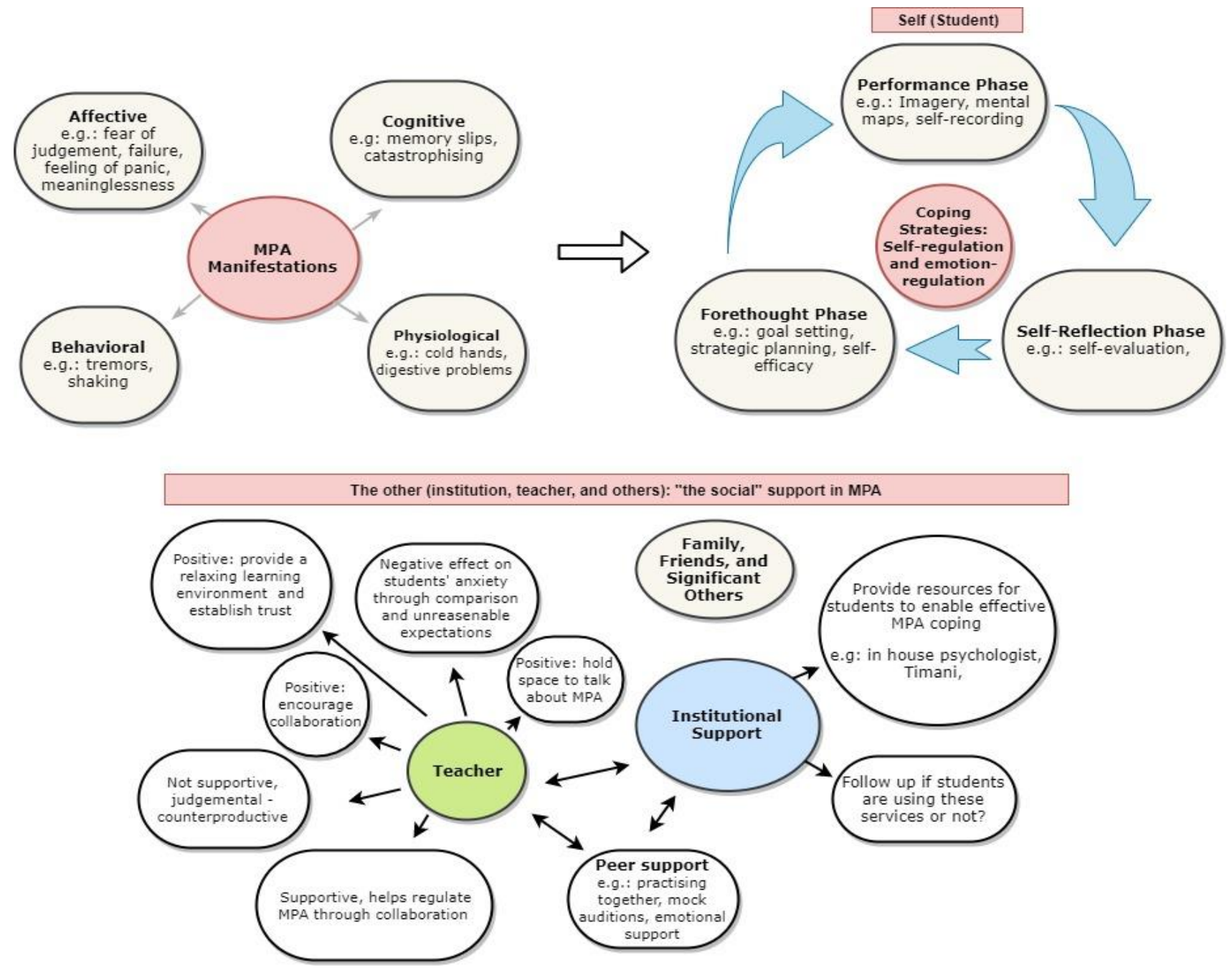

Figure 6 Initial Thematic Map 


\subsubsection{Defining and Naming Themes}

This phase involved the refinement of the themes compiled in the previous sections. Some of the potential themes were dropped as there was not enough data to support them empirically while others collapsed into each other ${ }^{5}$. I needed to refine the coding process until the thematic map produced was a full representation of the given data. This was a tedious phase; as I re-coded, I identified new themes and those that were relevant were included in the Final Thematic Map (see Figure 7). At the end of this phase, the main themes emerged, their relationship was justified and the overall story they tell about the data began to surface (Braun \& Clarke, 2006).

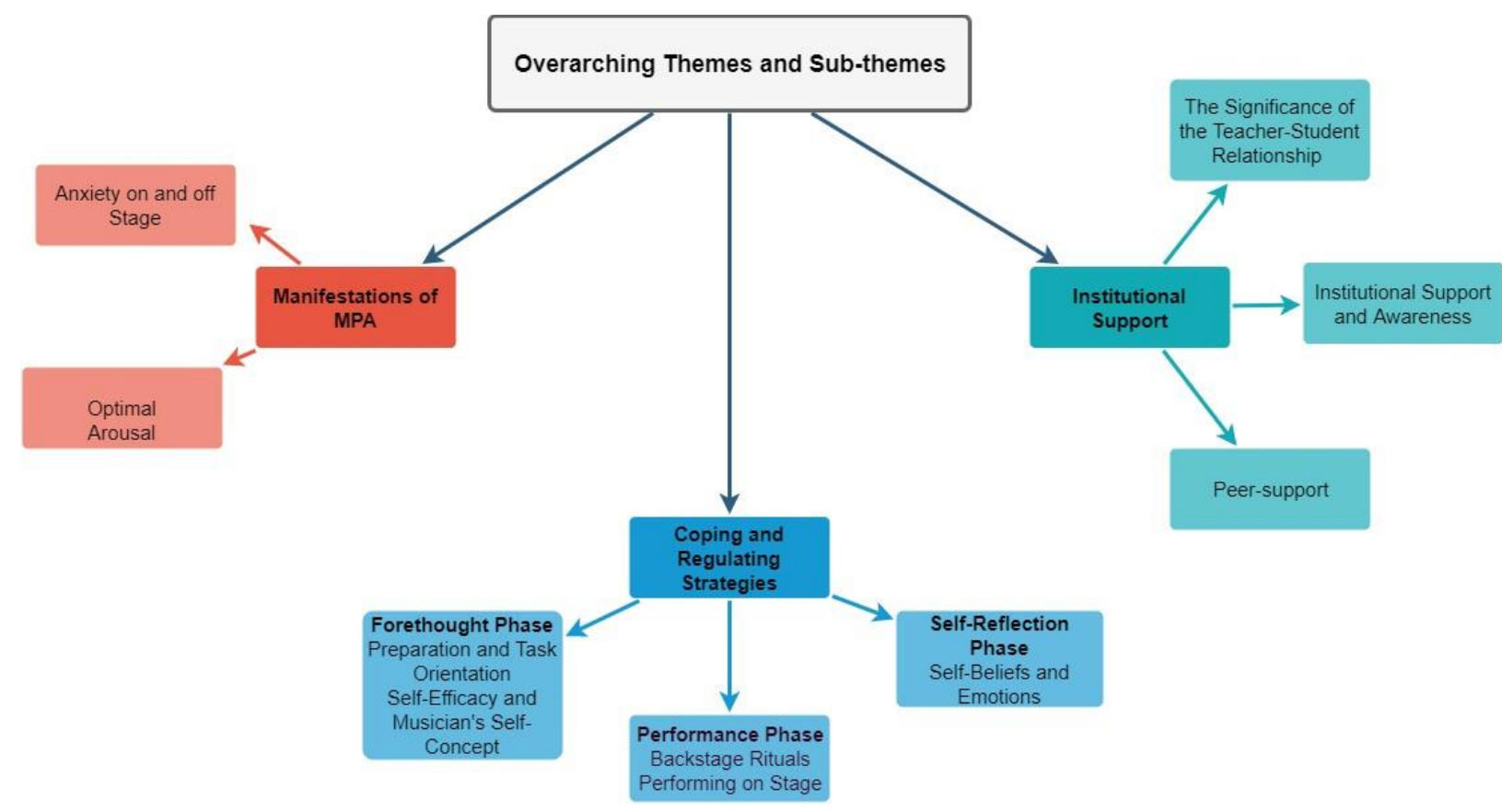

Figure 7 Final Thematic Map, Showing 3 Overarching Themes and Sub-themes

\subsubsection{Producing the Report}

The final step in thematic analysis is to produce a written report in response to the research questions. I analysed the data in light of the relevant literature discussed in the introductory chapters as well as the theoretical framework presented in Chapter 3. It is to be noted that the part of the interview that dealt with investigating regulation of emotions during a performance situation was conducted by asking students to situate themselves in a live

\footnotetext{
${ }^{5}$ Some of the potential themes that were not included in this thesis are discussed as potential future research directions in section 6.4 .
} 
performance experience and recall the coping strategies that they used. This is because investigating such phenomenon during a live performance would present various methodological and ethical problems. The thematic analysis generated from this data is documented in the next chapter followed by a discussion in Chapter 6 .

\subsection{Academic Rigour and Trustworthiness}

Academic rigour and trustworthiness are essential elements that ensure the research process is well conducted and the findings can be seen as credible (Bryman, 2016; Creswell \& Poth, 2017). Various prescriptive texts exist on the strategies for researchers to be employed to ascertain credibility of their work. Lincoln and Guba (1985) proposed four criteria to be employed by the investigator: credibility, transferability, dependability and confirmability. Their work provided the initial platform from which much of the current criteria on trustworthiness and rigour emerged (Bryman, 2016; Nowell, Norris, White, \& Moules, 2017). As such, credibility refers to internal validity, addressing the fit between the participant's views and the researchers' representation of them; transferability refers to the external validity of the study, in particular the generalisability of the inquiry undertaken; dependability is the reliability of the findings, which is assured through a well-documented research process that is logical and traceable; and finally confirmability refers to objectivity that the findings are derived from the data, which involves, on the researcher's part, documenting how conclusions and interpretations have been made (Bryman, 2016; Lincoln \& Guba, 1985; Nowell et al., 2017). With these guiding principles in mind, I describe in what follows the measures undertaken to ensure rigour and trustworthiness.

In order to ensure the credibility of my study I kept the records of all the data I collected, including the hand written notes, in a safe secure data base. The interview guide (see Appendix III) was created and presented in the appendix of this thesis to familiarise the reader with how the data collection phase was conducted. In addition, in the thematic analysis section of the methodology chapter, I aimed to provide a detailed and transparent descriptions of the steps undertaken to analyze the raw data. The process was guided by Braun and Clarke's (2006) six-step framework and was documented in detail with various samples taken from the initial coding to thematic mind maps. The research design was guided by methodology literature and the operational details of the data gathering was documented in detail. Employing an established procedure for the analysis contributed to the validity and enhanced the study's dependability. While presenting the findings, I aimed to provide thick 
descriptions of MPA by sharing participants' accounts through the use of direct quotations (Bryman, 2016). This was done with an aim to document experiential descriptions of MPA which in turn contributed to the transparency of the final work.

Finally, my position as a researcher conducting this project deserves a mention in this thesis as it further contributes to the credibility of this research. Prior to pursuing graduate studies in Education, I completed a Bachelor's degree in Music, while concurrently holding a part-time work-study position at the same faculty. After graduation, I decided to pursue an administrative career and continued working full-time at the same university. These experiences as a student and as an administrator at a music school helped guide the conceptualisation of this study and were influential in the development of the initial research idea. My knowledge of the field assisted me in gaining students' trust during the interview processes, sharing my own experiences of MPA placed me in a more understanding and sympathetic position when they shared their stories. Additionally, having this level of familiarity with the field allowed for a more interesting discussion where we were able to share a discipline-specific discourse without research participants having to explain concepts and procedures within their field of study. All things considered, due to my prior experiences, I bring certain biases to the study. In order to avoid my presumptions shaping the way I perceive and understand the gathered data, I remained reflexive throughout the research by maintaining awareness of my own assumptions and by placing a particular importance on objectivity.

\subsubsection{Ethical Considerations}

The Norwegian Centre for Research Data reviewed and approved this project. All participants of the study received a detailed outline of the purpose and modalities of the project - the nature of the study and its potential impact on them before they agreed to take part in the study. Consent forms, including confidentiality agreements by both parties, were provided before the interview process took place.

Participation in this study was voluntary and the participants had the right to withdraw at any time. Transparency was assured by allowing participants to ask questions, obtain copies of the personal transcriptions and the results of the study. The recordings, transcriptions and the signed consent forms were only accessible to me, and my supervisor only had access to the anonymised data. Any digital files of data and transcripts were exclusively stored on password protected devices. Subject names on documents were replaced 
by identification codes whenever possible. The direct quotations used did not contain any identifiable information and were labelled using the particular identification name (e.g. Participant \#3) assigned to that participant. I also anonymised the instrument names, and the institution. Participants were reminded that if any question arose that they did not feel comfortable responding to, they did not have to answer.

The interview process sometimes meant handling the complexity of the participants' lives as individuals and as musicians. I made efforts to keep my professionalism throughout my interactions with my participants, while maintaining a friendly atmosphere of trust and receptiveness so that each person felt comfortable sharing their personal experiences. The personal information that was not relevant to the research questions or to the other aspects of the current study was kept out of the data set subjected for analysis. 


\section{$5 \quad$ Findings}

Following the thematic analysis of the data, three central themes emerged responding to the research questions. The main research question aimed to investigate how students in Higher Music Education experience and manage music performance anxiety? In order to meaningfully address this inquiry, the study employed the following three sub-questions:

- What are the manifestations of MPA among the participants?

- What coping strategies do the participants use to regulate their MPA?

- What is the role of the educational environment in supporting students' MPA regulation?

The themes were organized in response to these research questions and are displayed in Table 4. In the following paragraphs, findings on each overarching theme and their constituent sub-themes are presented in detail with supporting descriptions from the participants.

Table 4 Over-arching themes and sub-themes emerging from the 10 interviews.

\section{Over-Arching Themes}

1. Manifestations of MPA

2. Coping Strategies

\section{Sub-Themes}

1.1. Anxiety On and Off Stage

1.2. Optimal Arousal

Forethought Phase

2.1. Preparation and Task Orientation

2.2. Self-Efficacy and Musicians' Self-Concept

Performance Phase

2.3. Backstage Rituals

2.4. Performing on Stage

Self-Reflection Phase

2.6. Self-beliefs and Emotions

3.1. The significance of the student-teacher relationship

3.2. The Institutional Support and MPA Awareness

3.3. Peer-support in MPA Regulation 


\subsection{Manifestations of MPA}

Being a music student immersed in the demands and the joys of performing in a highly competitive and evaluative environment brought specific challenges regarding physical and psychological wellbeing, which at times exhibited itself as MPA. All participants perceived themselves as experiencing music performance anxiety to some extent. The intensity of these experiences, however, varied immensely from one individual to another. All participants, without exception, expressed being more nervous for auditions than concerts in general. For the most part, MPA was mainly associated with heightened emotional states which student musicians considered to be a characteristic inherent to their discipline.

Existing research suggests that by analogy to other work on stress and emotion, the manifestations of MPA should be separated into four distinct elements: affective, cognitive, physiological and behavioural (Kenny, 2011; Steptoe, 2001). Findings gathered in this regard are illustrated as follows:

Table 5 Various manifestations of MPA reported in this study.

\begin{tabular}{|l|l|l|}
\hline Affective & Cognitive & Physiological and Behavioural \\
\hline Fear the worst & Inability to focus & Cold hands \\
\hline Fear of judgement & Memory slips & Feeling shaky \\
\hline $\begin{array}{l}\text { Fear of negative } \\
\text { Fternal evaluation }\end{array}$ & Dead pan expression & Increased or racing heart rate \\
\hline Fear of failure & $\begin{array}{l}\text { Decreased attention and } \\
\text { concentration }\end{array}$ & Digestive problems \\
\hline Fear of memory lapses & Negative thoughts & Changes in physical energy level. \\
\hline Feeling of panic & Catastrophising & Shortness of breath \\
\hline $\begin{array}{l}\text { Feeling of self- } \\
\text { worthlessness }\end{array}$ & Situation-irrelevant thinking & Dry mouth \\
\hline $\begin{array}{l}\text { Feeling of } \\
\text { meaninglessness }\end{array}$ & Perfectionism & Urge to urinate \\
\hline $\begin{array}{l}\text { Feeling of inability to } \\
\text { perform well }\end{array}$ & & Lack of precision: e.g. finger control \\
\hline Feeling not so sharp & & Difficulty sleeping \\
\hline Feeling cloudy & & Postural changes \\
\hline Feeling slow & Tremors \\
\hline Self-doubt & Fidgeting \\
\hline Lack of hope & & \\
\hline Lack of confidence & & \\
\hline
\end{tabular}

As can be seen from Table 5, the central experience of MPA for the current study appears to be closely related to affects (feelings). When discussing these feelings students described being "unreasonably nervous," "stressed," and "worried." These descriptions were further expanded into fear of negative evaluation, fear of losing the control of the performance, questioning one's self-worth, and anxious apprehension. Furthermore, experiences of 
cognitive manifestations such as "distraction" and "memory slips" were also mentioned. Additionally, students reported experiencing changes in behaviour, as in "fidgeting" and "tremor", as well as various accounts of physiological changes such as "dry-mouth" and "increased heart-rate." Some of these experiences are described in the following examples:

I felt like my mobility, everything just felt really slower, because I was feeling so hyper-aware, so I was just overly critical in that moment... Just the feeling of fluster, you know like your brain is on overload, just going through all these thoughts in your head, when you perform. All you should really do is click into a zone (Participant \#3).

I think many times I want to do everything perfect and start thinking "oh what if I miss?" and then I get stiff, perhaps a bit shaky and dry-mouth and it feels in a way your body is working against you (Participant \#7).

Shaking, that is the most common, sometimes dry-mouth, sweaty palms, and also really dry - if it is hot I sweat but all the moisture disappears from my mouth, once I felt all the water in my body disappeared, I had no saliva in my mouth (Participant \#8).

From these descriptions one can observe that the experiences of MPA vary not only from person to person but also from performance to performance for the same individual. In addition, the manifestations appear to be interactive yet also partially autonomous. For example, a student may experience postural impairment (e.g. stiff upper body) without feeling much mental anxiety, while another may experience their MPA mainly as a physiological disturbance, as in: “sometimes I am mentally nervous and don't feel it in my body. But sometimes I am not nervous in my head but my body knows and is nervous that I am going to play (Participant \#9)". As discussed in earlier chapters (see chapter 2) some of these manifestations are natural responses and are integral components of our adaptive biological system. However in a performance situation they may adversely influence musicians' finemotor skills and much needed dexterity (Valentine, 2002).

In a similar vein, participants often associated MPA, with a sense of uncontrollability that resulted in uncertainty about the performance outcome. Students' descriptions suggested that the negative experiences on stage somehow have the power to take over and assume control of the performance situation, therefore requiring them to take action in order to "control," "prevent," or "manage" the situation. The following examples are chosen to support this notion: 
I feel not so sharp... It is like there is a lid on my head... I lose track of fuller things, I get quite analytical and lose the sense of putting things together. I don't feel that much, I just lack feeling some joy and excitement. And feel like I don't really know what will happen or have the security that this will go well (Participant \#1).

For me it is mostly the feeling of being nervous [... in my head]. I think I have learnt to control my physical body (Participant \#6).

I used many different methods to feel very comfortable. I easily get stressed, sometimes I start to shake, and I want to have control over it. I know that it is a difficulty I have to work on (Participant \#8).

I usually get cold hands, increased heart-rate, sometimes I felt my foot shaking on the [instrument]. I felt like people were seeing my feet. When I practise I feel more control but when I go on stage I don't feel the same control (Participant \#9).

These quotations show that the ability to "control" anxiety is a desired skill for the student musicians. In addition, their understanding of a "successful" or "smooth" performance in the past or in the near future appear to be closely linked to their perceived ability to control, eliminate or overcome the negative manifestations of MPA. For the most part, the sense of having control over the performance was related not only to preparation and performance exposure but also ones self-efficacy beliefs which are discussed in detail in the following paragraphs.

One theme that emerged was the idea of prolonged MPA when some students mentioned experiencing various manifestations, both physiological and emotional, for hours or even days before the actual performance:

I was so nervous even in the morning; I got up in the morning it was already there. It wasn't something that hit me later or anything, when I was warming up it was there. I was still so nervous. I didn't have much confidence and felt scared - I felt like, oh there are many people applying, do I know the repertoire good enough? I went in there, had 30 minutes to play everything, I played the first piece and it went horribly (Participant \#8).

Sweating, you can't eat, throwing up, sometimes for many weeks in a row, I can't sleep, it happens that I sometimes can't sleep for 3 days (Participant \#5). 
I get dry-mouth, sweaty hands, feet and knees shaking that is what I often experience at performance but in the days approaching the concerts/audition I get so nervous in my stomach. The day before for example I often feel so prepared but my stomach still reacts; I get upset stomach and diarrhoea (Participant \#4).

I was feeling fine with the concertos but excerpts being so new to them, and to the whole experience I was feeling so vulnerable when I arrived. Even beforehand I was being so negative in my mind, how I am so new to this... how Is it possible that I would win this audition, and that negativity I was feeling, it was kind of all internal but it came out so much worse when I got to the audition (Participant \#3).

These descriptions are evidence that MPA is not always a "sudden" experience that happens on stage, yet it can be experienced long before the performance takes place. Thus, when viewed in light of these findings "stage fright" if used as a synonym for MPA is a misnomer, as the anxiety may occur much before the performance takes place on the actual "stage." These findings have implications for the preparatory period for students and educators, and are discussed in the next chapter.

Optimal arousal was another recurring theme in the data. This sub-theme emerged as the some of the participants brought up experiences of "positive" forms of anxiety, which they considered necessary for a successful performance. These experiences, however, were often paired with further descriptions such as "excitement about performing" or "finding the right balance." The following accounts in particular offer insightful descriptions of facilitative (adaptive) forms of music performance anxiety experienced by the students:

I think that people get nervous to a certain extent finding the right balance, but I think it helps up to a certain level, but passed that, it effects your performance negatively and before that it also effects your performance negatively if you don't care enough. Sometimes I am under stimulated. I feel just tired and lethargic, and need to somehow get nervous to be able to perform my best otherwise I might be daydreaming (Participant \#2).

The best feeling is you start getting nervous but you just do music and stop thinking about everything else and music comes from your inside and out and you don't care about anything else anymore. That is what I want to experience more and more. And I think that is something you can learn (Participant \#9). 
These descriptions provide evidence that some students are aware of and have experienced both adaptive and maladaptive forms of anxiety. Indeed such positive and negative aspects of anxiety are not unknown to researchers. The MPA literature suggests that sensations of arousal experienced by performers may facilitate a good performance while creating debilitating experiences in other performance situations (Steptoe, 2001; Valentine, 2002; Williamon, 2004). The interview data gathered from the current study support this notion; reasons behind these negative and positive associations in pre-performance remain unclear.

Finally, what is evident from these short descriptions is that students may handle the experiences of heightened emotional states differently and that the ability to effectively do so has an immense effect on the quality of their performance outcomes. The following account illustrates a student who experiences anxiety in performance situations. It also appears, however, that the student may or may not be able to effectively manage these emotions and/or experiences in a way that leads to a facilitative (adaptive) form of MPA. The perceived emotional stability is dependent on the anxiety response activated in performance - a process, which is referred to by the participant as having "two paths to nervousness":

I think many people like me, when you get nervous you get into this fight or flight mode. That is a kind of nervousness I had experienced a lot when I was young and until couple of years ago. Then I experienced a different kind of nervousness where I felt like I could do anything I want. There is completely different attitude of what you going to do. You can choose - I feel almost, you can choose which way to go: if you want to, you can go to this introverted mode and close off, or be it, allow things to take place, and be the biggest person in the room, so for me it is one or the other I am never in the middle. So now that I have these two paths to nervousness, I always want to go to the one where I can feel like I could do anything I want. It is so much harder because sometimes your body doesn't want to do it, it wants to do the opposite, just stay in one place - just be prepared to run to save yourself, but if you experience the other feeling of nervousness enough times you can rely on that happening more frequently (Participant \#8).

It is evident, not only in this particular example but in various other accounts shared above, that emotions play an important role in students' learning and performance. More importantly, it is the way these emotions are regulated, both during preparation and in performance phases, that makes a marked difference in student's perceived performance achievements. This 
evidence will segue into the findings presented in the next section on the coping strategies analysed through the lenses of the SR and ER frameworks.

\subsection{Findings on MPA Coping Strategies}

The students in this study had developed particular strategies in order to manage their musical performance anxiety. These strategies (see Table 6) and their continued use depended on their effectiveness in managing particular anxiety responses or in enhancing musical performance in a more general sense.

The following table was created based on participants' personal descriptions of their strategies utilised to manage MPA on and off stage. Some of these were mentioned verbatim (e.g. Grounding), while others were adapted based on the SRL analytical framework (e.g. Task-Focusing Strategies).

Table 6 Coping Strategies Reported by Music Students to Manage Performance Anxiety

\begin{tabular}{l|c|c|c}
\hline \multicolumn{1}{c|}{ Adaptive Coping Strategy } & Pre-Perf. & In- Perf. & Post-Perf. \\
\hline & & & \\
\hline Increasing practice time & $\mathrm{X}$ & & \\
\hline $\begin{array}{l}\text { Thorough preparation for performance (e.g., self- } \\
\text { recording, videotaping practice, various memorisation } \\
\text { techniques) }\end{array}$ & $\mathrm{X}$ & & \\
\hline $\begin{array}{l}\text { Mock Auditions or Mock Performance Preparation for } \\
\text { Concerts }\end{array}$ & $\mathrm{X}$ & & \\
\hline Deep Breathing & $\mathrm{X}$ & $\mathrm{X}$ & \\
\hline Positive self-talk & $\mathrm{X}$ & $\mathrm{X}$ & $\mathrm{X}$ \\
\hline $\begin{array}{l}\text { Visualisation, Imagery, Mental-Maps, Mental } \\
\text { Choreographies }\end{array}$ & $\mathrm{X}$ & $\mathrm{X}$ & \\
\hline Task-Focusing Strategies & $\mathrm{X}$ & $\mathrm{X}$ & \\
\hline Emotion-Focusing Strategies & $\mathrm{X}$ & & \\
\hline Sharing the music with the audience to reduce anxiety & & $\mathrm{X}$ & \\
\hline Familiarising self with the performance venue & $\mathrm{X}$ & & \\
\hline "Grounding" & $\mathrm{X}$ & $\mathrm{X}$ & \\
\hline Deep Breathing, and Relaxation Techniques & $\mathrm{X}$ & $\mathrm{X}$ & \\
\hline $\begin{array}{l}\text { Alternative Approaches: Yoga, Meditation, Alexander } \\
\text { Technique, Timani and Postural Awareness }\end{array}$ & $\mathrm{X}$ & & \\
\hline Self-induction to different emotional states & & $\mathrm{X}$ & \\
\hline Talk with teacher & $\mathrm{X}$ & & $\mathrm{X}$ \\
\hline Talk with significant other & $\mathrm{X}$ & & $\mathrm{X}$ \\
\hline Talk with peers & $\mathrm{X}$ & & $\mathrm{X}$ \\
\hline Physical exercise & $\mathrm{X}$ & $\mathrm{X}$ & \\
\hline Diet, and lifestyle & & $\mathrm{X}$ \\
\hline Widening Perspective on Life & & $\mathrm{X}$ \\
\hline Self - distraction/ avoidance & & \\
\hline Beta blockers & & \\
\hline
\end{tabular}


Students expressed that having these coping strategies in hand made the preparation time more effective and the experiences of MPA more manageable. Additionally, having particular coping strategies that are tailored towards tackling specific MPA responses resulted in increased confidence which was accompanied by decreases in feelings of stress and anxiety. In what follows, I discuss these strategies and other relevant findings that are potentially helpful in identifying potential sources of performance anxiety.

\subsubsection{Strategies Used in the Forethought Phase:}

In the context of musical performance preparation, the forethought and planning phase in the SRL cycle involves thinking about upcoming performance exams, concerts or auditions, as well as various other academic tasks or assignments with further planning of how to deal with them. This is the phase where students determine how to best plan and prepare for a public performance or an exam. All participants, without exception, mentioned increasing their practice time as the main strategy in order to manage their MPA. The typical preparation described by the participants in this study included laying the groundwork in technical matters, interpretation and performance, including some pre-performance anxiety simulation (e.g. mock auditions) - with consequent monitoring, evaluating and furtherplanning of the learning progress:

So every day I have a 3 hour plan, which is pretty much the same every day in a sense: 1 hour of warm up/scales/ etudes/ technique just very analytical work, the second hour is solo repertoire I work on musicality and getting through pieces, learning different pieces and the third hour is chamber music or orchestra. That is sort of the pillar I work with. I get quite a lot done sort of by going slowly through my repertoire (Participant \#2).

The preparation in MPA related matters showed some variations based on individual need. Often the goals students set were specifically tailored to tackle the particular anxiety response they experienced. For instance, many students have discussed having specific strategies to manage potential memory slips, such as:

You need to know the score so well that you can write it down on a piece of sheet paper with all the details. I do that, then I know the music better so I can trust myself. That relieves a lot of tension, mental tension. It is like implementing a photographic memory of the score in your head (Participant \#10). 
As such, mental practice of motor skills which involved imaginary rehearsal or a runthorough of a skill or a piece without using any muscular movement appeared to be a recurrent memorisation or "polishing" strategy among the participants. These metacognitive strategies in the examples above and their continued use depended on the students' beliefs/feelings about the effectiveness of them (In accordance with SRL literature, such as in Zimmerman, 2000), (e.g.: "that relieved a lot of tension, mental tension") and their perceived personal skills in implementing them (e.g.: "I do that, then I know the music better so I can trust myself").

These findings revealed that in order to manage MPA students engaged in activities involving task-orientation (e.g. memorisation) and strategic planning (e.g. structured practice time). They appear to set criteria that are shaped by external guidance, (e.g.: teacher, a recording, peers and so on), in order to judge how they are progressing and to make decisions on whether to continue practising a task the same way or implement any necessary changes:

I learn two lines (of music) for example for today, so if it is something difficult I might have to do the same part again for a few days in a row, just work on it with different rhythms and techniques and everything. I do try to work sort of systematically through, then I just decided in the moment I guess if I am going to move on (Participant \#2)

The forethought phase of self-regulation was found to be particularly important in coping with MPA. This appears to be the phase where self-efficacy beliefs develop out of perceived preparedness. For instance, students' self-conviction in their ability to handle an upcoming event (e.g.: performance exam) appears to more likely lead to feelings of hope and achievement, as in the following example:

I had really prepared, I really felt like I had something to offer with the music, the musicality, the expression, And I think that it went really really smooth, I didn't feel like I was judging myself, sometimes you get these inner voices when you are playing and it really tears you apart (Participant \#3).

Whereas feelings of being overwhelmed and the inability to handle potential MPA is more likely to cause further anxiety and distress:

Instead of just thinking "oh now I am going to go out and show everything I have prepared" I am more like "am I going to do this as well as I want to?", or "is someone going to 
judge me?", so instead of just showing everything I can, I get more worried or afraid of doing it right (Participant \#3).

Worrying about memory slips. I get worried that I might have a memory slip. Even when I play on stage I talk to myself negatively - oh am I going to remember this? I am planning a disaster - and expecting the worse (Participant \#10).

Thus, one can see that negative emotions that are prevalent in the forethought phase appear to emerge from a future-oriented worry or catastrophising about the upcoming performance experiences. This, in return, means that the students' self-efficacy beliefs in relation to their experiences of MPA are particularly important as they provide a valuable insight in identifying the potential sources of negative emotions.

Participants repeatedly mentioned that execution of a good public performance or an exam required not only thorough preparation but also a self-assurance that one is ready to skilfully master the required task (e.g. audition). Moreover, when discussing their experiences of MPA, students often attributed the past negative or positive performance experiences to their level of preparedness. The self-judgement of their capabilities to perform at a desired level had a direct impact on their MPA, for instance: "My anxiety depends on how secure I feel about the concerts, how well I know the pieces I play (Participant \#1)." Or as in: "I notice that if I am very well prepared I don't necessarily get that nervous but I still can if it is a very important event (Participant \# 10)." These descriptions suggest that there is a link between lower levels of self-efficacy and higher levels of music performance anxiety and vice versa. Additionally, for some students, the past negative performance experiences were ascribed to lack of preparation, accompanied by further self-monitoring, (e.g.: "I did not play enough in front of people") in order to identify both the gaps in that particular state of readiness, and future strategies to be employed:

That was the worst experience I had. I didn't get to do anything that I planned, and I didn't think that that could happen to me too. I have heard these stories, and I didn't think it could ever happen to me too. I think I wasn't prepared enough (Participant \#8).

I hadn't done enough preparation. I had definitely some insecurities during that time period. And I realised afterwards that I did not play enough in front of people (Participant \#3). 
In the educational research literature, perceived self-efficacy is defined as personal judgements of an individual's capabilities to organise and execute courses of action to produce a desired educational outcome (Bandura, 2010). The role of self-efficacy is seen as critically important in an MPA context as it is particularly salient in performance situation (McCormick \& McPherson, 2003; Papageorgi et al., 2007; Zimmerman, 2000).

Interestingly, findings in this study also indicate close links between these selfefficacy beliefs and the construction of the "self" concept as a musician. For instance in the following example one can observe that the participant's positive self-concept is shaped by their perceived competency in performance skills: "Basically my self-worth for a while depended on - and it still does to a certain degree- how well I play. So I feel like if you have a good day, you get lots of good feedback, then you are like a good person. (Participant \#2).” In another example a participant described self-judgement as a manifestation of MPA:

Mostly it is panic, negativity about me. The strangest thing is I judge myself as a person, it is so closely related to my human being and my experiences from the past. It is all connected. It goes so low I can't even describe.... How I am worthless as a person; it is like I shouldn't even exist, that kind of very deep and dark place. (Participant \# 5).

These descriptions provide evidence that there is a tight link between students' perceived selfefficacy and their self-concept as musicians, both of which offer insights in better interpreting the potential sources of MPA. Interestingly, despite all the preparation and resourcefulness students appeared to have, some still experienced significant MPA, which brought up the question of what is really missing from students' preparation. One students' description pointed out the potential gaps in this context: "I think we practise the technique, learn the notes, and music but we don't practise much being in the right mind set (Participant \#4)".

In summary, these findings provide evidence that the forethought phase is highly influential in shaping the performance outcomes. As students unanimously put forward the notion of increased practice as the most effective strategy to manage MPA, the importance of the forethought phase becomes self-evident. First, taken together, the results provide us with some evidence that self-efficacy beliefs, shaped mainly during this phase, have a particular importance in regulating anxiety on stage. Additionally, higher self-efficacy beliefs are the result of task-oriented preparation strategies (e.g.: memorisation) that are successfully acquired and proven to be effective in adaptively managing MPA in performance phase. 


\subsubsection{Strategies Used in the Performance Phase}

In line with the SRL framework, the performance phase in MPA coping has two major components: self-control and self-observation. In this phase students deploy their pre-decided strategies that were selected in the forethought phase.

Many students described the backstage as a place of heightened emotional states. In some examples, this appeared to be the time when anxiety was at its peak $(n=3 / 10)$. Students described having particular backstage strategies to regulate their heightened mental and physical states. This was often done through deep breathing and maintaining a focused mental state. One student mentioned that at times a reminder to breath can release preperformance tension: "Sometimes you are so stressed that you forget about breathing, so I just remember to breathe" (Participant \#6). Some students described focusing on an object or on a specific sound in order to calm down physically and mentally. This meditative approach adopted by one of the participants was thus described:

Before (going) in the audition room just focus on one sounds that you hear in the room, and just focus on that sound, maybe it is buzzing from a lamp or something and do some deep breathing, and try to find your centre before you go in, and then when you are in there just feel that you have the time and don't feel rushed to quickly set up your instrument and play (Participant \#3).

Furthermore, some of the strategies students used in this phase involved focusing on a task or an emotion. Many of the students mentioned imagining the performance situation beforehand and going through mental-rehearsals of the task multiple times during the forethought phase. In the performance phase, particularly when backstage, they then used this mental representation of their performance in order keep the focus on the task therefore keep the potential negative emotions at bay (e.g. negative self-talk). When describing the particularity of such strategies they used phrases such as creating "mental-choreography" or a "mapoverview" of the performance. One student described this representation and its place in performance preparation:

I try to really make a mental map - mental choreography imagining how I want to sound, just right before I play it, also imagining how I want to play it. ... so I try to implement that in my performance plan (Participant \#10).

Another student's response echoed a similar emotion-focusing strategy by immersing oneself in the mood of the music through use of imagery in the moments before stepping on stage: 
...a map overview. Just in my head, of course when you are practising a lot, I think over time it becomes more internalised. I visualise a lot actually especially before I go on stage, I visualise how I want to feel, often times just getting into the mood of the music (Participant \#3).

This “map-overview" represented students' personal ideas on what the music should convey to the listener, be it emotions, ideas, feelings and so on. By focusing on these various pleasant aspects of the performance, students appeared to enable effective coping that led to better management of MPA on stage.

Students reported having particular on-stage coping strategies for various manifestations of MPA. These included engaging in task- and emotion-focusing processes (e.g. focusing on the musical phrasing), as well as "grounding", thinking of the performance as communicating with the audience, self-induction to different emotional states, and musclespecific relaxation techniques. One student described thinking of happy memories on the way to the stage in order to "de-arm" the nervous system:

I think about happy memories. When I walk on stage I sometimes think of my summer house, happy memories from my childhood, my cat - then in a way I de-arm my nervous system (Participant \#7).

Another student described "grounding" oneself through postural awareness and mindful breathing before the performance on stage:

So basically you try to feel your feet, maybe bend your knees a little just feel like the ground is there and supporting you, and your whole body should feel like a bit heavy, so your shoulders drop, you feel more like you are playing from your stomach. My teacher often talks about playing more from your belly, like a singer sings from their belly. That usually helps (Participant \#2).

As seen in the described examples, particular strategies utilised during the performance phase appear to be pre-rehearsed and carefully prepared. Students discussed them to be part of their performance preparation that they aimed to implement in their practice time.

I just try and put my focus on the right things like on sharing a piece that I really love for example, that could put the focus instead of on your performance, and how well it goes during these takes than put it on just saying something with your music (Participant \#2). 
Taken together these results provide some valuable knowledge into the regulation of negative emotions during the performance phase. Most of the strategies utilised are pre-prepared and oriented towards managing and keeping MPA at constructive levels.

\subsubsection{Strategies Used in the Self-Reflection Phase}

In the self-reflection phase students self-evaluate and make sense of the performance outcome. Once the performance is completed, the self-reflection phase begins, where students' personal attributions surface based on the level of performance (negative or positive). The reflections students engage in during this phase appear to be shaped by how well they performed, also by the nature of the feedback they received from their peers, teachers, other relevant musicians and family members who were at the performance.

The most common MPA coping strategies students utilised following a performance were talking to family, friends, teachers; distraction (e.g. going out for a meal, exercising), or self-reflecting on life in a more general sense (e.g.: recognising the importance of family, friends, health and so on). One student mentioned how keeping a realistic perspective in life as a strategy to cope with the demands of his profession:

For me, many musicians who spend a lot of time in their studies they could over-romanticise a bit how important this being a musician idea is. It is important to find perspective, I play music and I want to have a good time. ...I try to build a nice life and have good relationships with family, friends, always make time for that. So when I play an audition and if it doesn't go well, not much is at stake, it is just one aspect of my life. The work part, and the rest with hobbies and friends and family is still there, of course it is an important part of my life on itself but if I compare it with the rest it is just a part of it, a slice in a pizza (Participant \#7).

Although there is no apparent point of transition where the students clearly move out of the self-reflection phase into the forethought phase for the next performance, there appears to be an obvious difference in terms of student's emotions and self-beliefs in these two phases. The most prevalent emotions described by the students during this phase were related to satisfaction such as pride and happiness or to dissatisfaction such as anger and disappointment. Specifically, these emotions that are experienced immediately after a performance appear to play an important role in student's self-beliefs and also on the various behaviours. One student mentioned: 
"I associate in a sense more nerves with more feeling of achievement after, because you conquer this big thing and you feel this rush of happiness after, yeah I did it! Just pride of having done something you thought was scary" (Participant \#2).

This example provides an example of where a positive performance experience resulted in continued or higher self-esteem and self-efficacy beliefs, therefore further motivation. On the other hand, the self-reflection phase may be the stage for the validation of students' view that they have MPA for the first time (e.g.: "That was the worst experience I had. I didn't get to do anything that I planned, . . . I have heard these stories, and I didn't think it could ever happen to me too" (Participant \#8)).

The self-reflection phase also sets the stage for identification of the gaps in one's preparation, these cues are then internalised to be carried forward into the forethought phase and translated into developing further strategies. The following descriptions show how intertwined the self-reflection and forethought phases are in management of MPA and performance preparation in general:

It is interesting because when you play an audition you come out and know exactly what you need to work on because you sink-you don't rise to the occasion-you sink to your preparation, you sink to the weakest points of your preparation (Participant \#10).

Interestingly however, it appeared that the emotions students experienced in the selfreflection phase are somewhat overlooked by the institutions or the instrumental teacher, while in the forethought phase students expressed receiving a lot of professional guidance in laying the groundwork for technical and musical matters. It is self-evident that preparation for a performance is the key component for a successful outcome and it is therefore no surprise that the forethought phase receives a lot of attention from students themselves and their teachers. This can also be observed in the resourcefulness of the coping strategies students mentioned employing in the forethought phase (see Table 6.). However, students also brought up the fact that how following a negative performance experience, the frequently "prescribed" solution by the teachers and the institution in general is to practise more. This solution, however, was often perceived as an attempt by the teacher to push the student forward into the next preparation phase without properly reflecting back on the emotional aspects of the most recent performance experiences. The students expressed the need to talk about things other than practice following a negative performance experience, some 
suggestions included "post-audition evaluation talk" or "audition support group". This highlighted the need for more varying coping strategies aimed at helping students to deal with the emotionally challenging aspects of the post-performance period before moving into the preparation for the next performance. Some of these tensions are discussed in detail in the following section.

\subsection{The Role of Social Support in Management of MPA}

The analysis of the interview data highlighted that family, significant others, peers and other various disciplinary connections were integral in sustaining overall wellbeing. In particular, perceived support within the institution, namely the primary instrumental teacher and peer support, were highly recurrent in discussions pertaining to MPA. In this section I discuss the findings on the role of the institutional support on students' MPA regulation efforts. The role of the instrumental teacher and peer-support were highly recurrent in discussions pertaining to coping within institutional settings; findings are presented with corresponding sub-headings below.

\subsubsection{The Significance of the Teacher-Student Relationship}

Without exception, all students highlighted the ways in which the various aspects of their relationship with an instrumental teacher influenced their musical learning. This work appeared to mainly focus on developing technical skills and musical interpretation.

Furthermore, many students also brought up the importance of being understood at an emotional level by their teacher. In this regard however, there was divergence between students who shared experiences of MPA with their teachers and those who did not feel comfortable doing so. One student explained that how being able to "talk about anything" with the teacher brought a sense of ease:

I talk a lot with my teacher - she is great, we talk about everything, she wants me to be open about everything in my head. I told her that sometimes I have to show something and I get tense then I can't get everything out that I have in myself. And she knows this very well too. During the lessons or something, she would say just relax and do your thing, and don't care about me sitting here. Hopefully, people have teachers they can be open with as I am. That is the most important part; there are always lots of thoughts surrounding the profession. It is good to talk to someone (Participant \#9). 
As in the example above, an empathetic teacher willing to meet students at an emotional level was highly appreciated. Another student shared how hearing about the instrumental teacher's personal experiences of MPA gave a sense of hope moving forward: "One of my teachers... he experienced the same thing when he was my age, he was at a big concert and his bow started to shake and stuff, but (as he got older) it stopped, that gave me a bit of hope for the future I guess" (Participant \#2). In this context, it appears that the student's motivation to tackle MPA is supported by the elements of empathy offered by the instrumental teacher, resulting in feelings of "hope." These various perceived positive interactions highlighted the role of the instrumental teacher as a facilitator of emotional regulation in educational settings.

Furthermore, it was also clear that offering empathy alone was not enough for many, the students appear to value and adopt the various approaches suggested by their teachers. There was a sense that performance success required more than a musical ability but life skills such as "risk taking" and "patience". Some examples included:

My instrumental teacher's approach is very good; he has a very simple approach. He advises us to not think too much and just practise and play. He always says to have patience and just practise good habits and try to do what you planned and prepared to do (Participant \#7).

My teacher is mostly in a mind-set of there is nothing to be afraid of, also in lessons he encourages you to make mistakes because he is there to help which eases your mind. He wants people to perform in class lessons so we get to play our pieces in front of each other (Participant \#2).

Some of the students, however, expressed that their teachers' willingness to assist them was only limited to developing technical and musical skills, but rarely about the emotional aspects of performing music. This tension arose, perhaps because the students perceived that the teachers with high professional standing had not much to offer when it comes to management of performance anxiety:

I think he just knows how to play the instrument really well and how to manage everything - that is it. He has mastered his instrument and I am not sure if he knows how to help me with my anxiety. I think it would be good to have more people involved in helping us with MPA, my teacher helps me with music phrasing and so on but he can't help me with mental preparation, maybe it is because he doesn't have the same problems (Participant \#4). 
My main teacher is not necessarily the best help in MPA. He is my best teacher in [instrumental] skills but not in chamber music or MPA for example. We have separate teachers in different subjects why can't we have more teachers in performance preparation? (Participant \#10).

These varied experiences of support (or lack thereof) among the students reflected the complexity of the teacher-student dynamic. Those who perceived being not supported by their teachers on MPA related issues, identified a need for a more collaborative support structure around the issue in their educational environment, where they envisioned receiving guidance in various aspects of music performance beyond those covered in studio lessons.

\subsubsection{Institutional Support and MPA Awareness}

Participants discussed the health and wellbeing initiatives that are readily available to them at their institution. Services such as an in-house psychologist, performance enhancement classes (e.g. Alexander Technique, or Timani) or orchestral excerpt class were put forth.

However the perceived helpfulness or the utilisation of such offerings varied immensely from student to student. For example, some students believed that the institution could provide a more continuous performance enhancement programme throughout the curriculum:

I think there can be more information about MPA in general that is provided by the institution. Because we have this course in the first year, and they tell you how you can book sessions with the psychologists and so on but there is not much of that in later years and I think many people forget about it or don't want to investigate what is offered to them. So maybe reminders would be good. And the psychologist can be more visible somehow (Participant \#7).

When I don't have these struggles that you don't see, visible ones then you don't get to take these classes.

I: If I understand you correctly do you mean physical struggles get more attention and care than the mental ones?

P: Yes, I think they are ignored because you are the one who has to talk about them and that is hard (Participant \#4).

Another student brought up how the institution could provide more tailored classes to enhance performance outcomes:

When you are auditioning, your focus has to be so much there in comparison to playing a whole piece through, you have to not only execute things very clearly but switch styles, and have that intense focus to do it in such a short time, like 5-10 
minutes. And I don't feel like in my education enough classes where we practised run through of excerpts, we do excerpt studies, and once or twice a year have like an exam where we play through repertoire needed for an orchestra, like part of a concerto. But I feel like it needs to be more of that, playing in front of people, like it would be nice to have classes dedicated to that (Participant \#3).

Additionally, it was clear that the students wanted a supportive educational environment where they can reflect on various experiences of MPA. One student described an ideal learning environment:

I think the whole community can be more helpful, instead of hiding insecurities and weaknesses and help each other to improve. The most important step for music education would be for institutions to provide a platform for discussions on MPA and create more opportunities for people to share experiences, and focus on creating this musician's community to grow and learn together. To collaborate more in general; from practising together - having methodological practice- and also mental awareness (Participant \#10).

Some students however believed that finding a solution for one's anxiety was an individual's responsibility. One student expressed that this responsibility came with honesty and willingness to ask for help:

But you have to fix it yourself, you can't expect that a teacher will appear to you and just take your anxiety away. It won't happen that someone is going to make the path for you, you just have to make it for yourself. It is quite individual. And it is more about the student being honest with themselves and be active and seek the help they need (Participant \#8).

Therefore, there did not necessarily appear to be a mutual view on the role of the institution on the management of MPA. The quotations above display the contrasts in students' views on the perceived helpfulness of some of the institutional offerings. This divergence was also apparent when discussing MPA awareness in educational settings.

Some students spoke about the culture of silence that appears to surround MPA; some of them described how breaking out of that allowed them to ask for help from teachers and peers: 
Early on when I got nervous I couldn't tell anyone because it was embarrassing - you don't want to feel vulnerable when you perform. Now it is like talking about anything. The good part is now when I play, everybody knows that I get nervous, I have had problems with it - it is easier to play for people who know what you are going through. If you never admit that you are nervous when you play they (teachers, peers) will never know. But if they do know, they will help you; they are not your enemies, right? Nobody will laugh if you say you are nervous (Participant \#8).

In my first year people didn't talk that much about it so I thought I was going through it all by myself. But when I actually talked to people they said it is the same for them, they do experience this (Participant \#4).

Some others however felt that there is a desperate need for more awareness around MPA. One student had strong feelings about the apparent damage of the "silence" around the issue:

The toilet is the dirtiest place during the auditions at [our school] [referring to students vomiting]. [MPA] is effecting everyone. But everyone pretends that it is all right. But nobody is talking about it. Many times I was in those situations, I had a problem like-I wanted to talk to someone but I couldn't (Participant \#5).

Another student described how she maybe would have reached out for help if the experiences of MPA were more "normalised" at her institution:

Maybe if I didn't need to knock on the [referring to the inhouse psychologist] door to ask for help... I think it should be a bit more normalised to get this help, I think more people struggle and not everyone is able to take charge of it-it takes courage to ask for help. I want them to normalise it and talk about it more openly. It is strange for people to talk about it, and search for help. If it was strange not to take it [referring to an MPA related service] for example as part of your studies then more people would openly talk about it (Participant \#10).

In summary, the two sub-themes above underlined the perceived helpfulness of the instrumental teacher and the institution. One of the most interesting findings of this study is that student's views of their educational environment and its perceived helpfulness with their concerns about MPA are highly influenced and perhaps shaped by their interaction with their 
instrumental teachers. For instance, students who expressed having a supportive relationship with their teacher see the health and wellbeing offerings and the institution generally in a more positive light. The reason perhaps for this is the encouragement of their use provided by the instrumental teacher. As such, an informed teacher who held space for MPA related matters appeared to have a direct influence on the student's help-seeking motivations, thus utilisation of the relevant services offered at the institution. On the other hand, those who, for various different reasons, were not able to share these negative experiences with their teachers identified a need for improvement at institutional level, and questioned the usefulness of the existing offerings.

\subsubsection{Regulation of Emotions Through Peer-Support}

The analysis of the interview data highlighted that being part of a musicians' community was very important to students. Having the support from peers on various aspect of performance, including performance psychology, appeared to be a factor that enabled various learning and MPA coping strategies. Students mentioned sharing their negative performance experiences with a "musician friend" who can understand them at a disciplinary level and in an open non-judgemental way:

After the competition I talked to my (flatmate) about (what happened). He is good at being entertained at the concept of me being frustrated. He is good at listening and rationalising it for me a bit. We just went to eat some good food. The best thing for me is to get rid of the bad emotions that follows so I distract myself with something I really like (Participant 1).

Another student emphasised that sharing her negative audition experience with a friend helped her identify the gaps in her mental readiness:

He is like a mentor to me, he works at a professional orchestra. I kind of explained (to him) what went down and how I was feeling. We did talk a bit about attitude, and how it can influence someone. It made me realise a lot that your attitude when you are practising, how you approach accomplishing tasks you set for yourself is so important to the entire process (Participant \#3).

These examples show that students often have the need to communicate their experiences of MPA with a friend as part of their self-reflection phase. In whichever way the support is used, be it spending time together, or identifying room for improvement in one's mental attitude, peers appear to be a vital component of a student's support structure and regulation. 
In addition, peers appear to have an important role in the preparatory phase for a performance. For example, many students described meeting with their peers to practise together or play for each other (e.g. "mock auditions") to help one another in a productive and non-judgemental space. One student described his immediate instrumental community as a place of collaborative learning:

If I know that my friend has a problem with articulation, sound, and they want to achieve something then I try to help them with that. I listen and come up with some tips and help them with that. I think my (instrument) collective is so friendly in general, and I have had so many people who are so open. Tt is not about competition; it is a very good community to be part of. (Participant \#8)

Furthermore, another student described how establishing closer relationships with her peers through extra-curricular activities made her feel safe and supported:

My teacher is working with other teachers to make students work together and bond. We go to concerts, restaurants and play together. School has recently sent my studio class to Vienna and we had a great time, and got close to each other during this trip. I have never felt judged, people are quite supportive. (Participant \#9)

This example also showed how the teachers and institutions can encourage peer-support and create platforms where students develop reflective interactions through various experiences that move beyond the borders of institutional settings.

Taken together, these results provide evidence that institutional support and relations with peers play an important role in the social and emotional landscape of student musicians' lives. Positive coping strategies appear to be acquired and sustained through social as well as self-sources of influence. Firstly, the instrumental teacher's openness and resourcefulness around MPA has a direct impact on the interactions of students with each other as a community and thus on the students' regulation efforts. Secondly, the role of the institution in providing opportunities, where performance skills are not only explored but also applied, is of the utmost importance in enhancing students' performance skills. Finally, it appears that more MPA awareness is needed, at both institutional and individual levels, including the teacher and the student. 


\section{Discussion}

This study was undertaken with the intent of exploring three overarching research questions concerning MPA. The first objective was to collect descriptive accounts of the everyday, lived experiences of MPA in educational settings. As a follow up, the second objective was to investigate the particular adaptive coping strategies students utilised in order to manage their MPA which were distilled from the data in light of an SRL framework. Finally, the institutional support around MPA, including the role of the instrumental teacher and peer-support, was investigated.

\subsection{On Manifestations of MPA}

With regards to the first research question, the findings of this study suggest that the experience of MPA is common among tertiary level students. All students interviewed perceived themselves as experiencing music performance anxiety to some extent; however, the intensity of these experiences varied immensely from one student to another. They all provided an idea of what MPA looks like (as in observing another person perform with MPA) or feels like through various descriptions of personal accounts and across different types of musical activity. The components of MPA varied immensely among the participants. The affective (e.g. fear of failure) and physiological (e.g. dry mouth) manifestations, however, were mentioned frequently. These findings align with existing literature that mention various aspects of performance anxiety (i.e., Kenny, 2011; Valentine, 2002; Williamon, 2004).

Additionally, the student performers interviewed in this study viewed performance anxiety as a natural part of their musical career, some even discussed the contribution of adaptive forms of anxiety to the spontaneity and excitement of their interpretation. These descriptions resulted in findings that align with existing research on "optimal arousal" in performance (i.e., Steptoe, 2001; Valentine, 2002; Williamon, 2004; Wilson \& Roland, 2002) addressing the benefits of certain amount of arousal to performance outcomes.

Importantly, only a few students interviewed mentioned experiencing MPA solely on stage. For the majority of them, however, the heightened emotional states were apparent for days, or weeks prior to the performance. As such, the term "stage fright" when used as a synonym for MPA appears to be a misnomer for this particular sample, as the anxiety was experienced much before the performance took place on the actual "stage." Pointing out the ambiguity of terminology describing these experiences is important since preparation which includes the self (in this case student) and other (support system around student e.g.: 
institutions, primary instrumental teacher) should be informed by the effects of MPA both on and off stage. Moreover, in a conventional sense, the preparatory process for a performance often deals with technical and musical matters with some pre-performance exposure to anxiety simulating experiences, (e.g. mock auditions). All of these mainly deal with the "stage" aspect of musical performance. However, another component in a performance preparation that requires attention is improving one's ability to regulate emotions during the preparatory phase in order to plan and execute performances more sustainably. Thus defining musical performance anxiety as a prolonged experience that is not limited to the stage is crucial in order to effectively implement support structures around the issue.

Collectively, these findings provide insight into various manifestations of MPA in educational settings. Such knowledge, acquired through personal descriptions of the phenomenon, is needed in order to effectively implement instructional interventions to enhance performance outcomes. Future research in this regard should identify the full range of emotions experienced by musicians on and off stage, and their variations across time, and experience level.

A closer inquiry into the manifestations of MPA within educational settings was needed in order to lay the groundwork to identify the coping strategies, regulation efforts, and the role of the institutional support. The following section addresses the coping strategies in response to the reported manifestations and also discusses the potential sources of maladaptive music performance anxiety that arises from low self-efficacy beliefs.

\subsection{Adaptive Coping and Regulation of MPA}

The students in this study believed that they needed to develop particular strategies to overcome the negative emotions associated with musical performance, including management of performance anxiety. Their preparation in musical and technical matters was unanimously mentioned as the key component in gaining self-confidence, leading to higher self-efficacy beliefs. Additionally, many also mentioned engaging in various other regulation strategies that they acquired through various activities, such as yoga and meditation, positive selfinstruction, and exercise, to complement their practice room preparation for future performances. For the most part, students described using these strategies with the purpose of reducing negative emotional states or to regulate physiological changes, such as shaking of the bow hand, which may bear on fine motor movements needed to play their instruments. In some cases however, these strategies were used as a preventative measure in order to maintain 
calm both emotional (e.g.: thinking of happy memories at the summer house) and physically (e.g.; relax the shoulders down, or breathe deeply).

The role of self-efficacy beliefs were identified to be one of the most important factors in management of MPA. When analysed within an SRL framework, the self-beliefs, including a self-concept as a musician, appeared to be shaped both during the forethought and selfreflection phases. In this regard, negative emotions such as disappointment, and hopelessness in the self-reflection phase led to lower post-performance self-efficacy beliefs. On the other hand, emotions related to positive performance outcomes such as pride and satisfaction were positively related to higher levels of self-efficacy beliefs and a positive concept of self as a musician to be carried forward into future performances. Thus, the positive or negative view of self may be linked to one's perceived self-efficacy that develops under the influence of both past performance experiences and the current state of preparation for the upcoming performances. This is consistent with previous research documenting the importance of a positive self-concept in management of MPA. The acquisition of a positive self-concept for performing musicians appears to be an important strategy in maintaining confidence, as well as self-esteem, characteristics that help students enable adaptive coping strategies (Craske \& Craig, 1984; Papageorgi et al., 2007).

Moreover, besides the emotional referencing, past performance experiences were used to develop new task strategies and/or also to assess the effectiveness of the existing strategies to be carried forward. For example, following a negative performance experience, in addition to feeling somewhat embarrassed about a memory slip (emotional respond to be regulated) a student described developing task-specific coping strategies tailored to better memorise repertoire. However, it appeared that despite increasing competency in memorising repertoire through new adaptive strategies some continued to experience MPA, as in "worry" or "anxiety" about having a memory slip again at their upcoming performance. These findings suggested that emotions following a performance play an important role in student musicians' future achievements and the management of these emotions may be crucial for future performance and on the overall experiences of learning and performing music. This is important from an instructional point of view and when implementing support structures around MPA in educational settings. As the participants' accounts revealed that the postperformance evaluation, namely the self-reflection phase in the SRL cycle, is overlooked by the teachers and even by the students themselves this may be the phase where more work is needed in order to enable effective coping. In other words, further inquiry into post- 
performance self-reflection may help identify the potential source of MPA. Given this evidence, future research should include intervention that is targeted towards particular postperformance emotion regulation strategies for MPA management.

The analysis of the data also highlighted the extensive metacognitive skills student musicians employed to propel their learning and performances forward. Metacognition in this context refers to the learner's ability to adjust behavioural, environmental and emotional processes in response to changing academic or performance related demands (Zimmerman, 1989). From their descriptions, it was apparent that they were highly resourceful in implementing solutions to various problems encountered. They continuously engaged in selfobservation of their progress and appeared to have a keen understanding of their strengths and weaknesses both technically and musically. The MPA coping strategies they employed in preparation for a public performance, an exam or an audition were adapted in response to what was needed for that particular state of readiness, indicating high levels of task- and goalorientation. These findings align with some of the sub-processes delineated by Zimmerman (2002) that were discussed in Chapter. 3. Accordingly, one can conclude that self-regulated learning help students regulate MPA by promoting the use of more effective learning strategies tailored to tackle their particular performance challenges. Interestingly, all of the strategies students mentioned as adaptive could be taught by various professionals, such as meditation teachers, coaches, and mentors. This finding aligns with Roland's (1994) study reporting with a similar implication nearly three decades ago. Such indications provide new research avenues into further exploration of the notion of MPA coping as a learning challenge.

Finally, the strategies employed by students were mostly directed towards enhancing cognitive aspects of learning and performing music which they acquired through extended deliberate practice and guidance mainly by the primary instrumental teacher. However, they seem to need more resources regulating various affects (emotions), meaning either sustaining a positive emotion, such as hope or curiosity, or managing and regulating a negative one, such as fear, or hopelessness. The lack of emotional regulation strategies at times effected student's preparation as the performances seem to fluctuate on stage despite thorough technical and musical preparation. Therefore, given the importance of emotions in musical performance, this thesis recommends that their regulation should be included in music students' training through instructional interventions and continued institutional support. 


\subsubsection{Theoretical Implications}

The findings of this bring insights to students' experiences and management of MPA in educational settings. The self-regulated framework used for the analysis of the data provides support for the fitness of certain self-regulatory processes in students' MPA regulation efforts. The socio-cognitive model of SRL used as part of the analysis in this study (see Figure 5, pg. 29) posits that self-regulation is an active constructive process that occurs in a cyclical manner (Bandura, 2010; Zimmerman, 1989, 2000). Additionally, students' selfefficacy beliefs are highly important in facilitating regulation and future motivation. The results of the current study appeared to be consistent with the general structure of the SRL model as the students engaged in all three phases (forethought, performance and selfreflection respectively) and certain sub-processes such as task orientation and goal-setting. However, the sequential nature of the model appeared to be more intertwined in a performance-based activity, namely, with music students' preparation and learning processes for an upcoming performance. For example, music students engaged in various performance exercises in the forethought phase where they practiced deploying the skills and strategies at their disposal. In other words, various simulation trainings they engaged in (such as mock auditions or playing the repertoire for peers) appeared to reverse the sequential structure of the SRL mode. More specifically, during the forethought phase, these various performance simulation practices, provided feedback loops where the student at times returned back to the preparation (forethought) phase to re-structure and amend certain aspects of their performance. Additionally, at times they appeared to return back to the self-reflection phase where they engaged in self-appraisal, positive or negative, which later appeared to have a direct impact on their future performances. Additionally, the institutional support which is a situational factor in the analytical framework (See section 3.3) appeared play a more significant role in facilitating students MPA regulation than anticipated. These results suggest that MPA regulation, and music performance preparation to larger extent, does not occur in a sequential manner, as such the SRL phases of learning and strategy acquisition are more intertwined and highly dynamic. 
The following model was created to summarise the theoretical implications that are discussed above in a visual format:

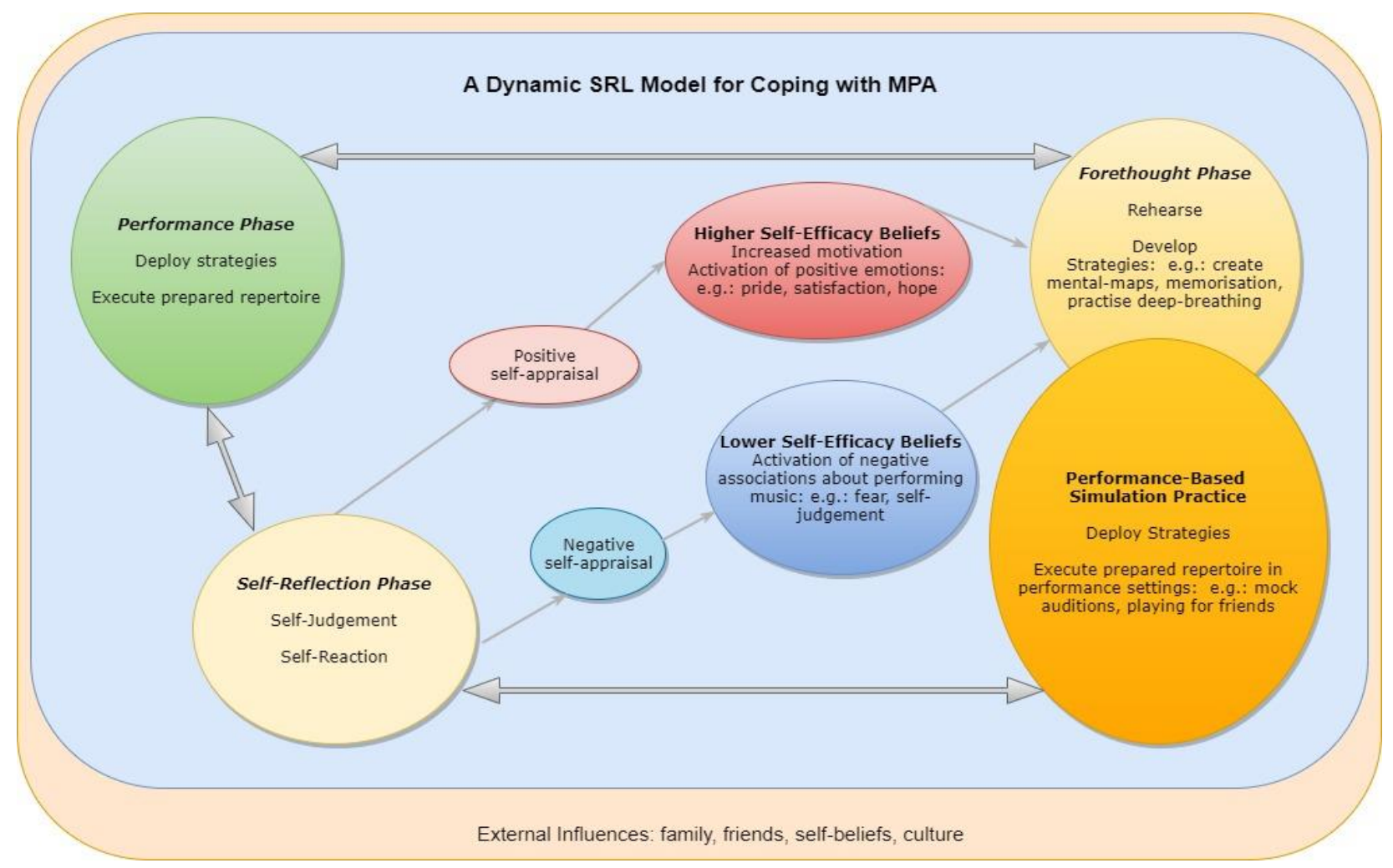

Figure 8 Theoretical Implications - A Multi-Directional SRL Model

As it can be seen in the model above, the findings of this study suggest that the cyclical nature of the SRL phases are multi-directional and quite dynamic in a performance-based activity. Following a mock-audition for example, students engage in a self-reflective phase where they judge their performance based on the internal (self) and the external (e.g.: teacher's expectations) criteria. In other words, it appears that in a performance-based activity the forethought and the performance phases are highly intertwined creating a multidirectional cycle as oppose to a sequential one. As result of that self-reflection, students' self-efficacy beliefs are shaped.

Correspondingly, when discussing the cyclical nature of SRL processes, Winne and Perry (2000) stated that SRL is weakly sequenced as the information attained in one cycle may feed into other phases or back into itself (Philip H Winne \& Perry, 2000). This appears to be highly relevant in a music performance context as students prepare and perform within the forethought phase creating a multidirectional reference loops that may feed into the forethought phase or into the other SRL phases. Given these results, this thesis suggests that future MPA studies involving self-regulation should explore various theory-driven 
approaches with "simulation" aspects of musicians' performance practice and its effects on the cyclical nature of SRL.

\subsection{Institutional Support and MPA}

The findings of the study indicated that students' attitudes towards and management of MPA are highly influenced by the social support around them. The instrumental teachers' role in particular appeared to be highly significant. A positive teacher attitude toward management of MPA encouraged student's external help-seeking efforts. More specifically, students who perceived their instrumental teacher as empathetic and understanding on the matter appeared more likely to use the institutional offerings on the management of MPA and also to view them as being helpful.

A large majority of students interviewed mentioned that they could benefit from a more continuous institutional support in performance enhancement. A majority of the participants took the first year course on performance psychology offered at their institution but mentioned needing more continuous and varied support in the matter. The most commonly mentioned expectations from the institution were providing tuition specifically on performance anxiety management techniques such as yoga, meditation, mental skills training, and post-audition consultation and various other offerings to follow-up students' progress. Students were open to these classes being offered by non-music professionals.

They also brought up the fact that there is need for more awareness around MPA. More specifically, recognising MPA as an academic emotion in the music domain in order to more meaningfully address the challenges encountered.

\subsubsection{Implications for Higher Music Education}

In terms of educational implications, the findings suggest that increasing students' self-efficacy beliefs and supporting them to acquire a positive self-concept may help reduce negative emotions associated with performing music. Helping students gain control over their emotions may improve their performance outcomes as it may help them activate more constructive academic emotions, such as curiosity, and excitement, that are facilitative for future learning and achievement (Boekaerts, 2011; Pekrun et al., 2002; Pekrun \& Linnenbrink-Garcia, 2012). Based on the findings of this study, various directions emerge that may help students regulate their emotions and learning in educational settings. 
One approach is to increase the effectiveness of practice time by providing students with tools to regulate their emotions while practising. This is important as all the students, without an exception, in this study mentioned increasing practice time on their instruments as the main MPA coping strategy, however, their practice time mainly involved increasing competency on technical and musical matters. As many of them mentioned they continuously are in search of better practice habits to improve their mental attitude, additional instructional interventions on that matter are needed. This can be done by institutionally initiated practice time that is offered in a group setting and guided by a skilled professional who may or may not be a professional musician depending on the strategy that is conveyed at that particular session. For example, modelling effective emotion regulation with strategies taken from mindfulness practices may provide students with an opportunity to practice them in guidance of a knowledgeable teacher. If students feel that they can improve their performance skills by managing challenges during practice time, then they may be better equipped to do so in the days approaching the performance and also on stage. Moreover their beliefs in their ability to tackle such challenges may increase their self-efficacy beliefs and help them attain a positive self-concept. Additionally, offering the session in a group setting may inspire team-work that may provide co-regulation and socially shared regulation among the students when challenges are encountered (Hadwin, Järvelä, \& Miller, 2011; Järvenoja \& Järvelä, 2009). Such initiatives may also increase MPA awareness that may curb further understanding and support among peers.

Another approach is to increase performance-based training opportunities for students in order to provide them with tools to better manage challenges encountered on stage. This can be offered through various simulation training platforms where students run through their audition or concert repertoire under the guidance of a professional and given a productive feedback not only on musical and technical matters but on emotion regulation strategies. One approach is to offer institutionally encouraged mock audition platforms where students are given immediate feedback on stage with effective tools to be applied as the performance unfolds. For example, providing students with task-focusing or emotion-focusing strategies to use if their performance is deteriorating during their mock audition. This is relevant as some students in this study mentioned how they did not have the self-regulatory tools to "recover" from a mistake on stage or to "get back to their level" of proficiency. Therefore providing tailored and immediate feedback on the performance, as well as additional opportunities to perform again could improve students' performance skills and enhance their self-efficacy 
beliefs. Many students also mentioned having the need to discuss their experiences following an actual performance with a knowledgeable professional. Some suggestions on their part, such as post-audition evaluation session, and an audition-support club, were made.

More broadly, findings from this research suggest that there is need for more MPA awareness among students and educators at the institutional level. Students and educators should be informed about the health care resources at the institution through various platforms. Those in charge of health and wellbeing recourses, such as mental health counsellors, and others, should make themselves more visible and inform the community that performing arts medicine experts are available and willing to help to those in need. Increasing awareness can be achieved through various channels. For example, organizing a biannual event on Music Students' Health and Wellbeing where professionals and students can meet and discuss potential challenges and the help available in-house and externally. This would not only inform the educators and students of the resources available but also may encourage them to use these services at their disposal.

Finally, the establishment of emotional and psychological support structures as part of the compulsory music curricula is needed in order to enhance the health and wellbeing of student musicians (also see: Ginsborg et al., 2009; Kenny et al., 2014; Papageorgi et al., 2007). Many students in this study mentioned the performance enhancement classes as being offered as an elective course at their institution. However, most of them preferred to take a sonata or a chamber music class as their elective choice over such classes. As such, music educators and curricula designers should consider offering health and wellbeing courses in a compulsory format and continuously assess and evaluate their effectiveness through course evaluation schemes.

\subsection{Limitations and Future Research Directions}

There were some limitations in the present study that should be addressed before discussing future directions. The first limitation of the study was the sample size. A small number of participants $(\mathrm{n}=10)$ was involved in the interviews. While this number of participants provided a valuable insight into the MPA phenomenon, generalisations on the topic cannot be made. Perhaps interviewing a greater number of students from a variety of Higher Music Education institutions would have been beneficial, as it would have further validated the current findings. 
Secondly, having the instrumental teachers and administrators voices on the matter would have provided a valuable insight into how MPA is handled at the institutional level. Unfortunately, undertaking a study that involves a larger student population, as well as teachers and administrators would not have been possible to execute within the timeline given for this particular degree.

Finally, the interview questions were not shared with the students before the interview, therefore this might have shortened their time to reflect back to their MPA experiences and not recalling them as vividly as if they had given more time (e.g.: sharing the interview questions in an email beforehand). Similarly, the manner of the interview process also created certain limitations, as the students were asked to recall a time they experienced MPA in the past. This posed limitations identifying some of the coping strategies during the performance and self-reflection phases as the memory of the event may not have been as fresh as if it had just happened. This did not pose a challenge in identifying the coping strategies in the forethought phase as most of the students at the time were preparing for an upcoming concert, thus were in their forethought phase in their SRL cycle. Given the methodological possibilities at hand, this was the only way possible to conduct this research with this design. Nonetheless, giving students the opportunity reflect on their experiences immediately after (e.g. backstage after a concert or during an intermission) might have yielded somewhat different results.

Based on the findings of the current study, a couple research directions emerged in furthering our understanding of the experiences and management of MPA in educational settings. First, it would be beneficial to utilise qualitative methods to generate knowledge on the instrumental teachers' understanding of MPA and coping strategies they aim to convey through their teaching. Across all participants, there was a mention of how students' coping strategies were heavily influenced by the teacher's suggestions on the matter. Additionally, some students brought up how they perceived their instrumental teachers to be ill equipped to deal with MPA issues when they did arise, which brought up tensions in regards to teachers' preparedness in handling such issues. Therefore, it would be valuable to hear from instrumental teachers, either through an interview research or focus group discussions, to understand their thoughts and practices when guiding students with MPA. Generating such knowledge would provide a valuable insight into teaching and learning aspects of MPA coping in educational settings. 
Secondly, the role of the family, particularly the mother's influence, in the earlier years of musical learning and performance surfaced as another theme but the results were not included in the findings as they were not directly relevant to the research questions at hand. However, mother and teenager interactions in regards to performance expectations and management of MPA was brought up surprisingly frequently when students recalled their earliest experiences of MPA. It appeared when the teens' concerns about performing in public were received in a nurturing way by the caregivers they expressed staying motivated to continue and to look for better coping strategies. Therefore, an inquiry into younger musicians' learning environments which encompasses the role of the family in particular would provide a valuable insight into identifying earlier sources of MPA.

Finally, co-regulation and socially-shared regulation of music performance anxiety surfaced as another theme that was brought up by the students in this study but the results did not generate enough data to be presented in the findings. These aspects of regulation came up in examples involving various forms of peer support (e.g. orchestral excerpt practice time together) and when performing music collaboratively (e.g. chamber music and orchestra concerts). Co-regulation and socially-shared regulation of learning has been recognised as a new and growing framework in the field of self-regulated learning theory over the last decade (Hadwin et al., 2011; Järvenoja \& Järvelä, 2009). As such, from a teaching and learning perspective, it would be beneficial to investigate what MPA coping might mean when studied as a collective effort that takes place in the shared space of music making. 


\subsection{Concluding Remarks}

The results of this study provide implications for the broader community of music students, educators and administrators as it lays the groundwork in identifying ways to address students' needs, emotional or otherwise, to regulate performance anxiety in educational settings. It contributes to our understanding of the phenomenon by providing access to first-person accounts of students' experiences and management of MPA. The study highlighted that MPA is widespread and at times problematic for Higher Music Education students. As such, it is necessary to broaden our understanding of performance psychology and implement instructional practices that assist students overcoming the hindering effects of MPA. The findings suggest that educational researchers and music educators should consider ways to facilitate emotion-regulation and self-regulated learning strategies in management of MPA through modelling exercises, instructional practices and various communal initiatives. Increasing MPA awareness through various means, both at policy and practice level, is a necessary step forward in order to normalise MPA as an academic emotion for music students. 


\section{Bibliography}

Aufegger, L., Perkins, R., Wasley, D., \& Williamon, A. (2017). Musicians' perceptions and experiences of using simulation training to develop performance skills. Psychology of Music, 45(3), 417-431. doi:10.1177/0305735616666940

Bandura, A. (1986). Social foundations of thought and action : a social cognitive theory. Englewood Cliffs, N.J: Prentice-Hall.

Bandura, A. (2010). Self-efficacy. The Corsini encyclopedia of psychology, 1-3. doi:10.1002/9780470479216.corpsy0836

Barlow, D. H. (2000). Unraveling the mysteries of anxiety and its disorders from the perspective of emotion theory. American psychologist, 55(11), 1247. doi:10.1037/0003-066X.55.11.1247

Boekaerts, M. (2011). Emotions, emotion regulation, and self-regulation of learning. In D. H. Schunk \& B. J. Zimmerman (Eds.), Handbook of self-regulation of learning and performance (pp. 408-425). New York, NY: Routledge.

Braun, V., \& Clarke, V. (2006). Using thematic analysis in psychology. Qualitative research in psychology, 3(2), 77-101. doi:10.1191/1478088706qp063oa

Braun, V., Clarke, V., Hayfield, N., \& Terry, G. (2019). Thematic analysis. Handbook of Research Methods in Health Social Sciences, 843-860. doi:10.1007/978-981-10-52514_103

Brodsky, W. (1996). Music performance anxiety reconceptualized. Medical Problems of Performing Artists, 11(1), 88-98.

Brugués, A. O. (2011a). Music performance anxiety—part 1. A review of its epidemiology. Medical Problems of Performing Artists, 26(2), 102-105.

Brugués, A. O. (2011b). Music performance anxiety-part 2. A review of treatment options. Medical Problems of Performing Artists, 26(3), 164-171.

Bryman, A. (2016). Social research methods: Oxford university press.

Butler, D. L., \& Winne, P. H. (1995). Feedback and Self-Regulated Learning: A Theoretical Synthesis. Review of Educational Research, 65(3), 245-281. doi:10.3102/00346543065003245

Cannon, W. B. (1932). The wisdom of the body. New York: Norton.

Cervone, D., \& Pervin, L. A. (2015). Personality, binder ready version: theory and research: John Wiley \& Sons.

Chang, J. C., Midlarsky, E., \& Lin, P. (2003). Effects of meditation on music performance anxiety. Medical Problems of Performing Artists, 18(3), 126-131. 
Cox, W. J., \& Kenardy, J. (1993). Performance anxiety, social phobia, and setting effects in instrumental music students. Journal of Anxiety Disorders, 7(1), 49-60. doi:10.1016/0887-6185(93)90020-L

Craske, M. G., \& Craig, K. D. (1984). Musical performance anxiety: The three-systems model and self-efficacy theory. Behaviour Research and Therapy, 22(3), 267-280. doi:10.1016/0005-7967(84)90007-X

Creswell, J. W., \& Poth, C. N. (2017). Qualitative inquiry and research design: Choosing among five approaches: Sage publications.

Ericsson, K. A., Krampe, R. T., \& Tesch-Römer, C. (1993). The role of deliberate practice in the acquisition of expert performance. Psychological review, 100(3), 363. doi:10.1037/0033-295X.100.3.363

Fehm, L., \& Schmidt, K. (2006). Performance anxiety in gifted adolescent musicians. Journal of Anxiety Disorders, 20(1), 98-109. doi:10.1016/j.janxdis.2004.11.011

Fishbein, M., Middlestadt, S. E., Ottati, V., Straus, S., \& Ellis, A. (1988). Medical problems among ICSOM musicians: overview of a national survey. Medical Problems of Performing Artists, 3(1), 1-8.

Flesch, C. (1939). The Art of Violin Playing. New York: Carl Fischer. In: Inc.

Ginsborg, J., Kreutz, G., Thomas, M., \& Williamon, A. (2009). Healthy behaviours in music and non-music performance students. Health Education, 109(3), 242-258. doi:10.1108/09654280910955575

Gross, J. J. (1998). The emerging field of emotion regulation: An integrative review. Review of general psychology, 2(3), 271-299. doi:doi.org/10.1037/1089-2680.2.3.271

Hadwin, A. F., Järvelä, S., \& Miller, M. (2011). Self-regulated, co-regulated, and socially shared regulation of learning. In D. H. Schunk \& B. J. Zimmerman (Eds.), Handbook of self-regulation of learning and performance (Vol. 30, pp. 65-84). New York, NY: Routlegde.

Hallam, S., Rinta, T., Varvarigou, M., Creech, A., Papageorgi, I., Gomes, T., \& Lanipekun, J. (2012). The development of practising strategies in young people. Psychology of Music, 40(5), 652-680. doi:doi.org/10.1177/0305735612443868

Hatfield, J. L. (2016). Performing at the top of one's musical game. Frontiers in psychology, 7, 1356. doi:doi.org/10.3389/fpsyg.2016.01356

Hatfield, J. L., \& Lemyre, P.-N. (2016). Foundations of intervention research in instrumental practice. Frontiers in psychology, 6, 2014. doi:10.3389/fpsyg.2015.02014

Holden, J. (2006). Effects of heart-rate variability biofeedback training and emotional regulation on music performance anxiety in university students. Unpublished Doctoral Dissertation) University of North Texas, Dentin. 
Järvenoja, H., \& Järvelä, S. (2009). Emotion control in collaborative learning situations: Do students regulate emotions evoked by social challenges. British Journal of Educational Psychology, 79(3), 463-481. doi:10.1348/000709909X402811

Jørgensen, H. (2004). Strategies for individual practice. Musical excellence: Strategies techniques to enhance performance, 85-103.

Kaspersen, M., \& Götestam, K. G. (2002). A survey of music performance anxiety among Norwegian music students. The European journal of psychiatry, 16(2), 69-80.

Kendrick, M. J., Craig, K. D., Lawson, D. M., \& Davidson, P. O. (1982). Cognitive and behavioral therapy for musical-performance anxiety. Journal of consulting clinical psychology, 50(3), 353. doi:10.1037/0022-006X.50.3.353

Kenny, D. (2005). A Systematic Review of Treatments for Music Performance Anxiety. Anxiety, Stress, \& Coping, 18(3), 183-208. doi:10.1080/10615800500167258

Kenny, D. (2006). Music performance anxiety: Origins, phenomenology, assessment and treatment: In Special Issue: Renegotiating musicology. International Journal of Stress Management, 31, 51.

Kenny, D. (2011). The psychology of music performance anxiety: Oxford University Press.

Kenny, D., Driscoll, T., \& Ackermann, B. (2014). Psychological well-being in professional orchestral musicians in Australia: A descriptive population study. Psychology of Music, 42(2), 210-232. doi:10.1177/0305735612463950

Khalsa, S. B. S., Shorter, S. M., Cope, S., Wyshak, G., \& Sklar, E. (2009). Yoga ameliorates performance anxiety and mood disturbance in young professional musicians. Applied psychophysiology biofeedback, 34(4), 279. doi:10.1007/s10484-009-9103-4

Klein, S. D., Bayard, C., \& Wolf, U. (2014). The Alexander Technique and musicians: a systematic review of controlled trials. BMC complementary alternative medicine, 14(1), 414. doi:10.1186/1472-6882-14-414

Koole, S. L., Van Dillen, L. F., \& Sheppes, G. (2011). The self-regulation of emotion. In K. D. Vohs \& R. F. Baumeister (Eds.), Handbook of self-regulation: Research, theory, applications (Vol. 2, pp. 22-40). New York, NY: The Guilford Press.

Kvale, S. (1996). Interviews: An introduction to qualitative research interviewing: Sage Publications, Inc.

Kvale, S., \& Brinkmann, S. (2015). Interviews: Learning the craft of qualitative research interviewing (3 ed.): Sage.

Land, S. M., \& Hannafin, M. (2000). Student-centered learning environments. In D. Jonassen \& S. M. Land (Eds.), Theoretical foundations of learning environments (pp. 1-23). Mahwah, NJ: Lawrence Erlbaum Associates, Inc.

Lederman, R. (1999). Medical treatment of performance anxiety. Medical Problems of Performing Artists, 14(3). 
Lehmann, A. C., Sloboda, J. A., \& Woody, R. H. (2007). Psychology for musicians: Understanding and acquiring the skills: Oxford University Press.

Lehrer, P. M. (1987). A review of the approaches to the management of tension and stage fright in music performance. Journal of Research in Music Education, 35(3), 143-153. doi:doi.org/10.2307/3344957

Lincoln, Y. S., \& Guba, E. G. (1985). Naturalistic inquiry. Beverly Hills, California: Sage.

Marchant-Haycox, S. E., \& Wilson, G. D. (1992). Personality and stress in performing artists. Personality and Individual Differences, 13(10), 1061-1068. doi:10.1016/01918869(92)90021-G

Matei, R., \& Ginsborg, J. (2017). Music performance anxiety in classical musicians-what we know about what works. BJPsych international, 14(2), 33-35. doi:10.1192/S2056474000001744

McCormick, J., \& McPherson, G. (2003). The Role of Self-Efficacy in a Musical Performance Examination: An Exploratory Structural Equation Analysis. Psychology of Music, 31(1), 37-51. doi:10.1177/0305735603031001322

McGinnis, A. M., \& Milling, L. S. (2005). Psychological Treatment of Musical Performance Anxiety: Current Status and Future Directions. Psychotherapy: Theory, Research, Practice, Training, 42(3), 357-373. doi:10.1037/0033-3204.42.3.357

McPherson, G. E., \& McCormick, J. (1999). Motivational and Self-Regulated Learning Components of Musical Practice. Bulletin of the Council for Research in Music Education(141), 98-102.

McPherson, G. E., \& McCormick, J. (2006). Self-efficacy and music performance. Psychology of Music, 34(3), 322-336. doi:10.1177/0305735606064841

McPherson, G. E., Miksza, P., \& Evans, P. (2018). Self-regulated learning in music practice and performance. Handbook of self-regulation of learning and performance, 181-193.

McPherson, G. E., \& Renwick, J. M. (2011). Self-regulation and mastery of musical skills. In D. H. Schunk \& B. J. Zimmerman (Eds.), Handbook of self-regulation of learning and performance (pp. 234-248). New York, NY: Routledge.

Miksza, P., \& Tan, L. (2015). Predicting collegiate wind players' practice efficiency, flow, and self-efficacy for self-regulation: An exploratory study of relationships between teachers' instruction and students' practicing. Journal of Research in Music Education, 63(2), 162-179. doi:10.1177/0022429415583474

Nicol, D. J., \& Macfarlane-Dick, D. (2006). Formative assessment and self-regulated learning: a model and seven principles of good feedback practice. Studies in Higher Education, 31(2), 199-218. doi:10.1080/03075070600572090

Nielsen, S. (1999). Regulation of learning strategies during practice: A case study of a single church organ student preparing a particular work for a concert performance.

Psychology of Music, 27(2), 218-229. doi:10.1177/0305735699272015 
Nielsen, S. (2001). Self-regulating Learning Strategies in Instrumental Music Practice. Music Education Research, 3(2), 155-167. doi:10.1080/14613800120089223

Nielsen, S. (2004). Strategies and self-efficacy beliefs in instrumental and vocal individual practice: A study of students in higher music education. Psychology of Music, 32(4), 418-431. doi:10.1177/0305735604046099

Nowell, L. S., Norris, J. M., White, D. E., \& Moules, N. J. (2017). Thematic analysis: Striving to meet the trustworthiness criteria. International Journal of Qualitative Methods, 16(1), 1-13. doi:10.1177/1609406917733847

Osborne, M. S., \& Franklin, J. (2002). Cognitive processes in music performance anxiety. Australian Journal of Psychology, 54(2), 86-93.

Osborne, M. S., \& Kenny, D. T. (2008). The role of sensitizing experiences in music performance anxiety in adolescent musicians. Psychology of Music, 36(4), 447-462. doi: $10.1177 / 0305735607086051$

Papageorgi, I., Hallam, S., \& Welch, G. F. (2007). A conceptual framework for understanding musical performance anxiety. Research Studies in Music Education, 28(1), 83-107. doi:10.1177/1321103X070280010207

Pekrun, R., Goetz, T., Titz, W., \& Perry, R. P. (2002). Academic Emotions in Students' SelfRegulated Learning and Achievement: A Program of Qualitative and Quantitative Research. Educational Psychologist, 37(2), 91-105. doi:10.1207/S15326985EP3702_4

Pekrun, R., \& Linnenbrink-Garcia, L. (2012). Academic emotions and student engagement. In Handbook of research on student engagement (pp. 259-282): Springer.

Perry, N. E., \& Rahim, A. (2011). Studying Self-Regulated Learning in Classrooms In Handbook of self-regulation of learning and performance (pp. 136-150). University of British Columbia, Vancouver, Canada: Routledge.

Pintrich, P. R., \& Zusho, A. (2002). Student motivation and self-regulated learning in the college classroom. In Higher education: Handbook of theory and research (pp. 55128): Springer.

Polkinghorne, D. E. (2005). Language and meaning: Data collection in qualitative research. Journal of counseling psychology, 52(2), 137. doi:10.1037/0022-0167.52.2.137

Rae, G., \& McCambridge, K. (2004). Correlates of performance anxiety in practical music exams. Psychology of Music, 32(4), 432-439. doi:10.1177/1321103X9400200105

Roland, D. (1994). How professional performers manage performance anxiety. Research Studies in Music Education, 2(1), 25-35.

Ryan, C. (2005). Experience of musical performance anxiety in elementary school children. International Journal of Stress Management, 12(4), 331.

Saldaña, J. (2015). The coding manual for qualitative researchers: Sage. 
Salmon, P. G. (1990). A psychological perspective on musical performance anxiety: a review of the literature. Medical Problems of Performing Artists; Narberth, 5(1), 2-11.

Schneider, E., \& Chesky, K. (2011). Social Support and Performance Anxiety of College Music Students. Medical Problems of Performing Artists; Narberth, 26(3), 157-163.

Spahn, C. (2015). Treatment and prevention of music performance anxiety. In Progress in brain research (Vol. 217, pp. 129-140): Elsevier.

Steptoe, A. (1989). Stress, coping and stage fright in professional musicians. Psychology of Music, 17(1), 3-11. doi:10.1177/0305735689171001

Steptoe, A. (2001). Negative emotions in music making: The problem of performance anxiety. In Music and emotion: Theory and research (pp. 291-307). New York, NY, US: Oxford University Press.

Steptoe, A., \& Fidler, H. (1987). Stage fright in orchestral musicians: A study of cognitive and behavioural strategies in performance anxiety. British Journal of Psychology, 78(2), 241-249. doi:10.1111/j.2044-8295.1987.tb02243.x

Tamborrino, R. A. (2001). An examination of performance anxiety associated with solo performance of college-level music majors. ProQuest Information \& Learning, US. APA PsycNET database.

Thurber, M. R., Bodenhamer-Davis, E., Johnson, M., Chesky, K., \& Chandler, C. K. (2010). Effects of Heart Rate Variability Coherence Biofeedback Training and Emotional Management Techniques to Decrease Music Performance Anxiety. Biofeedback, 38(1), 28-40. doi:10.5298/1081-5937-38.1.28

Vaag, J., Bjørngaard, J. H., \& Bjerkeset, O. (2016). Symptoms of anxiety and depression among Norwegian musicians compared to the general workforce. Psychology of Music, 44(2), 234-248. doi:10.1177/0305735614564910

Valentine, E. (2002). The fear of performance. In Musical performance: A guide to understanding. (pp. 168-182). Cambridge: Cambridge University Press.

Van Kemenade, J. F., Van Son, M. J., \& Van Heesch, N. (1995). Performance anxiety among professional musicians in symphonic orchestras: a self-report study. Psychological reports, 77(2), 555-562. doi:10.2466/pr0.1995.77.2.555

Van Manen, M. (1996). Researching lived experience: Human science for an action sensitive pedagogy: Routledge.

Varela, W., Abrami, P. C., \& Upitis, R. (2016). Self-regulation and music learning: a systematic review. Psychology of Music, 44(1), 55-74. doi: $10.1177 / 0305735614554639$

Vohs, K. D., \& Baumeister, R. F. (2016). Handbook of self-regulation: Research, theory, and applications: Guilford Publications. 
Wesner, R. B., Noyes, R., \& Davis, T. L. (1990). The occurence of performance anxiety among musicians. Journal of Affective Disorders, 18(3), 177-185. doi:10.1016/01650327(90)90034-6

Williamon, A. (2004). Musical excellence: Strategies and techniques to enhance performance: Oxford University Press.

Williamon, A., Aufegger, L., \& Eiholzer, H. (2014). Simulating and stimulating performance: introducing distributed simulation to enhance musical learning and performance. Frontiers in psychology, 5, 25. doi:10.3389/fpsyg.2014.00025

Wilson, G. D., \& Roland, D. (2002). Performance anxiety. In R. Parncutt \& G. McPherson (Eds.), The Science and Psychology of Music Performance: Creative Strategies for Teaching and Learning (pp. 47-61). New York: Oxford University Press.

Winne, P. H., \& Hadwin, A. F. (2010). Self-Regulated Learning and Socio-Cognitive Theory. In P. Peterson, E. Baker, \& B. McGaw (Eds.), International Encyclopedia of Education (Third Edition) (pp. 503-508). Oxford: Elsevier.

Winne, P. H., \& Perry, N. E. (2000). Measuring self-regulated learning. In Handbook of selfregulation (pp. 531-566): Elsevier.

Wolters, C. A. (2003). Regulation of motivation: Evaluating an underemphasized aspect of self-regulated learning. Educational Psychologist, 38(4), 189-205. doi:10.1207/S15326985EP3804_1

Zimmerman, B. J. (1989). A social cognitive view of self-regulated academic learning. Journal of educational psychology, 81(3), 329.

Zimmerman, B. J. (2000). Attaining Self-Regulation-Chapter 2:A Social Cognitive Perspective: Elsevier Inc.

Zimmerman, B. J. (2002). Becoming a self-regulated learner: An overview. Theory into practice, 41(2), 64-70.

Zimmerman, B. J. (2011). Motivational Sources and Outcomes of Self-Regulated Learning and Performance: Graduate Center of City University of New York. In Handbook of self-regulation of learning and performance (pp. 63-78): Routledge.

Zimmerman, B. J., \& Schunk, D. H. (2001). Self-Regulated Learning and Academic Achievement: Theoretical Perspectives: Routledge. 


\section{Appendices}

Appendix I - Recruitment Advertisement

\section{RESEARCH PARTICIPATION OPPORTUNITY}

\section{REVISITING MUSIC PERFORMANCE ANXIETY}

A PROJECT ABOUT STUDENTS' EXPERIENCES OF MUSIC PERFORMANCE ANXIETY
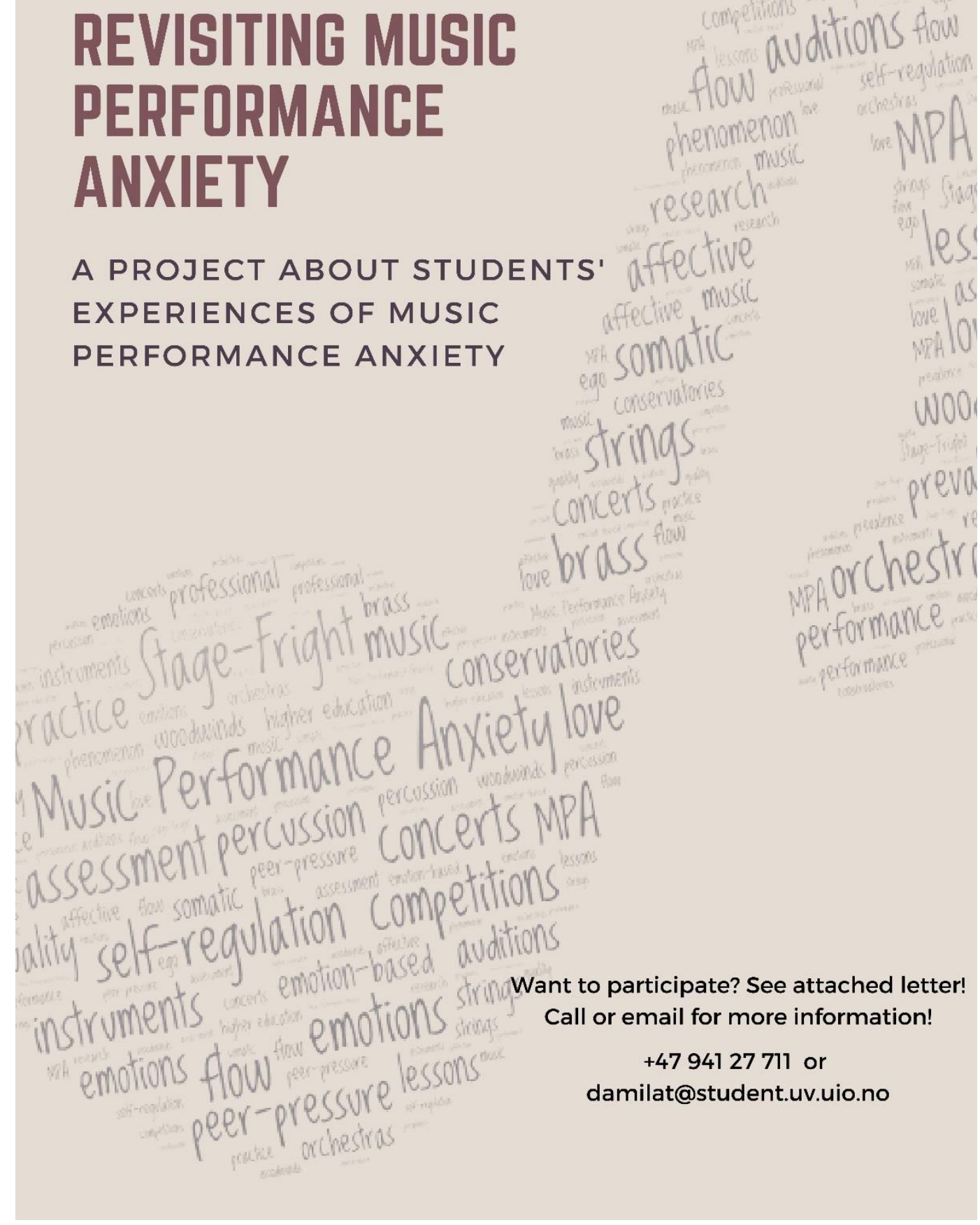
Appendix II - Information and Consent Letter

\section{Are you interested in taking part in the research titled \\ “A Project about students' experiences of \\ Music Performance Anxiety"?}

To help you make an informed decision regarding your participation, this letter will explain what the study is about, and your rights as a research participant. If you do not understand something in the letter, please ask the investigator prior to consenting to the study. You will be provided with a copy of the information and consent form if you choose to participate in the study.

\section{Purpose of the project}

You are invited to participate in a research study about music performance anxiety (MPA). The main purpose of the study is to investigate students' experiences with MPA, and ways of coping, including teacher guidance and other forms of institutional support. The second purpose is to identify some of the self-regulatory influences that help students achieve their performance goals.

Research Questions: 6

1. How do instrumental teachers support students with MPA, and/or MPA related issues?

2. What instrumental students say about their experiences and understanding of MPA?

3. What are the self-regulatory tools students employ to prepare for an optimal performance?

This master thesis is being conducted for the requirements of master of philosophy degree at the Faculty of Educational Sciences at the University of Oslo.

Who is responsible for the research project?

University of Oslo (UiO), Faculty of Educational Sciences is the institution responsible for the project.

\section{Why are you being asked to participate?}

The MPA phenomenon will be investigated by collecting data on student's perceptions, and experiences. Approximately 10-12 students will be recruited for the study. Main data collection method will be qualitative interviews with students.

What does participation involve for you?

\footnotetext{
${ }^{6}$ These research questions were later amended and the final version of them can be seen in Chapters 1 and 5 . Please see the section 4.2 in the methodology chapter for more information.
} 
- If you chose to take part in the project, this will involve participation in an interview that will be scheduled based on your availability. The discussion that will take approx. 60-90 minutes. Topics will include musical performance anxiety, personal experiences, and the support received from your instrumental teachers, peers, your institution and other. The discussion will be recorded electronically

- I also plan to interview 3 orchestral instrument teachers and investigate their understanding of the MPA phenomenon. I will record the interviews and will take notes.

\section{Participation is voluntary}

Participation in the project is voluntary. If you chose to participate, you can withdraw your consent at any time without giving a reason. The data you provided up to that date will not be used unless agreed otherwise. There will be no negative consequences for you if you chose not to participate or later decide to withdraw.

\section{Your personal privacy - how we will store and use your personal data}

We will only use your personal data for the purposes specified in this information letter. We will process your personal data confidentially and in accordance with data protection legislation (the General Data Protection Regulation and Personal Data Act).

- The information you share will be kept confidential by assigning an ID code so that individual names are not associated with the data.

- Your information will be securely stored on a password protected computer

- Any data that will be stored on a mobile device (e.g., laptop, tablet, etc.) will be encrypted.

- Only I, the student investigator, will have access to the data coupled with ID codes, and my supervisor will have access to the anonymised data.

\section{What will happen to my personal data at the end of the research project?}

The project is scheduled to end by December 2019. The personal data, including the digital recordings, will be transcribed and anonymised and all audio recordings will be deleted at this time.

\section{Your rights}

As long as you can be identified in the collected data, you have the right to:

- access the personal data that is being processed about you

- request that your personal data is deleted

- request that incorrect personal data about you is corrected/rectified

- receive a copy of your personal data, including the transcription of the focus group discussion and

- send a complaint to the Data Protection Officer or The Norwegian Data Protection Authority regarding the processing of your personal data 


\section{Will I receive anything for participating in the study?}

To thank you for your time you will receive an OsloCity gift card in 300 NOK value.

What gives us the right to process your personal data?

We will process your personal data based on your consent.

Based on an agreement with Faculty of Educational Sciences at the UiO, NSD - The Norwegian Centre for Research Data AS has assessed that the processing of personal data in this project is in accordance with data protection legislation.

\section{Where can I find out more?}

If you have questions about the project, or want to exercise your rights, contact:

- University of Oslo, Faculty of Educational Sciences

- Faculty Supervisor: Monika Bærøe Nerland, Telephone: +47 22858172

- Student Investigator: Damla Tahirbegi, Telephone: +47 94127711

- Our Data Protection Officer: Maren Magnus Voll, Telephone: +47 228597 78, University of Oslo.

- NSD - The Norwegian Centre for Research Data AS, by email: (personverntjenester@nsd.no) or by Telephone: +4755 582117.

Yours sincerely,

Damla Tahirbegi

Student Investigator

Email: damilat@student.uv.uio.no

m.b.nerland@iped.uio.no

Telephone: +4794127711

72
Monika Bærøe Nerland

Supervisor

Email:

Telephone: +47228581

\section{Consent form}

I have received and understood information about the project titled, A project about

students' experiences of Music Performance Anxiety, and have been given the opportunity to ask questions.

I give consent to the following:

\begin{tabular}{|l|l|}
\hline $\begin{array}{l}\text { Audio recording for } \\
\text { transcription/analysis } \\
\text { purposes only: }\end{array}$ & $\begin{array}{l}\square \text { I agree to my interview being audio recorded to ensure accurate transcription } \\
\text { and analysis. }\end{array}$ \\
\hline $\begin{array}{l}\text { Use of anonymous } \\
\text { quotations: }\end{array}$ & $\begin{array}{l}\square \text { I agree to the use of anonymous quotations in any thesis or publication that } \\
\text { comes from this research. }\end{array}$ \\
\hline
\end{tabular}


I give consent for my personal data to be processed until the end date of the project, December 2019

(Signed by participant, date) 


\section{Appendix III - Interview Guide}

\section{Introduction}

Thanks and welcome - Introduce the project

The main purpose of the study is to investigate students' experiences with MPA, and ways of coping, including teacher guidance and other forms of institutional support. Another purpose is to identify some of the self-regulatory influences that help students achieve their performance goals.

Remind them to

O feel free to ask questions at anytime

$\circ$ there are no right or wrong answers

○ help self with refreshments

$\circ$ audio recording protocol

○ consent forms

Participation in the project is voluntary. If you chose to participate, you can withdraw your consent at any time without giving a reason. The information you share will be kept confidential by assigning an ID code so that individual names are not associated with the data. Your information will be securely stored on a password protected computer. Any data that will be stored on a mobile device (e.g., laptop, tablet, etc.) will be encrypted. Only I, the student investigator, will have access to the data coupled with ID codes, and my supervisor will have access to the anonymised data.

○ Questions or concerns?

\section{MAIN THEMES}

- First hand experiences of MPA. General feelings about music performance anxiety.

- Physical and emotional manifestations

- Preparation, self-regulatory influences

- Support around MPA

- Suggestions for other types of support that your institution can offer 


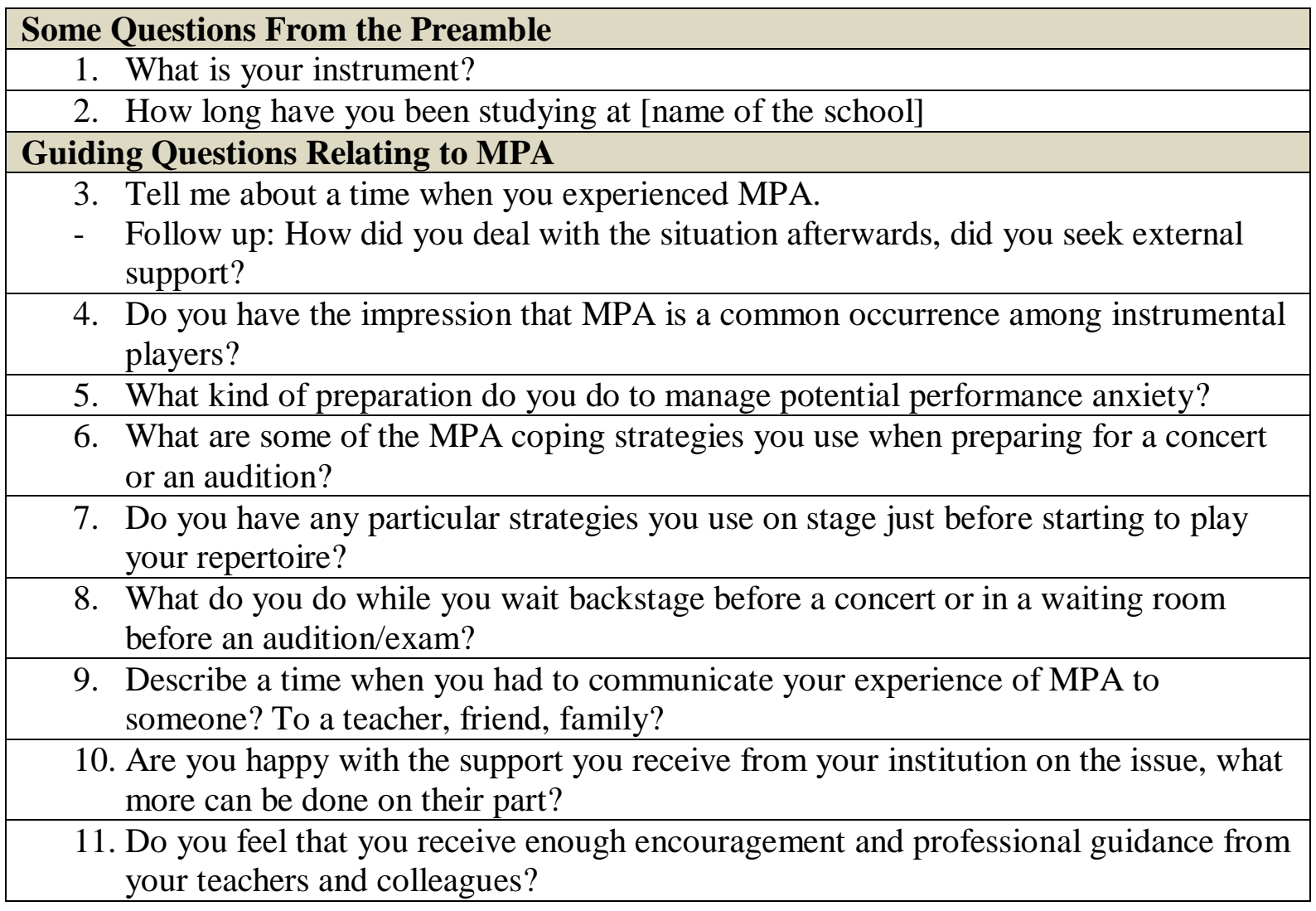

Note to self:

Structuring questions: 'I would now like to move on to a different topic'.

Follow-up questions: 'Could you say some more about that?'; 'What do you mean by that . .?' What did you do then?

Interpreting questions: 'Do you mean that your experiences of MPA has had ... impact on your future performances? 'Is it fair to say that the issues related to MPA are still not openly discussed in professional circle?' 
NSD NORSK SENTER FOR FORSKNINCSDATA

\section{NSD sin vurdering}

\section{Prosjekttittel}

Music Performance Anxiety, Self-Regulated Learning and Emotion Regulation

\section{Referansenummer}

760174

\section{Registrert}

14.12.2018 av Damla Tahirbegi - damilat@uiono

Behandlingsansvarlig institusjon

Universitetet i Oslo / Det utdanningsvitenskapelige fakultet / Institutt for pedagogikk

Prosjektansvarlig (vitenskapelig ansatt/veileder eller stipendiat)

Monika Bærøe Nerland, m.b.nerland@iped.uio.no, tlf: 22858172

\section{Type prosjekt}

Studentprosjekt, masterstudium

Kontaktinformasjon, student

Damla Tahirbegi, damla.tahirbegi@gmail.com, tlf: 94127711

Prosjektperiode

$01.02 .2019-31.12 .2019$

Status

31.01.2019 - Vurdert

Vurdering (1)

\subsubsection{9 - Vurdert}

Det er vår vurdering at behandlingen av personopplysninger i prosjektet vil være $i$ samsvar med personvernlovgivningen så fremt den gjennomfores i tråd med det som er dokumentert i meldeskjemaet med vedlegg den 31.01.2019. Behandlingen kan starte.

MELD ENDRINGER

Dersom behandlingen av personopplysninger endrer seg, kan det være nødvendig å melde dette til NSD ved å oppdatere meldeskjemaet. På våre nettsider informerer vi om hvilke endringer som må meldes. Vent på svar for hutps://meldeskjema.nsd-nowurdering/5c136bc3-dac7-4ba5-9e1a-661e8 1153d8a 